\title{
Sulfur Hexafluoride Treatment of Used Nuclear Fuel to Enhance Separations
}

\section{Fuel Cycle Research \& Development}

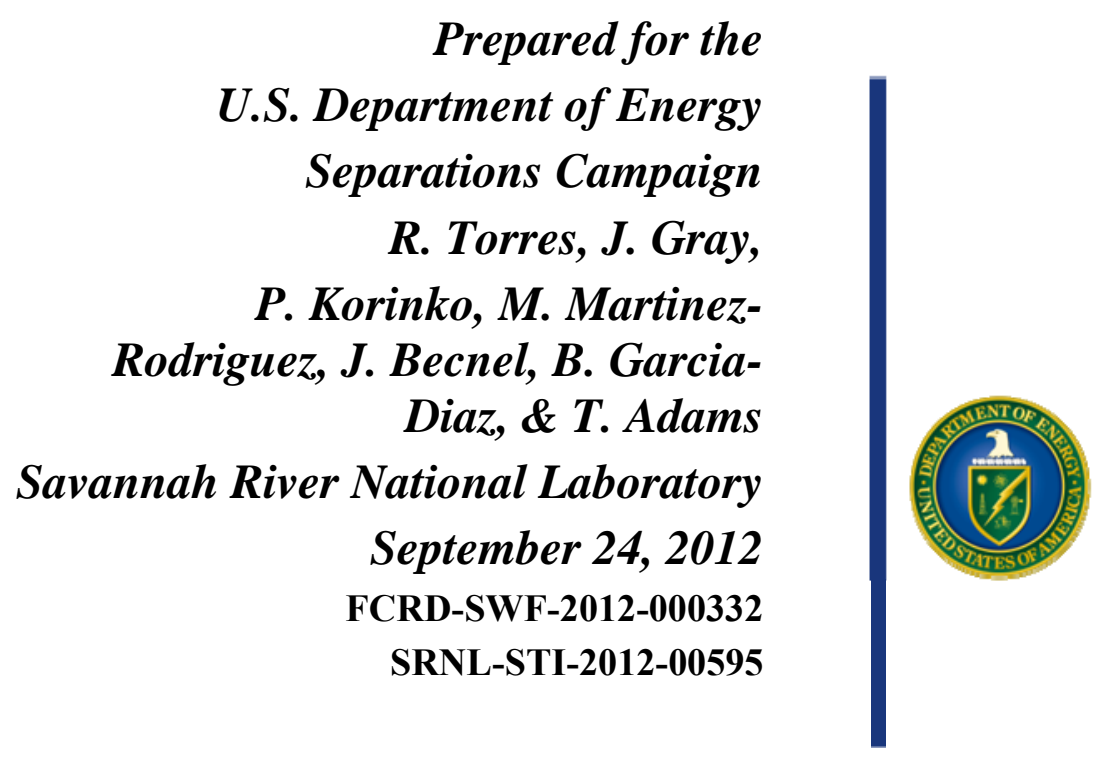




\section{DISCLAIMER}

This information was prepared as an account of work sponsored by an agency of the U.S. Government. Neither the U.S. Government nor any agency thereof, nor any of their employees, makes any warranty, expressed or implied, or assumes any legal liability or responsibility for the accuracy, completeness, or usefulness, of any information, apparatus, product, or process disclosed, or represents that its use would not infringe privately owned rights. References herein to any specific commercial product, process, or service by trade name, trade mark, manufacturer, or otherwise, does not necessarily constitute or imply its endorsement, recommendation, or favoring by the U.S. Government or any agency thereof. The views and opinions of authors expressed herein do not necessarily state or reflect those of the U.S. Government or any agency thereof. 


\section{SUMMARY}

Reactive Gas Recycling (RGR) technology development has been initiated at Savannah River National Laboratory (SRNL), with a stretch-goal to develop a fully dry recycling technology for Used Nuclear Fuel (UNF). This approach is attractive due to the potential of targeted gas-phase treatment steps to reduce footprint and secondary waste volumes associated with separations relying primarily on traditional technologies, so long as the fluorinators employed in the reaction are recycled for use in the reactors or are optimized for conversion of fluorinator reactant. The developed fluorination via $\mathrm{SF}_{6}$, similar to the case for other fluorinators such as $\mathrm{NF}_{3}$, can be used to address multiple fuel forms and downstream cycles including continued processing for LWR via fluorination or incorporation into a aqueous process (e.g. modified FLUOREX) or for subsequent pyro treatment to be used in advanced gas reactor designs such metal- or gas-cooled reactors. This report details the most recent experimental results on the reaction of $\mathrm{SF}_{6}$ with various fission product surrogate materials in the form of oxides and metals, including uranium oxides using a high-temperature DTA apparatus capable of temperatures in excess of $1000^{\circ} \mathrm{C}$. The experimental results indicate that the majority of the fission products form stable solid fluorides and sulfides, while a subset of the fission products form volatile fluorides such as molybdenum fluoride and niobium fluoride, as predicted thermodynamically. Additional kinetic analysis has been performed on additional fission products. A key result is the verification that $\mathrm{SF}_{6}$ requires high temperatures for direct fluorination and subsequent volatilization of uranium oxides to $\mathrm{UF}_{6}$, and thus is well positioned as a head-end treatment for other separations technologies, such as the volatilization of uranium oxide by $\mathrm{NF}_{3}$ as reported by colleagues at PNNL, advanced pyrochemical separations or traditional full recycle approaches.

Based on current results of the research at $\mathrm{SRNL}$ on $\mathrm{SF}_{6}$ fluoride volatility for $\mathrm{UNF}$ separations, $\mathrm{SF}_{6}$ treatment renders all anticipated volatile fluorides studied to be volatile, and all non-volatile fluorides studied to be non-volatile, with the notable exception of uranium oxides. This offers an excellent opportunity to use this as a head-end separations treatment process because:

1. $\mathrm{SF}_{6}$ can be used to remove volatile fluorides from a UNF matrix while leaving behind uranium oxides. Therefore an agent such as $\mathrm{NF}_{3}$ should be able to very cleanly separate a pure $\mathrm{UF}_{6}$ stream, leaving compounds in the bottoms such as $\mathrm{PuF}_{4}, \mathrm{SrF}_{2}$ and $\mathrm{CsF}$ after the UNF matrix has been pre-treated with $\mathrm{SF}_{6}$.

2. Due to the fact that the uranium oxide is not separated in the volatilization step upon direct contact with $\mathrm{SF}_{6}$ at moderately high temperatures $\left(\leq 1000^{\circ} \mathrm{C}\right)$, this fluoride approach may be wellsuited for head-end processing for Gen IV reactor designs where the LWR is treated as a fuel stock, and it is not desired to separate the uranium from plutonium, but it is desired to separate many of the volatile fission products.

3. It is likely that removal of the volatile fission products from the uranium oxide should simplify both traditional and next generation pyroprocessing techniques.

4. $\mathrm{SF}_{6}$ treatment to remove volatile fission products, with or without treatment with additional fluorinators, could be used to simplify the separations of traditional aqueous processes in similar fashion to the FLUOREX process.

Further research should be conducted to determine the separations efficiency of a combined $\mathrm{SF}_{6} / \mathrm{NF}_{3}$ separations approach which could be used as a stand-alone separations technology or a head-end process. 


\section{CONTENTS}

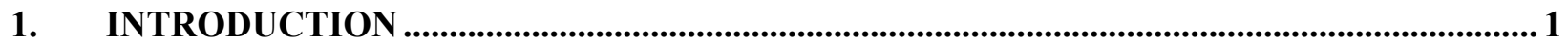

1.1 Overview of Fluoride Volatility Processes .................................................................... 1

1.2 Previous Results: Reactive Gas Thermodynamic Analysis .............................................2

1.3 Development of Reaction Pathway and Kinetic Modeling ............................................... 3

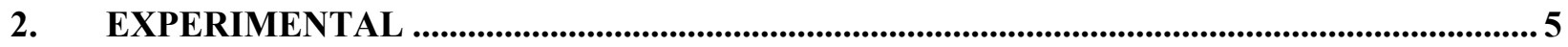

2.1 Thermogravimetric Analysis with $\mathrm{SF}_{6}$ Reactive Gas ..................................................5

2.2 Anticipated Thermophysical Behavior of Samples.......................................................... 25

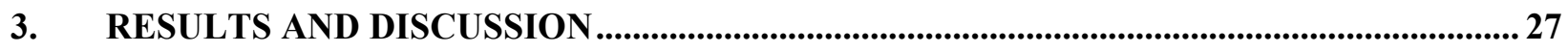

3.1 Non-U Fission Products - Representative UNF Matrix ................................................ 27

3.2 Uranium Oxides .......................................................................................................31

3.3 Process Flowsheet Development for Separations Based on Fluorination via $\mathrm{SF}_{6} \ldots . . . . . . .42$

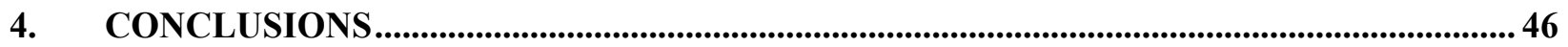

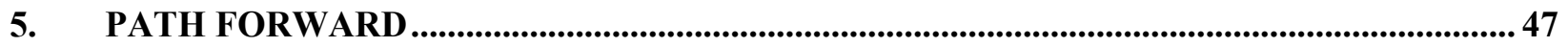

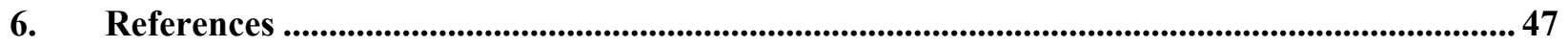




\section{FIGURES}

Figure 1. Thermogravimetic analysis unit for testing reactivity of nuclear surrogates and $\mathrm{U}_{3} \mathbf{O}_{8}$.

Figure 2. Sketch of modified TGA furnace tube for reactive gas experiments.

Figure 3. Differential Thermal Analysis unit for testing reactivity of and $\mathrm{U}_{3} \mathrm{O}_{8}$ .25

Figure 4. TGA thermal profiles of uranium oxides at varied $\mathrm{SF}_{6}$ concentration and an ultimate temperature of $800^{\circ} \mathrm{C}$ (variable isotherm hold times).

Figure 5. TGAthermal profiles of $\mathrm{MoO}_{3}, \mathrm{Nb}_{2} \mathrm{O}_{5}$, and $\mathrm{U}_{3} \mathrm{O}_{8}$ runs at varied $\mathrm{SF}_{6}$ concentration 33

Figure 6. DTA profile of $\mathrm{U}_{3} \mathrm{O}_{8}$ sample exposed to various $\mathrm{SF}_{6}$ concentrations as a function of temperature

Figure 7. Fitting of solid-state kinetic models to TGA data for $\mathrm{Gd}_{2} \mathrm{O}_{3}$ under $22 \% \mathrm{SF}_{6}$ concentration and an ultimate temperature set to $625^{\circ} \mathrm{C}$. Actual isotherm corresponds to $630^{\circ} \mathrm{C}$

Figure 8. Proposed reaction mechanisms for $\mathrm{Gd}_{2} \mathrm{O}_{3}$ by comparison of XRD characterization of reaction product and fitted solid-state kinetic models $\left(22 \% \mathrm{SF}_{6}, 6^{\circ} 5^{\circ} \mathrm{C}\right)$.

Figure 9. Determination of kinetic parameters $\left(E_{a}, A\right)$ for the reaction of $\operatorname{Gd}_{2} \mathrm{O}_{3}$ and $\mathrm{SF}_{6}$. 38

Figure 10. Fitting of solid-state kinetic models to TGA data for $\mathrm{Gd}_{2} \mathrm{O}_{3}$ under $25 \% \mathrm{SF}_{6}$ concentration and an ultimate temperature set to $600^{\circ} \mathrm{C}$.

Figure 11. XRD pattern of $\mathrm{Sm}_{2} \mathrm{O}_{3}$ powder reacted with $25 \% \mathrm{SF}_{6}$ to an ultimate temperature of $625^{\circ} \mathrm{C}$.

Figure 12. Solid-state kinetic models from Table 3 in terms of $\alpha$ as function of the reduced time scale. Models are compared with the isothermal portion of the TGA data for $\mathrm{Y}_{2} \mathrm{O}_{3}$ under $22 \% \mathrm{SF}_{6}$ concentration and an ultimate temperature set to $625^{\circ} \mathrm{C}$. Actual isotherm corresponds to $630^{\circ} \mathrm{C}$.

Figure 13. Linear form of the R3-model compared with the isothermal portion of the TGA data for $\mathrm{Y}_{2} \mathrm{O}_{3}$ under $22 \% \mathrm{SF}_{6}$ concentration and an ultimate temperature set to $625^{\circ} \mathrm{C}$. Actual isotherm corresponds to $633^{\circ} \mathrm{C}$.

Figure 14. Solid-state kinetic models from Table 3 in terms of $\alpha$ as function of the reduced time scale. Models are compared with the isothermal portion of the TGA data for $\mathrm{RuO}_{2}$ under $22 \% \mathrm{SF}_{6}$ concentration and an ultimate temperature set to $625^{\circ} \mathrm{C}$. Actual isotherm corresponds to $633^{\circ} \mathrm{C}$

Figure 15. Block Flow Diagram of Reference UNF Fluorination Process. .......................................... 45

Figure 16. Simplified Process Flow Diagram Incorporating $\mathrm{SF}_{6}$ as the Fluorinating Agent ............ 45

Figure 17. Process Diagram for combined $\mathrm{SF}_{6}$ and $\mathrm{NF}_{3}$ Separations Process which Includes 


\section{TABLES}

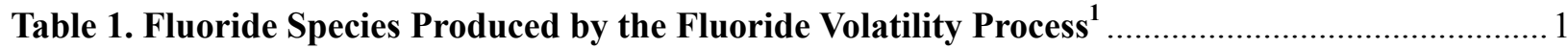

Table 2. Separation Efficiency of Elements Using the Fluoride Volatility Method. ${ }^{3}$.......................... 2

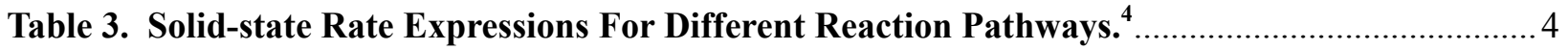

Table 4. Oxides and metals characterized by TGA, expected fluoride products and relevant thermophysical properties. ${ }^{3,4,5,6}$

Table 5. Extrapolated onset and inflection points of surrogate weight changes as measured by TGA.

Table 6. Summary of reactivity results of fission product surrogates as measured by TGA. 30

Table 7. Summary of identified products of reactive oxides/metals based on EDS spectra $\left(22 \%\right.$ SF6, ultimate temperature: $\left.625^{\circ} \mathrm{C}\right)$. 


\section{ACRONYMS}

ASTM American Society for Testing and Materials

EDS Energy Dispersive X-ray Spectroscopy

FCRD Fuel Cycle Research and Development

ISO International Organization for Standardization

RGR Reactive Gas Recycle

SEM Scanning Electron Microscopy

SRNL Savannah River National Laboratory

TGA Thermogravimetric Analysis

UNF Used Nuclear Fuel 



\section{INTRODUCTION}

\subsection{Overview of Fluoride Volatility Processes}

Fluoride volatility is a recycling process for UNF that utilizes fluorine gas or another fluorinating agent to react with fuel rod elements. ${ }^{1,2}$ Many elements of UNF volatilize when fluorinated, including uranium and neptunium, while others remain stable in the solid form. The differences in thermophysical properties of these products can be utilized as a starting point to effectively separate, isolate and collect product streams with different elemental concentrations for further processing.

Table 1 lists the fluorinated compounds produced after fluorination of UNF elements. ${ }^{1}$ The main compound in the volatile phase will be $\mathrm{UF}_{6}$, but other species will also be volatilized including $\mathrm{PuF}_{6}$, $\mathrm{NbF}_{6}, \mathrm{MoF}_{6}, \mathrm{TcF}_{6}, \mathrm{RuF}_{6}$, and $\mathrm{TeF}_{6}$.

Table 1. Fluoride Species Produced by the Fluoride Volatility Process ${ }^{1}$

\begin{tabular}{|c|c|c|c|c|}
\hline \multirow[b]{2}{*}{ Group } & \multirow[b]{2}{*}{ Elements } & \multirow[b]{2}{*}{$\begin{array}{c}\text { Contents in Used Fuel } \\
(\mathbf{w t} \%)^{*}\end{array}$} & \multicolumn{2}{|c|}{ Behavior in the fluorination process } \\
\hline & & & Chemical form & Vol./Non-volatile \\
\hline \multirow[t]{6}{*}{ Actinides } & $\mathrm{U}$ & 92.9 & $\mathrm{UF}_{6}$ & Volatile \\
\hline & & & $\mathrm{UF}_{4}$ & Non-volatile \\
\hline & $\mathrm{Pu}$ & 1.30 & $\mathrm{PuF}_{6}$ & Volatile \\
\hline & & & $\mathrm{PuF}_{4}$ & Non-volatile \\
\hline & $\mathrm{Np}$ & 0.11 & NpF6 & Volatile \\
\hline & $\mathrm{Am}$ & 0.05 & $\mathrm{AmF}_{3}$ & Non-volatile \\
\hline Alkali metals & $\mathrm{Cs}$ & 0.42 & $\mathrm{CsF}$ & Non-volatile \\
\hline Alkaline earth metals & $\mathrm{Sr}$ & 0.14 & $\mathrm{SrF}_{2}$ & Non-volatile \\
\hline \multirow[t]{5}{*}{ Transition metals } & $\mathrm{Zr}$ & 0.60 & $\mathrm{ZrF}_{4}$ & Non-volatile \\
\hline & $\mathrm{Nb}$ & $4.5 \times 10^{-7}$ & $\mathrm{NbF}_{5}$ & Volatile \\
\hline & Mo & 0.55 & $\mathrm{MoF}_{6}$ & Volatile \\
\hline & Tc & 0.12 & $\mathrm{TcF}_{6}$ & Volatile \\
\hline & $\mathrm{Ru}$ & 0.37 & $\mathrm{RuF}_{5}$ & Volatile \\
\hline Typical elements & $\mathrm{Te}$ & 0.08 & $\mathrm{TeF}_{6}$ & Volatile \\
\hline \multirow[t]{3}{*}{ Lanthanides } & $\mathrm{La}$ & 0.20 & $\mathrm{LaF}_{3}$ & Non-volatile \\
\hline & $\mathrm{Ce}$ & 0.39 & $\mathrm{CeF}_{3}$ & Non-volatile \\
\hline & $\mathrm{Nd}$ & 0.67 & $\mathrm{NdF}_{3}$ & Non-volatile \\
\hline
\end{tabular}

Table 2 shows the projected separation efficiencies of the principal UNF elements using the fluoride volatility pathway. ${ }^{2}$ Thermodynamic calculations have been performed to understand the volatilization and potential separation of these elements based on their thermophysical properties. 
Table 2. Separation Efficiency of Elements Using the Fluoride Volatility Method. ${ }^{3}$

\begin{tabular}{|c|c|}
\hline Chemical Elements & Separation Efficiency (\%) \\
\hline $\mathrm{U}$ & $95-99.5$ \\
\hline $\mathrm{Pu}$ & $\sim 98-99.5$ \\
\hline $\mathrm{Np}$ & $\sim 60-70$ \\
\hline $\mathrm{Nb}, \mathrm{Ru}$ & $\sim 95-99$ \\
\hline $\mathrm{Am}, \mathrm{Cm}$ & Individually separable \\
\hline Fission products forming solid fluorides & Individually separable \\
\hline
\end{tabular}

The FLUOREX process combines elements of the fluoride volatility process with separation of some UNF elements using aqueous techniques similar to the PUREX process. ${ }^{1}$ The FLUOREX process has mostly been proposed by Hitachi as a flexible method that can be adapted for both legacy light water reactors and future fast breeder reactors. The preparation and fluorination steps are similar to the fluoride volatility process with similar trapping of $\mathrm{PuF}_{6}$ using $\mathrm{UO}_{2} \mathrm{~F}_{2}$. In the FLUOREX process, the non-volatile substances are converted to oxides using pyrohydrolysis, which reacts the metal fluorides with steam to produce metal oxides and HF. The metal oxides are dissolved in nitric acid and undergo extraction with TBP similar to the aqueous processes. The advantage of the FLUOREX process compared to aqueous processes is that the volatilization step significantly reduces the amount of high level waste. ${ }^{1}$ However, the use of pure fluorine gas involves complex safety issues for transportation and handling due to its highly toxic and corrosive nature. Consequently, the identification and application of safer and less harmful fluorinating agents would minimize some of these issues.

\subsection{Previous Results: Reactive Gas Thermodynamic Analysis}

In previous work ${ }^{3}$, a series of thermodynamic calculations for the equilibrium system composition were carried out on different UNF compositions using the thermodynamics software package HSC Chemistry Version 7.0. The calculations were performed to determine the volatile products that might form using a large list of potential standard industrial gases $\left(\mathrm{H}_{2}, \mathrm{H}_{2} \mathrm{O}, \mathrm{O}_{2}, \mathrm{~N}_{2}, \mathrm{~F}_{2}, \mathrm{~N}_{2} \mathrm{O}, \mathrm{NH}_{3}, \mathrm{Cl}_{2}, \mathrm{~F}_{2}, \mathrm{HCl}\right.$, I, and $\left.\mathrm{Br}\right)$, as well as alternate fluorinating agents such as $\mathrm{SF}_{6}, \mathrm{NF}_{3}$ and $\mathrm{XeF}_{2}$. For reference, literature values for the melting and boiling points for many of the fluoride materials are given in 
Table 4 which may help to clarify the extent of volatility for these compounds. These calculations were also used to suggest some preliminary process flow diagrams. Emergent from this work was the decision to focus experimental analysis on the use of $\mathrm{SF}_{6}$ as an alternate fluorinating agent. Thermodynamic calculations have been performed on a representative surrogate matrix for major UNF components exposed to $\mathrm{SF}_{6}$ to help project the feasibility of separations based on this gas stream, as well as to help guide interpretation of collected experimental data. It has been reported that uranium oxides, such as U${ }_{3} \mathrm{O}_{8}$, should fluorinate to $\mathrm{UF}_{6}$ upon exposure to $\mathrm{SF}_{6}$ and become volatile at modest (moderate) temperatures. Most other constituents of the fuel matrix are stable to higher temperatures (maximum desired temperature is $600-700^{\circ} \mathrm{C}$ ), There are also a limited number of other components predicted to be volatile fluorides, such as $\mathrm{Re}, \mathrm{Rh}, \mathrm{Ru}, \mathrm{Tc}, \mathrm{Mo}$, and $\mathrm{Np}$.

\subsection{Development of Reaction Pathway and Kinetic Modeling}

Chemical kinetic modeling is commonly used to investigate reaction mechanisms and traditionally, TGA has been used to obtain kinetic information. However, the reaction mechanisms cannot be developed based on kinetic data alone and complementary techniques to analyze the products, such as spectroscopy and x-ray diffraction, should be used to support the model or proposed mechanisms. The rate of reaction can be generally described by:

$$
\frac{d \alpha}{d t}=k(T) f(\alpha)
$$

where $t$ represents the time, $T$ is the temperature, $k(T)$ is the temperature-dependent rate constant, $f(\alpha)$ is the reaction model, and $\alpha$ is the conversion fraction. The rate constant is described by the Arrhenius equation as

$$
k(T)=A e^{-\frac{E_{a}}{R T}}
$$

where $A$ is the preexponential factor, $E_{a}$ is the activation energy and $R$ is the gas constant. For a thermogravimetric analysis $\alpha$ is defined as

$$
\alpha=\frac{m_{0}-m}{m_{0}-m_{\infty}}
$$

where $m_{0}$ is the initial sample weight, $m$ is the sample weight at time $t$ for isothermal measurements or at temperature $T$ for nonisothermal measurements, and $m_{\infty}$ is the final sample weight. For nonisothermal conditions and a constant heating rate, $\beta=d T / d t$, Eq. 1 is expressed as

$$
\frac{d \alpha}{d T}=\frac{1}{\beta} \frac{d \alpha}{d t}=\frac{k(T)}{\beta} f(\alpha)
$$

Separating the variables of Eq. 1 and Eq. 4, and incorporating Eq. 2 gives the integral forms for the isothermal and nonisothermal conditions, respectively: 


$$
g(\alpha)=\int_{0}^{\alpha} \frac{1}{f(\alpha)} d \alpha=A e^{-\frac{E_{a}}{R T} t}
$$

and

$$
g(\alpha)=\int_{0}^{\alpha} \frac{1}{f(\alpha)} d \alpha=\frac{A}{\beta} \int_{0}^{T} e^{-\frac{E_{a}}{R T}} d T
$$

These expressions specify the reaction kinetics by the kinetic triplet reaction model, $A$ and $E_{a}$.

In homogeneous kinetics, the mechanism refers to the chemical reaction steps that lead the reactants converted to products and $f(\alpha)$ is described in terms of reactant and/or product concentrations. Conversely, in heterogeneous kinetics, such as the case of solid-gas reactions, the mechanism involves identifying a reaction model that includes factors like nuclei formation, interface advance, diffusion and geometrical shape of solid particles. Therefore, $f(\alpha)$ is described as an empirical function or derived from mechanistic assumptions. These models can be classified as nucleation, geometrical contraction, diffusion and reaction order as shown in Table $3^{6,7}$.

- Nucleation - The rate limiting step is the formation and growth of nuclei, where the nuclei growth rate is different from the nucleation rate.

- Geometrical contraction - Nucleation is assumed to be instantaneous and the rate limiting step is the reaction interface progress towards the center of the particle, where the model depends on the particle shape assumed.

- Diffusion - The rate limiting step is the diffusion of reactants into the reaction sites.

- Reaction order - The rate expression is based on a reaction order, similar to the homogeneous kinetic expressions.

Table 3. Solid-state Rate Expressions For Different Reaction Pathways. ${ }^{4}$ 


\begin{tabular}{|c|c|c|}
\hline Model & Differential Form $^{a} f(\alpha)=\frac{1}{k} \frac{\mathrm{d} \alpha}{\mathrm{d} t}$ & Integral Form $^{a} g(\alpha)=k t$ \\
\hline $\begin{array}{l}\text { Nucleation models } \\
\text { Power law (P2) } \\
\text { Power law (P3) } \\
\text { Power law (P4) } \\
\text { Avarami-Erofe'ev (A2) } \\
\text { Avarami-Erofe'ev (A3) } \\
\text { Avarami-Erofe'ev (A4) } \\
\text { Prout-Tompkins (B1) }\end{array}$ & $\begin{array}{c}2 \alpha^{(1 / 2)} \\
3 \alpha^{(2 / 3)} \\
4 \alpha^{(3 / 4)} \\
2(1-\alpha)[-\ln (1-\alpha)]^{1 / 2} \\
3(1-\alpha)[-\ln (1-\alpha)]^{2 / 3} \\
4(1-\alpha)[-\ln (1-\alpha)]^{3 / 4} \\
\alpha(1-\alpha)\end{array}$ & $\begin{array}{c}\alpha^{(1 / 2)} \\
\alpha^{(1 / 3)} \\
\alpha^{(1 / 4)} \\
{[-\ln (1-\alpha)]^{1 / 2}} \\
{[-\ln (1-\alpha)]^{1 / 3}} \\
{[-\ln (1-\alpha)]^{1 / 4}} \\
\ln [\alpha /(1-\alpha)]\end{array}$ \\
\hline $\begin{array}{l}\text { Geometrical Contraction models } \\
\text { Contracting area (R2) } \\
\text { Contracting volume (R3) }\end{array}$ & $\begin{array}{l}2(1-\alpha)^{1 / 2} \\
3(1-\alpha)^{2 / 3}\end{array}$ & $\begin{array}{l}{\left[1-(1-\alpha)^{1 / 2}\right]} \\
{\left[1-(1-\alpha)^{1 / 3}\right]}\end{array}$ \\
\hline $\begin{array}{l}\text { Diffusion models } \\
\text { 1-D diffusion (D1) } \\
\text { 2-D diffusion (D2) } \\
\text { 3-D diffusion-Jander eqn.(D3) } \\
\text { Ginstling-Brounshtein (D4) }\end{array}$ & $\begin{array}{c}1 / 2 \alpha \\
{[-\ln (1-\alpha)]^{-1}} \\
3(1-\alpha)^{2 / 3} / 2\left(1-(1-\alpha)^{1 / 3}\right) \\
\left(3 / 2\left((1-\alpha)^{-1 / 3}-1\right)\right.\end{array}$ & $\begin{array}{c}\alpha^{2} \\
{[(1-\alpha) \ln (1-\alpha)]+\alpha} \\
{\left[1-(1-\alpha)^{1 / 3}\right]^{2}} \\
1-(2 \alpha / 3)-(1-\alpha)^{2 / 3}\end{array}$ \\
\hline $\begin{array}{l}\text { Reaction-order models } \\
\text { Zero-order (F0/R1) } \\
\text { First-order (F1) } \\
\text { Second-order (F2) } \\
\text { Third-order (F3) }\end{array}$ & $\begin{array}{c}1 \\
(1-\alpha) \\
(1-\alpha)^{2} \\
(1-\alpha)^{3}\end{array}$ & $\begin{array}{c}\alpha \\
-\ln (1-\alpha) \\
(1-\alpha)^{-1}-1 \\
0.5\left((1-\alpha)^{-2}-1\right)\end{array}$ \\
\hline
\end{tabular}

${ }^{a}$ In some references $\mathrm{f}(\alpha)$ and $\mathrm{g}(\alpha)$ have opposite designations.

\section{EXPERIMENTAL}

\subsection{Thermogravimetric Analysis with $\mathrm{SF}_{6}$ Reactive Gas}

Thermogravimetric analysis (TGA) has been the primary technique to investigate the volatility of the UNF materials studied by SRNL when exposed to $\mathrm{SF}_{6}$. TGA is a versatile characterization technique that measures a change of mass in a sample as a function of temperature for nonisothermal experiments and mass change as a function of time for isothermal experiments. The results to be discussed in this report summarize the TGA results on the reactivity of a large matrix of nuclear surrogate materials under different experimental conditions, i.e. variable reactive gas $\left(\mathrm{SF}_{6}\right)$ concentrations and ultimate (highest exposed) temperatures. The regions of instability and temperature onsets for the formation of other reaction products are also discussed. Figure 1 shows the modified Dupont 951 Thermogravimetric Analyzer instrument used for the experiments. The TGA quartz furnace tube was modified in order to deliver the reactive gas directly to the sample (See

\section{Non-U Fission Products - Representative UNF Matrix}

Preliminary studies in the early 1970s of the interaction of SF6 with metals and oxides, revealed the possibility of utilizing this non-toxic gas as an active fluorinating agent. Those results indicated that both metals and oxides reacted with pure streams of SF6 over temperature ranges of $500-600^{\circ} \mathrm{C}$ and 600 $700^{\circ} \mathrm{C}$, respectively. ${ }^{11}$ Additionally, previous experiments by McNamara et al. showed that the thermal profile for the reaction of $\alpha-\mathrm{U} 3 \mathrm{O} 8$ powder and 5\% NF3 gas exhibits a rapid, exothermic mass loss onset around $440^{\circ} \mathrm{C}$ at a heating rate of $10 \mathrm{oC} / \mathrm{min}$ and corresponding to the release of UF6. Based on these results, initial experiments with the SF6 reactive gas were planned at the same heating rate with a maximum temperature $\left(625^{\circ} \mathrm{C}\right)$, similar to the Opalovsky et al. results and above that reported for the NF3 gas (reference?). Each sample was then held for 60 minutes at $625^{\circ} \mathrm{C}$ to monitor reaction rate changes. 
Table 5 lists the extrapolated onset temperatures and inflection temperatures from the TGA thermograms of all the characterized oxides/metals for the different conditions. The onset point denotes the temperature at which the mass gain or loss begins. It is extrapolated from the curves since it is a reproducible calculation specified by ASTM and ISO standards. The inflection point characterizes the peak of the first derivative of the curve, which indicates the point of greatest rate of mass change after the onset. Table 6 includes a summary of the experimental data for the reactivity of the surrogate materials on exposure to SF6, while Table 7 includes a summary of the products identified after the reaction was complete using EDS. 
Sulfur Hexafluoride Treatment of Used Nuclear Fuel to Enhance Separations

FCRD-SWF-2012-000332

September 28, 2012

Table 5. Extrapolated onset and inflection points of surrogate weight changes as measured by TGA.

\begin{tabular}{|c|c|c|c|c|c|}
\hline $\begin{array}{l}\text { Characterized } \\
\text { Oxide / Metal }\end{array}$ & $\begin{array}{c}\text { SF6 } \\
\text { Concentration } \\
(\%)\end{array}$ & $\begin{array}{c}\text { Extrapolated } \\
\text { Onset Time } \\
\text { (min)* }\end{array}$ & $\begin{array}{c}\text { Corresponding } \\
\text { Onset } \\
\text { Temperature } \\
\left({ }^{\circ} \mathrm{C}\right)\end{array}$ & $\begin{array}{l}\text { Inflection } \\
\text { Time } \\
\text { (min)* }\end{array}$ & $\begin{array}{c}\text { Corresponding } \\
\text { Inflection } \\
\text { Temperature } \\
\left({ }^{\circ} \mathbf{C}\right) \\
\end{array}$ \\
\hline \multirow[t]{2}{*}{$\mathrm{CeO} 2$} & 10 & 79.7 & 529 & 86.4 & 609 \\
\hline & 22 & 79.3 & 499 & 86.8 & 587 \\
\hline \multirow[t]{3}{*}{$\mathrm{Gd} 2 \mathrm{O} 3$} & 10 & 85.3 & 612 & 88.0 & 640 \\
\hline & 22 & 73.3 & 483 & 81.5 & 573 \\
\hline & 10 & 85.1 & 600 & 93.0 & 688 \\
\hline \multirow[t]{3}{*}{$\mathrm{Sm} 2 \mathrm{O} 3$} & 10 & 85.1 & 613 & 88.0 & 642 \\
\hline & 22 & 82.4 & 579 & 85.0 & 608 \\
\hline & 10 & $\begin{array}{c}88.5(1) \\
108.1(2) \\
\end{array}$ & $\begin{array}{l}633 \\
747 \\
\end{array}$ & $\begin{array}{c}97.0(1) \\
107.5(2)\end{array}$ & $\begin{array}{l}724 \\
747 \\
\end{array}$ \\
\hline \multirow[t]{3}{*}{$\mathrm{Y} 2 \mathrm{O} 3$} & 10 & 82.6 & 578 & 107.0 & 631 \\
\hline & 22 & 83.5 & 593 & 99.0 & 632 \\
\hline & 10 & $\begin{array}{l}88.5(1) \\
98.8(2) \\
\end{array}$ & $\begin{array}{l}638(1) \\
739(2) \\
\end{array}$ & $97.3(1)$ & $722(1)$ \\
\hline \multirow[t]{2}{*}{$\mathrm{SrO}$} & 10 & $\begin{array}{l}71.5(1) \\
79.6(2)\end{array}$ & $\begin{array}{l}429(1) \\
523(2)\end{array}$ & $\begin{array}{l}77.7(1) \\
86.5(2)\end{array}$ & $\begin{array}{l}501(1) \\
604(2)\end{array}$ \\
\hline & 22 & $\begin{array}{l}71.4(1) \\
80.1(2)\end{array}$ & $\begin{array}{l}399(1) \\
499(2)\end{array}$ & $\begin{array}{l}77.2(1) \\
83.6(2)\end{array}$ & $\begin{array}{l}465(1) \\
539(2)\end{array}$ \\
\hline \multirow[t]{2}{*}{ HfO2 } & 10 & \multicolumn{4}{|c|}{ no change } \\
\hline & 22 & \multicolumn{4}{|c|}{ no change } \\
\hline \multirow[t]{2}{*}{$\mathrm{ZrO} 2$} & 10 & \multicolumn{4}{|c|}{ no change } \\
\hline & 22 & \multicolumn{4}{|c|}{ no change } \\
\hline \multirow[t]{2}{*}{$\mathrm{RuO} 2$} & 10 & 85.3 & 617 & \multicolumn{2}{|c|}{ undefined - linear } \\
\hline & 22 & 84.8 & 610 & \multicolumn{2}{|c|}{ undefined - linear } \\
\hline \multirow[t]{3}{*}{$\mathrm{Rh} 2 \mathrm{O} 3$} & 10 & $\begin{array}{l}52.3(1) \\
75.5(2) \\
84.5(3) \\
87.1(4)\end{array}$ & $\begin{array}{l}231.5(1) \\
490.5(2) \\
593.8(3) \\
622.7(4)\end{array}$ & $\begin{array}{c}60.4(1) \\
81.6(2) \\
85.5(3) \\
127.2(4)\end{array}$ & $\begin{array}{l}319.1(1) \\
559.7(2) \\
604.9(3) \\
622.2(4)\end{array}$ \\
\hline & 22 & $\begin{array}{l}51.9(1) \\
75.5(2) \\
84.7(3) \\
89.3(4)\end{array}$ & $\begin{array}{l}207.6(1) \\
457.7(2) \\
565.0(3) \\
598.9(4)\end{array}$ & $\begin{array}{c}63.7(1) \\
81.5(2) \\
87.8(3) \\
123.7(4)\end{array}$ & $\begin{array}{l}327.1(1) \\
527.2(2) \\
600.9(3) \\
594.4(4)\end{array}$ \\
\hline & 10 & $\begin{array}{l}53.9(1) \\
74.7(2) \\
85.2(3) \\
95.0(4) \\
97.7(5)\end{array}$ & $\begin{array}{l}246.2(1) \\
479.6(2) \\
599.6(3) \\
708.3(4) \\
737.1(5)\end{array}$ & $\begin{array}{c}65.7(1) \\
81.3(2) \\
93.1(3) \\
96.8(4) \\
102.8(5)\end{array}$ & $\begin{array}{l}376.5(1) \\
555.1(2) \\
687.6(3) \\
727.8(4) \\
747.9(5)\end{array}$ \\
\hline $\mathrm{Re} 2 \mathrm{O} 3$ & 10 & 72.8 & & 78.3 & \\
\hline $\mathrm{Ru}$ & 10 & 81.0 & 561 & \multicolumn{2}{|c|}{ undefined } \\
\hline & 22 & 84.2 & 603 & \multicolumn{2}{|c|}{ undefined } \\
\hline $\mathrm{Rh}$ & 10 & \multicolumn{4}{|c|}{ no change } \\
\hline & 22 & \multicolumn{4}{|c|}{ no change } \\
\hline $\operatorname{Re}$ & 10 & 68.5 & 596 & unde & ed - linear \\
\hline
\end{tabular}


* Times include the 30 min purge period at $25^{\circ} \mathrm{C}$. Parenthesis indicates if multiple onsets.

Table 6. Summary of reactivity results of fission product surrogates as measured by TGA.

\begin{tabular}{|c|c|c|c|c|c|}
\hline $\begin{array}{l}\text { Characterized } \\
\text { Oxide / Metal }\end{array}$ & $\begin{array}{c}\text { SF6 } \\
\text { Concentration } \\
(\%)\end{array}$ & $\begin{array}{c}\text { Ultimate / } \\
\text { Isotherm } \\
\text { Temperature - } \\
\text { Nominal }\left({ }^{\circ} \mathbf{C}\right)\end{array}$ & $\begin{array}{c}\text { Ultimate / } \\
\text { Isotherm } \\
\text { Temperature - } \\
\text { Experimental }\left({ }^{\circ} \mathbf{C}\right)\end{array}$ & $\begin{array}{c}\text { Max. } \\
\text { Weight } \\
\text { Change }(\%)\end{array}$ & $\begin{array}{l}\text { Stable / } \\
\text { Volatile }\end{array}$ \\
\hline \multirow[t]{2}{*}{$\mathrm{CeO} 2$} & 10 & 625 & 620 & +5.9 & Stable \\
\hline & 22 & 625 & 593 & +9.7 & Stable \\
\hline \multirow[t]{3}{*}{$\mathrm{Gd} 2 \mathrm{O} 3$} & 10 & 625 & 633 & +11.3 & Stable \\
\hline & 22 & 625 & 630 & +12.0 & Stable \\
\hline & 10 & 750 & 745 & +21.1 & Stable \\
\hline \multirow[t]{3}{*}{$\mathrm{Sm} 2 \mathrm{O} 3$} & 10 & 625 & 634 & +7.4 & Stable \\
\hline & 22 & 625 & 629 & +8.3 & Stable \\
\hline & 10 & 750 & 750 & +16.2 & Stable \\
\hline \multirow[t]{3}{*}{ Y2O3 } & 10 & 625 & 630 & +17.1 & Stable \\
\hline & 22 & 625 & 630 & +19.0 & Stable \\
\hline & 10 & 750 & 732 & +18.8 & Stable \\
\hline \multirow[t]{2}{*}{$\mathrm{SrO}$} & 10 & 625 & 611 & +16.4 & Stable* \\
\hline & 22 & 625 & 584 & +18.3 & Stable* \\
\hline \multirow[t]{2}{*}{ HfO2 } & 10 & 625 & 635 & no change & Stable \\
\hline & 22 & 625 & 638 & no change & Stable \\
\hline \multirow[t]{2}{*}{$\mathrm{ZrO} 2$} & 10 & 625 & 630 & no change & Stable \\
\hline & 22 & 625 & 630 & no change & Stable \\
\hline \multirow[t]{2}{*}{$\mathrm{RuO} 2$} & 10 & 625 & 633 & -10.1 & Volatile \\
\hline & 22 & 625 & 633 & -18.4 & Volatile \\
\hline \multirow[t]{3}{*}{$\mathrm{Rh} 2 \mathrm{O} 3$} & 10 & 625 & 622 & no change & Stable \\
\hline & 22 & 625 & 594 & -2.5 & Volatile \\
\hline & 10 & 750 & 743 & -7.0 & Volatile \\
\hline $\mathrm{Re} 2 \mathrm{O} 3$ & 10 & 625 & 630 & -100 & Volatile \\
\hline \multirow[t]{2}{*}{$\mathrm{Ru}$} & 10 & 625 & 625 & +6.8 & Stable \\
\hline & 22 & 625 & 632 & +7.3 & Stable \\
\hline \multirow[t]{2}{*}{$\mathrm{Rh}$} & 10 & 625 & 620 & no change & Stable \\
\hline & 22 & 625 & 629 & no change & Stable \\
\hline $\operatorname{Re}$ & 10 & 625 & 630 & -74.0 & Volatile \\
\hline
\end{tabular}

Table 7 summarizes the identified reaction products from the reaction of the different fission products and SF6 at a concentration of $22 \%$. Continuing studies are focused on additional characterization of the reaction products of these fission products by DTA testing. 
Table 7. Summary of identified products of reactive oxides/metals based on EDS spectra (22\% SF6, ultimate temperature: $625^{\circ} \mathrm{C}$ )

\begin{tabular}{|c|c|c|c|}
\hline Characterized Oxide / Metal & $\begin{array}{c}\text { Formed } \\
\text { Fluoride Product }\end{array}$ & $\begin{array}{c}\text { Formed } \\
\text { Sulfide } \\
\text { Product }\end{array}$ & $\begin{array}{c}\text { Other } \\
\text { Formed } \\
\text { Products }\end{array}$ \\
\hline $\mathrm{CeO} 2$ & $\mathrm{CeF} 3$ & $\mathrm{CeSO} 4$ & \\
\hline $\mathrm{Gd} 2 \mathrm{O} 3$ & $\begin{array}{c}\mathrm{GdF} 3, \\
\mathrm{Gd} 2 \mathrm{O} 3 \cdot 2 \mathrm{GdF} 3\end{array}$ & & \\
\hline $\mathrm{Sm} 2 \mathrm{O} 3$ & $\mathrm{SmOF}$ & & $\mathrm{YO} 2 \mathrm{SO} 4$ \\
\hline $\mathrm{Y} 2 \mathrm{O} 3$ & $\mathrm{YOF}$ & $\mathrm{SrSO} 4$ & $\begin{array}{c}\mathrm{SrCO} 3, \\
\mathrm{Sr}(\mathrm{OH})_{2} \cdot \mathrm{H} 2 \mathrm{O}, \\
\mathrm{SrO}(\mathrm{OH})_{2} \cdot 8 \mathrm{H} 2 \mathrm{O}\end{array}$ \\
\hline $\mathrm{SuO} 2$ & $\mathrm{SrF} 2$ & & \\
\hline $\mathrm{Rh} 2 \mathrm{O} 3$ & & & \\
\hline $\mathrm{Ru}$ & & & \\
\hline
\end{tabular}

\subsection{Uranium Oxides}

Uranium trioxide (UO3) and triuranium octoxide (U3O8) samples were tested at multiple temperatures, concentrations and total gas flow rates. These higher stability oxides were chosen for initial testing with the assumption that a voloxidation step will precede any fluorination process, which would convert the used UO2 fuel into pulverized U3O8.

Figure 4 shows thermograms for the oxides with varied SF6 concentrations at a flow rate of $150 \mathrm{sccm}$. All samples were heated at $10^{\circ} \mathrm{C}$ min- 1 to an ultimate temperature of $800^{\circ} \mathrm{C}$, followed by a variableduration isothermal hold. The results show that the UO3 sample readily reacts at temperatures as low as $300 \mathrm{oC}$ and ambient pressure, although this may be attributed to water loss and not necessarily formation of a volatile product such as UF6. Lengthening the time of the isothermal hold at $800^{\circ} \mathrm{C}$ from 60 to 120 min results in an increased mass loss from 13.3 to $49.0 \%$. Note that at this temperature corrosion of the quartz balancing rod that supports the sample pan may result in an additional mass loss, which must be deconvoluted from the sample weight change. The characterized U3O8 sample was obtained from SRNL house stock and no previous history could be obtained. The XRD pattern of the sample was consistent with the ICCD database, with a smaller presence of UO3 $\cdot 0.8 \mathrm{H} 2 \mathrm{O}$. The results for this U3O 8 sample suggest that this oxide is non-reactive up to $800^{\circ} \mathrm{C}$, which we attribute to the material being a hightemperature fired $(\beta)$ version of the oxide. SRNL is in talks with PNNL to acquire a lower-temperature fired version $(\alpha)$ for characterization. Based on the apparently stability of the U3O8 samples, and difficulty of deconvoluting the UO3 in the TGA, it was decided to explore the reactivity in the DTA due to its enhanced stability at higher temperatures. 


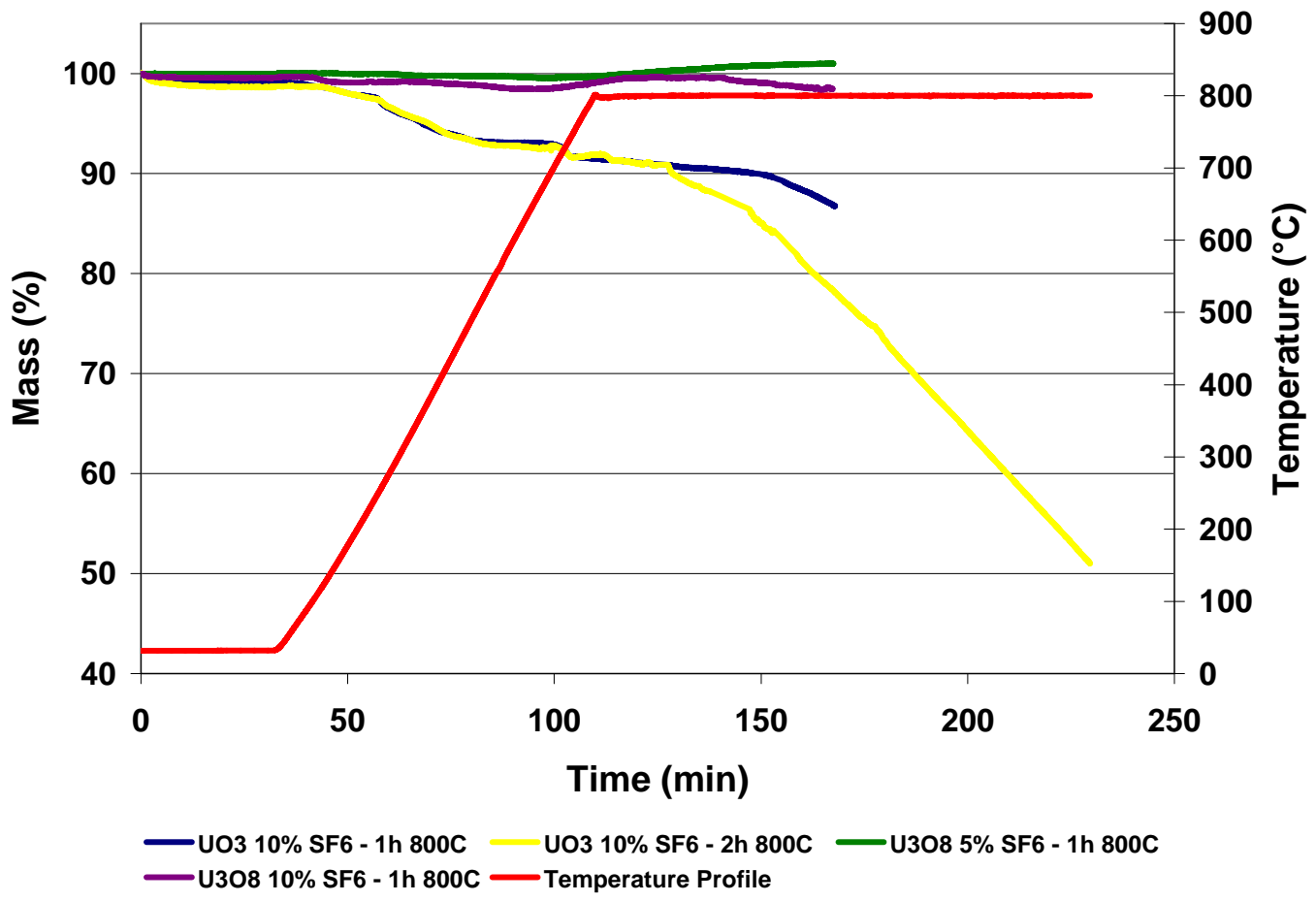

Figure 4. TGA thermal profiles of uranium oxides at varied SF6 concentration and an ultimate temperature of $800^{\circ} \mathrm{C}$ (variable isotherm hold times).

Figure 5 below shows a run of U3O8 exposed to an elevated 50\% concentration of SF6 compared to data for $\mathrm{MoO} 3$ and $\mathrm{Nb} 2 \mathrm{O} 5$ exposed to a nominal concentration of $25 \% \mathrm{SF} 6$. While the data for U3O8 appears to show rapid weight loss at temperatures greater than $825 \mathrm{oC}$, this data is not easily interpreted as the effect is difficult to deconvolute from fluorination and subsequent volatilization of the quartz balancing rod supporting the sample pan. However, the data for the $\mathrm{MoO} 3$ and $\mathrm{Nb} 2 \mathrm{O} 5$ is interesting, particularly when compared to the behavior of UO3 exposed to SF6 as it indicates that both of these compounds will stay in the solid with the other non-volatiles at lower temperatures. However, Mo oxide is usually regarded as a potential contaminant in the volatile fluoride stream, but these data suggest that it could be effectively left in the ash at temperatures of $\leq 800 \mathrm{oC}$. 


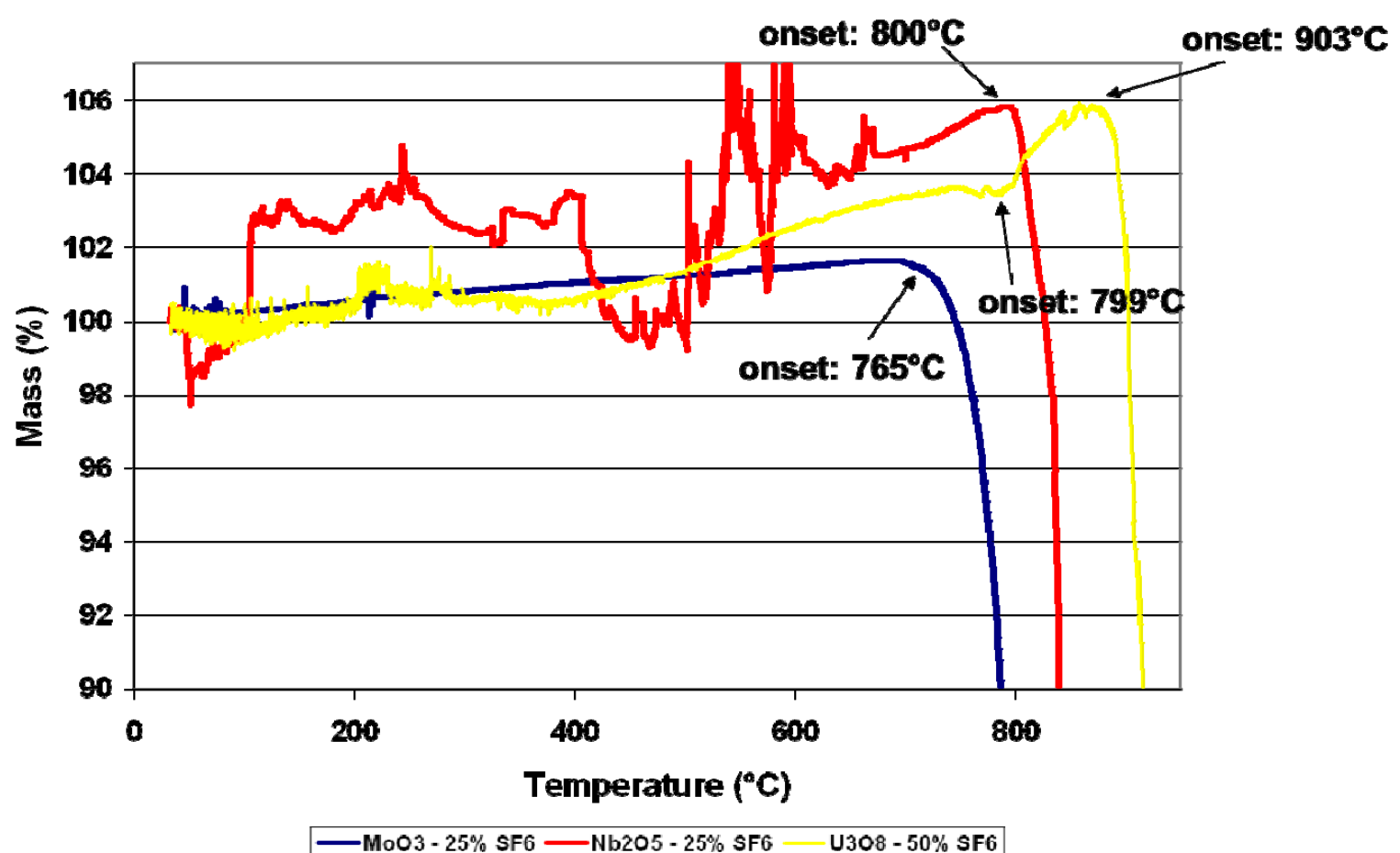

Figure 5. TGAthermal profiles of MoO3, Nb2O5, and U3O8 runs at varied SF6 concentration

Figure 6 shows the DTA thermal profile of U3O8 exposed to different concentrations of SF6. Initial results suggest that the highly stable oxide does not fluorinate even at concentrations as high as $100 \%$ SF 6 $(35 \mathrm{sccm})$ up to a temperature of $1100^{\circ} \mathrm{C}$. Comparison of the three thermal profiles $(0 \%, 25 \%$ and $100 \%$ SF6) suggests that the variations in the $25 \%$ SF6 thermogram are likely the result of instrument noise. Continuing studies are focused on the verification of the U3O8 results at different flow rates, increasing the SF6 resonance time in the sample through modifications of the tortuosity of the gas outlet, as well as the characterization of the reactivity of the lower oxides, UO3 and UO2. 


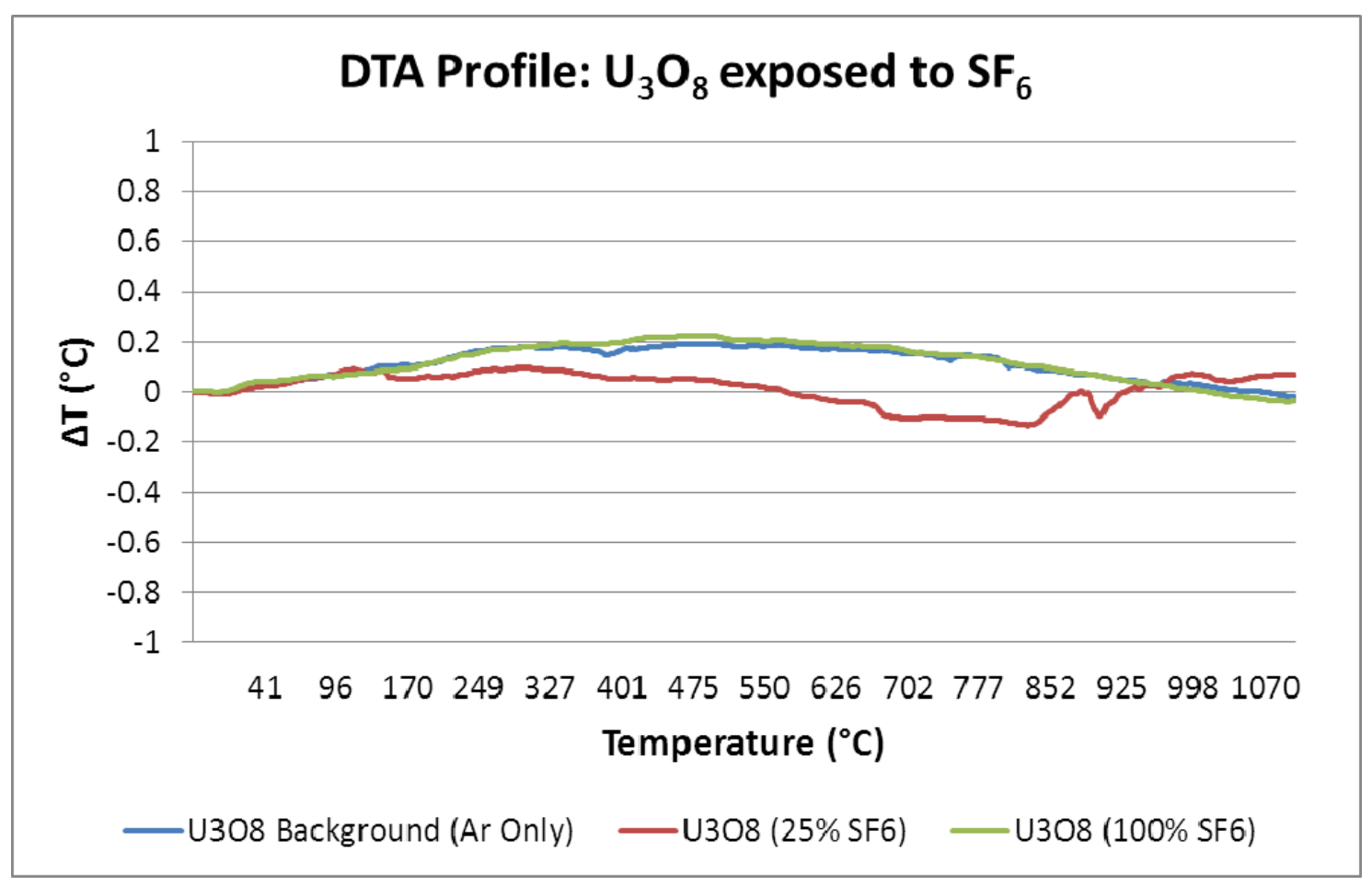

Figure 6. DTA profile of U3O8 sample exposed to various SF6 concentrations as a function of temperature 


\section{Reaction Pathway and Kinetic Modeling Analysis for Fluorination of UNF with SF6}

The solid-state kinetic models described in Section 1.3 were used and compared with TGA data for some samples to infer possible reaction mechanisms occurring when the surrogates are exposed to SF6. Reduced time plots for the models in Table 3 are shown in Figure 12. The use of fractional conversion as function of a reduced time scale, such as $t / t_{0.5}$, where $t_{0.5}$ corresponds to $\alpha=0.5$, is a convenient method to compare the experimental data with the models. For example, combining the contracting volume (R3) model in Table 3 with. Eq. 5 for $\alpha=0.5$ produce the following expressions:

$$
g(0.5)=0.2063=k t_{0.5}
$$

or

$$
k=\frac{0.2063}{t_{0.5}}
$$

Substituting Eq. 8 back into Eq. 5 gives

$$
1-(1-\alpha)^{\frac{1}{3}}=0.2063 \frac{t}{t_{0.5}}
$$

Solving for $\alpha$ gives

$$
\alpha=1-\left(1-0.2063 \frac{t}{t_{0.5}}\right)^{3}
$$

Similarly, the remaining models in Table 3 can be expressed as function of $t / t_{0.5}$. The advantage of this method is that evaluation of the kinetic parameters is not required for an initial assessment of the mechanism while the dependence of $\alpha$ in other variables, such as temperature and pressure, is captured in $t_{0.5}$.

The models shown in Figure 12 are grouped by the mechanism type: nucleation (P and A-series), reaction order (F-series), geometrical contractions (R-series), and diffusion (D-series). According to their shape, the P-series represent the acceleratory models in which conversion is faster with time. The A-series correspond to the sigmoidal shape in which conversion is faster with time until $\alpha=0.5$ and then slower with time. Except for F0, which represents a constant conversion over time, F, R, and D-series represent the deceleratory models in which conversion is slower with time.

Figure 7 shows new analysis of the isothermal $\left(625^{\circ} \mathrm{C}, 22 \% \mathrm{SF} 6\right)$ portion of the TGA data for Gd2O3 in terms of fractional conversion as function of the reduced time scale. In this plot, $t=0$ represents the time at which the sample starts the isothermal reaction. Under these test conditions, Gd2O3 starts as an F3 model, i.e. third order kinetics. The initial reaction into GdF3 eventually experiences diffusion limitations, shifting to a D4 model, i.e. a radial steady-state diffusion model known as the Ginstling- 
Brounshtein model. The reaction data then shifted to a third kinetic model (D3), the Jander model, which was developed by modeling diffusion through a plane and then extending it to a spherical geometry.

Expanded analysis of this $\mathrm{Gd} 2 \mathrm{O} 3$ data is shown in Figure 8 in terms of the integral form of the fractional conversion as a function of reduced time scale. This plot also includes XRD analysis performed on the reaction product, which showed the formation of stable GdF3, the anticipated product, as well as an additional by-product, a Gd2O3.GdF3 complex. This additional complex could provide an explanation for the shifts in reaction kinetics experienced by the powder. Initially, the reactive gas fluorinates the surface of the oxide powder creating the anticipated fluoride product at a third-order rate. The reactive gas then experiences diffusion limitations through the GdF3 outer layer of the particle, yielding a second internal layer with a crystal structure of $\mathrm{Gd} 2 \mathrm{O} 3 \cdot \mathrm{GdF} 3$. This layer forms at a steady state, until increased diffusion limitations further slow the reaction of the reactive gas with the particle core.

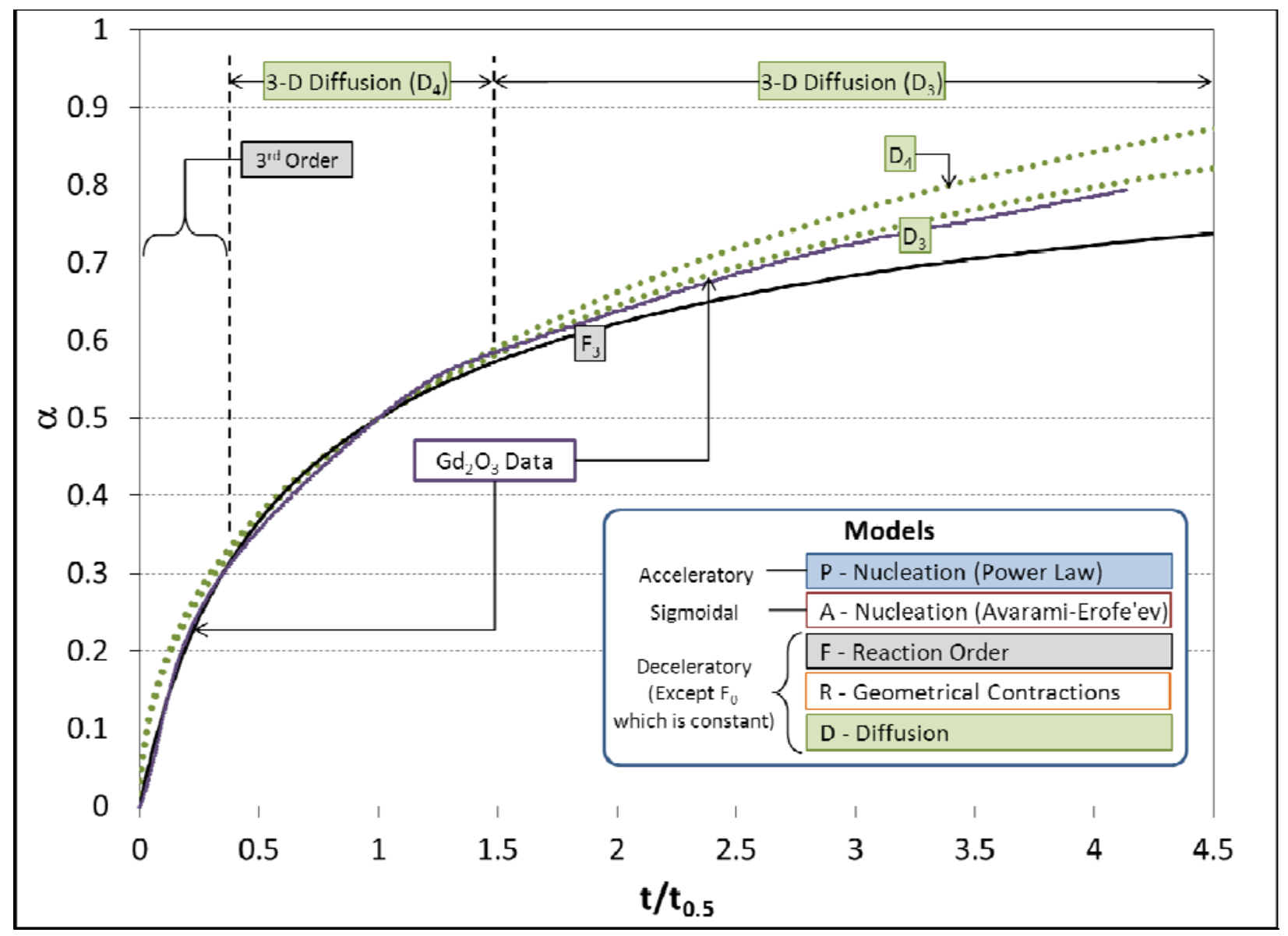

Figure 7. Fitting of solid-state kinetic models to TGA data for Gd2O3 under $22 \%$ SF6 concentration and an ultimate temperature set to $625^{\circ} \mathrm{C}$. Actual isotherm corresponds to $630^{\circ} \mathrm{C}$. 


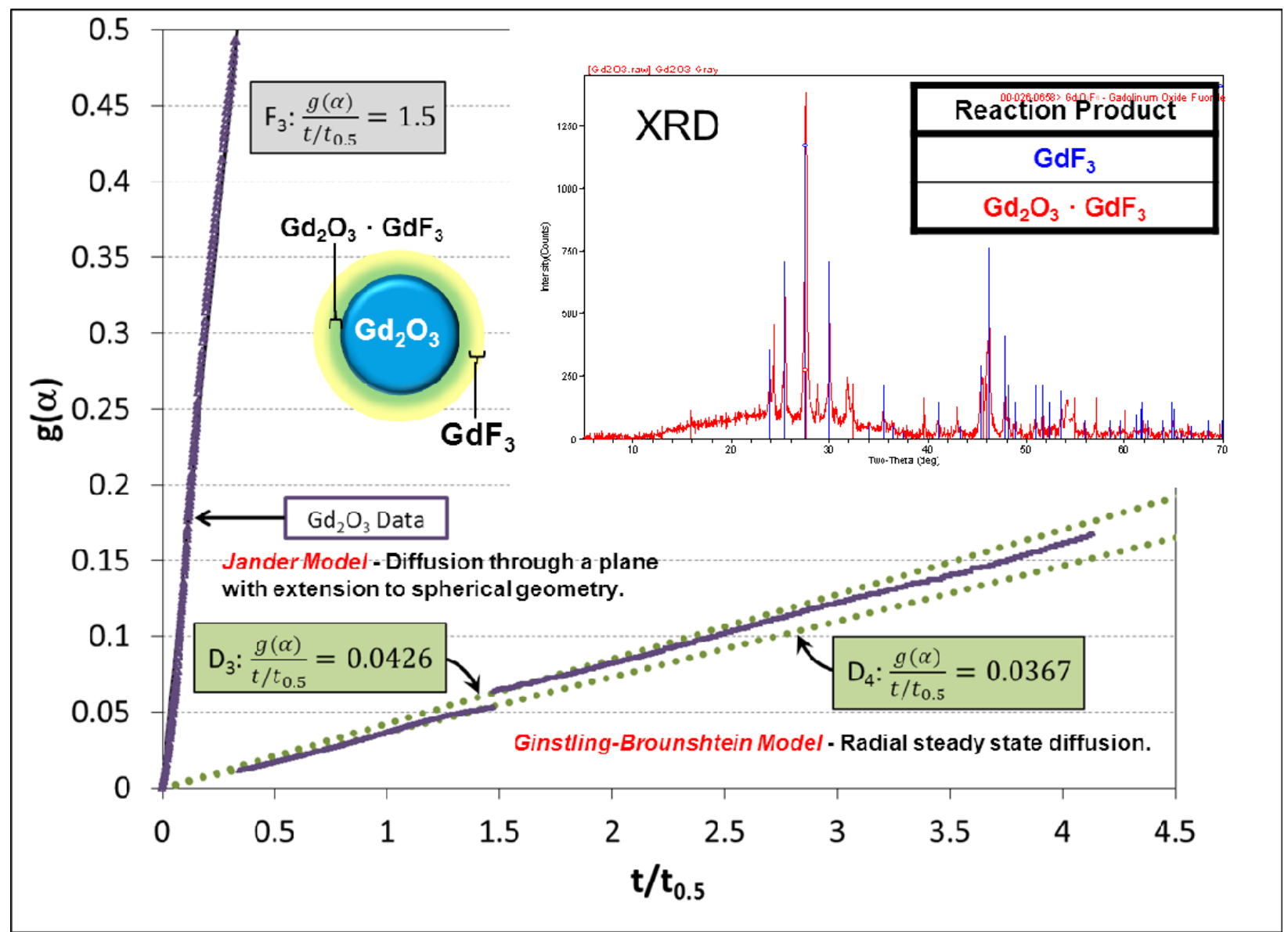

Figure 8. Proposed reaction mechanisms for Gd2O3 by comparison of XRD characterization of reaction product and fitted solid-state kinetic models $\left(22 \% \mathrm{SF6}, 625^{\circ} \mathrm{C}\right)$.

TGA data was obtained at different temperatures for the $\mathrm{Gd} 2 \mathrm{O} 3$ surrogate to determine the reaction parameters for the fluorination of Gd2O3 with SF6, as defined by the kinetic triplet model (Section 1.3), specifically the activation energy, $E a$, and pre-exponential factor $A$. These parameters can be used to predict the reaction rates at a temperature within the empirical range used for the analysis. Figure 9 shows the results of this analysis. 


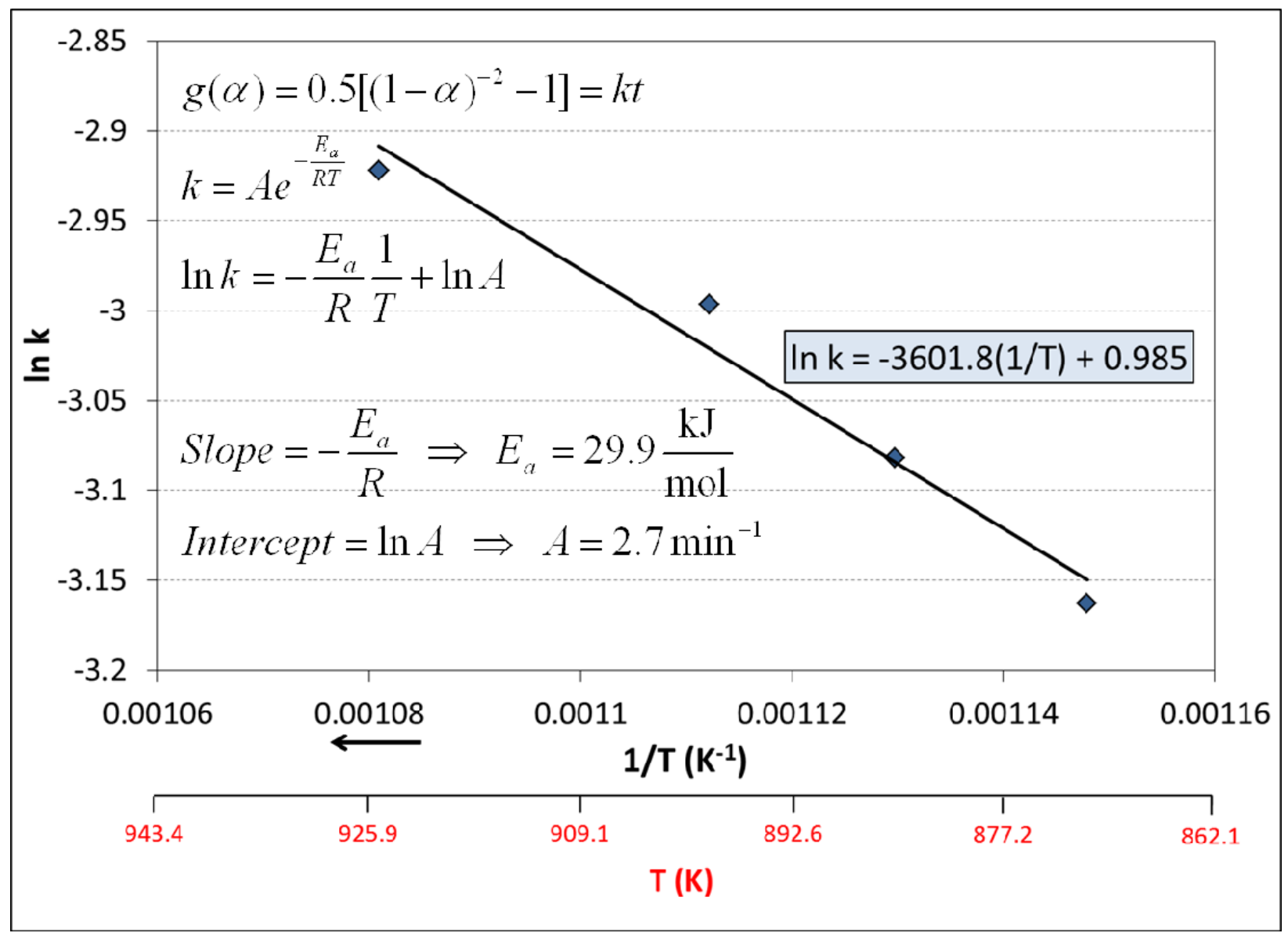

Figure 9. Determination of kinetic parameters $(E a, A)$ for the reaction of Gd2O3 and SF6.

Similar analysis was performed on TGA data of Sm2O3, which confirmed that the reaction with SF6 initially follows third-order kinetics. As a stable product layer is formed on the surface of the oxide particles, the reaction rate slows and follows a 1-D diffusion-limited model. Previously presented XRD data confirmed the formation of only one stable oxyfluoride product, SmOF. This appears to also be the initial stable product from fluorination with another fluorinating agent. Additional data (not shown) from characterization at $650^{\circ} \mathrm{C}$ showed increased divergence form the 1-D model at increased reaction times, which could indicate the formation of a secondary product layer further limiting gas diffusion, potentially $\mathrm{SmF}$. The similar diffusion-limited behavior of $\mathrm{Sm} 2 \mathrm{O} 3$ and $\mathrm{Gd} 2 \mathrm{O} 3$ suggests that lanthanide fission products might behave similarly, as they have similar oxidation states (typically 3) and electronegativities. 


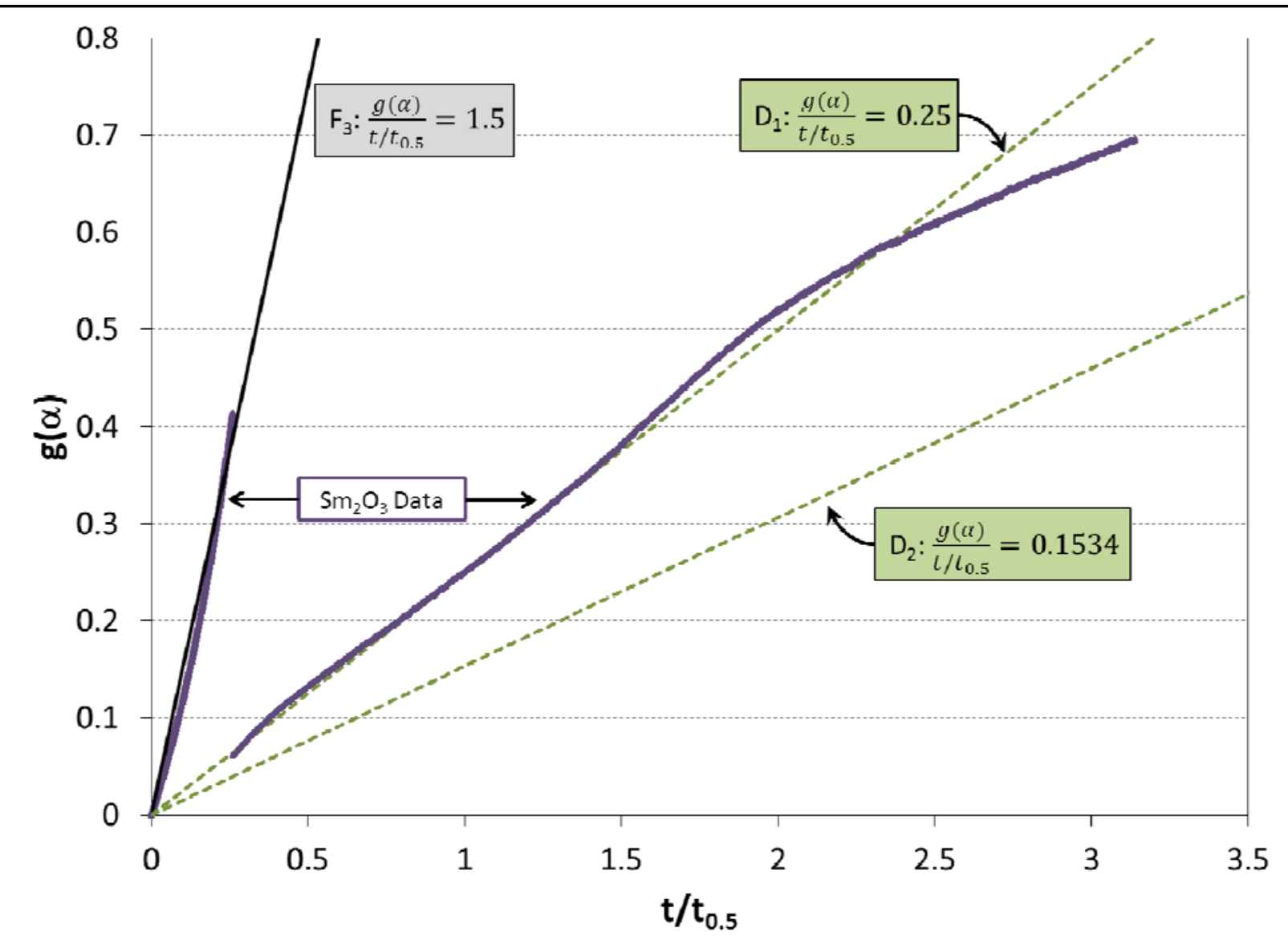

Figure 10. Fitting of solid-state kinetic models to TGA data for Gd2O3 under $25 \%$ SF6 concentration and an ultimate temperature set to $600^{\circ} \mathrm{C}$.

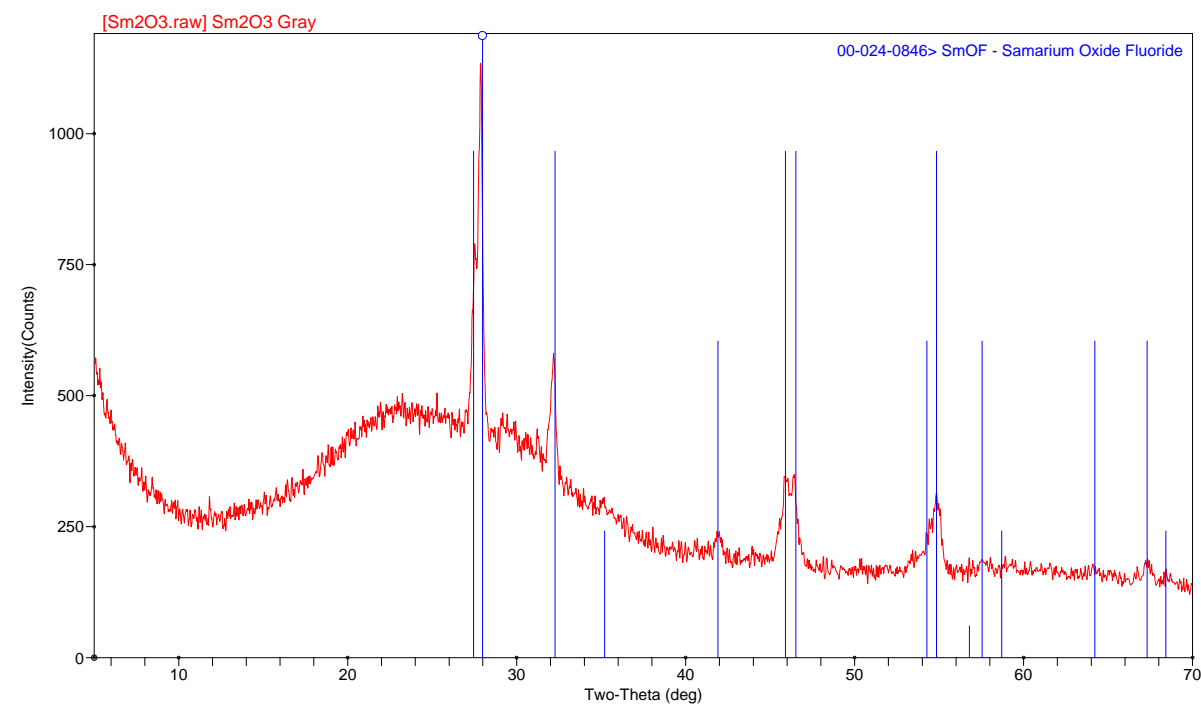

Figure 11. XRD pattern of Sm2O3 powder reacted with $25 \%$ SF6 to an ultimate temperature of $625^{\circ} \mathrm{C}$. 
The isothermal portion of the TGA data for Y2O3 (Figure 12), in terms of fractional conversion as function of the reduced time scale,was also previously reportedas an example to compare with the models. In Figure 12, $t=0$ represents the time at which the sample start the isothermal process. It is evident that, under the tested conditions, Y2O3 follows the R3-model. Although the R3-model is in the category of geometrical contractions, in this case it represents a 3D or volumetric increase in the solid particles as measured by the mass increase measured by TGA. This is supported by the XRD and EDS results previously reported, in which oxyfluoride and oxysulfate species, such as YOF and Y2O2SO4 were found in the reacted $\mathrm{Y} 2 \mathrm{O} 3$ powder. Another way to compare the data is by plotting $g(\alpha) \mathrm{vs} t / t_{0.5}$. According to Eq. 9 for the R3-model, this will result in a straight line with slope $=0.2063$. Figure 13 shows that the R3-model is a close fit to the isothermal portion of the TGA data for Y2O3 under 22\% SF6 concentration.

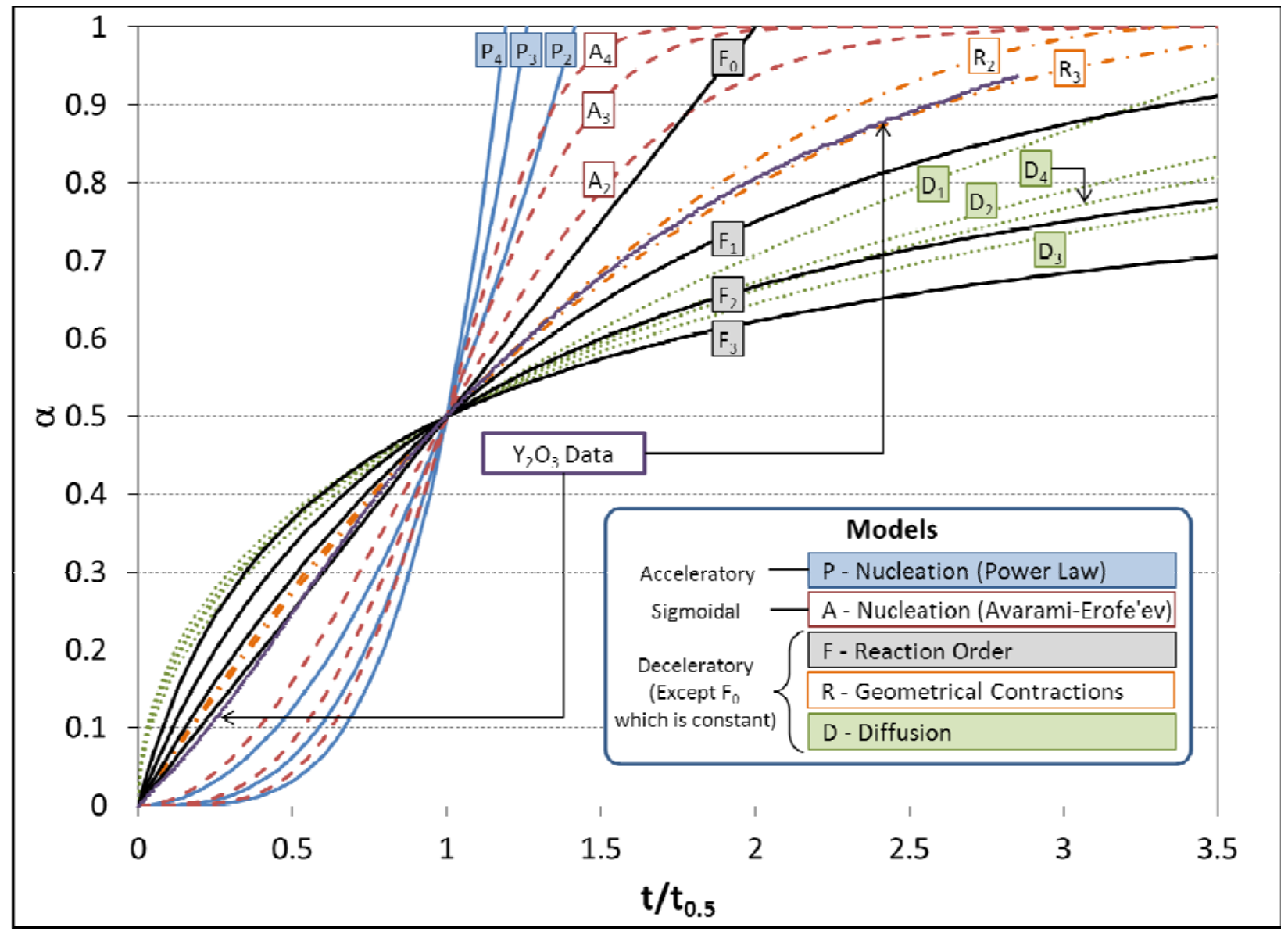

Figure 12. Solid-state kinetic models from Table 3 in terms of $\alpha$ as function of the reduced time scale. Models are compared with the isothermal portion of the TGA data for Y2O3 under $22 \%$ SF6 concentration and an ultimate temperature set to $625^{\circ} \mathrm{C}$. Actual isotherm corresponds to $630^{\circ} \mathrm{C}$. 


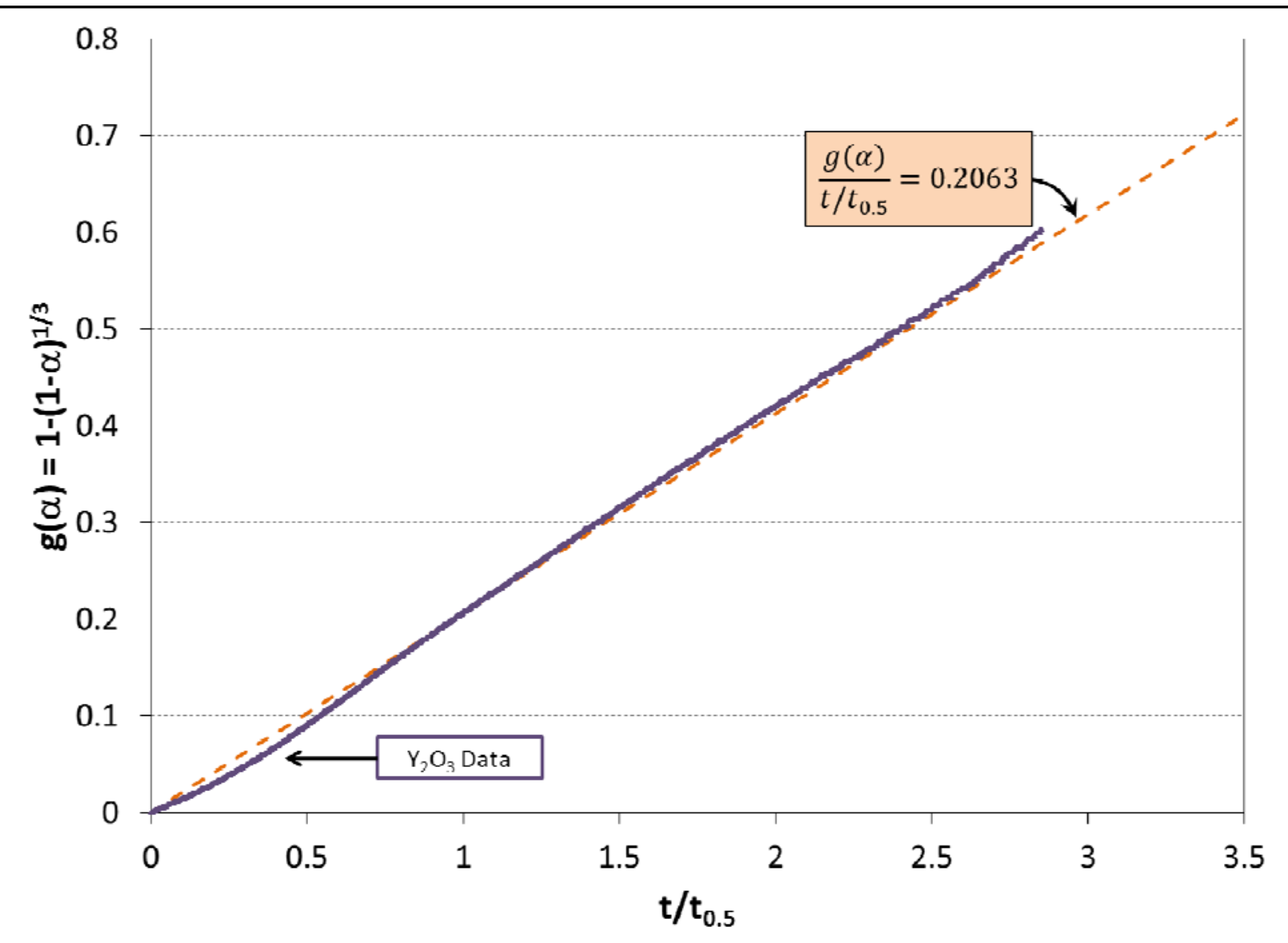

Figure 13. Linear form of the R3-model compared with the isothermal portion of the TGA data for Y2O3 under $22 \%$ SF6 concentration and an ultimate temperature set to $625^{\circ} \mathrm{C}$. Actual isotherm corresponds to $633^{\circ} \mathrm{C}$.

As a final example, additional analysis of the isothermal portion of the TGA data for $\mathrm{RuO} 2$ is presented in Figure 14. For this case, $\mathrm{RuO} 2$ follows a zero-order kinetics mode (F0). This analysis supports a simple reaction mechanism produces a volatile fluoride species, leaving a fresh oxide surface for continuous reaction. Previously reported XRD and EDS characterization of the material retained in the TGA panconfirmed that only $\mathrm{RuO} 2$ is present in the reacted powder, which is the original species present at the beginning of the test.

This section showed how the gas-solid reaction models were compared with the experimental data to obtain some insight of the mechanism undertaking for the different surrogates exposed to SF6. It is intended to apply similar analysis to the remaining surrogates and to the uranium species samples. However, additional experiments at different isothermal temperatures and heating rates are required to elucidate kinetic parameters. Non-isothermal analyses are also possible by applying approximations or numerical methods to evaluate Eq. 6 or using a model-free approach such as the isoconversional method"”. 


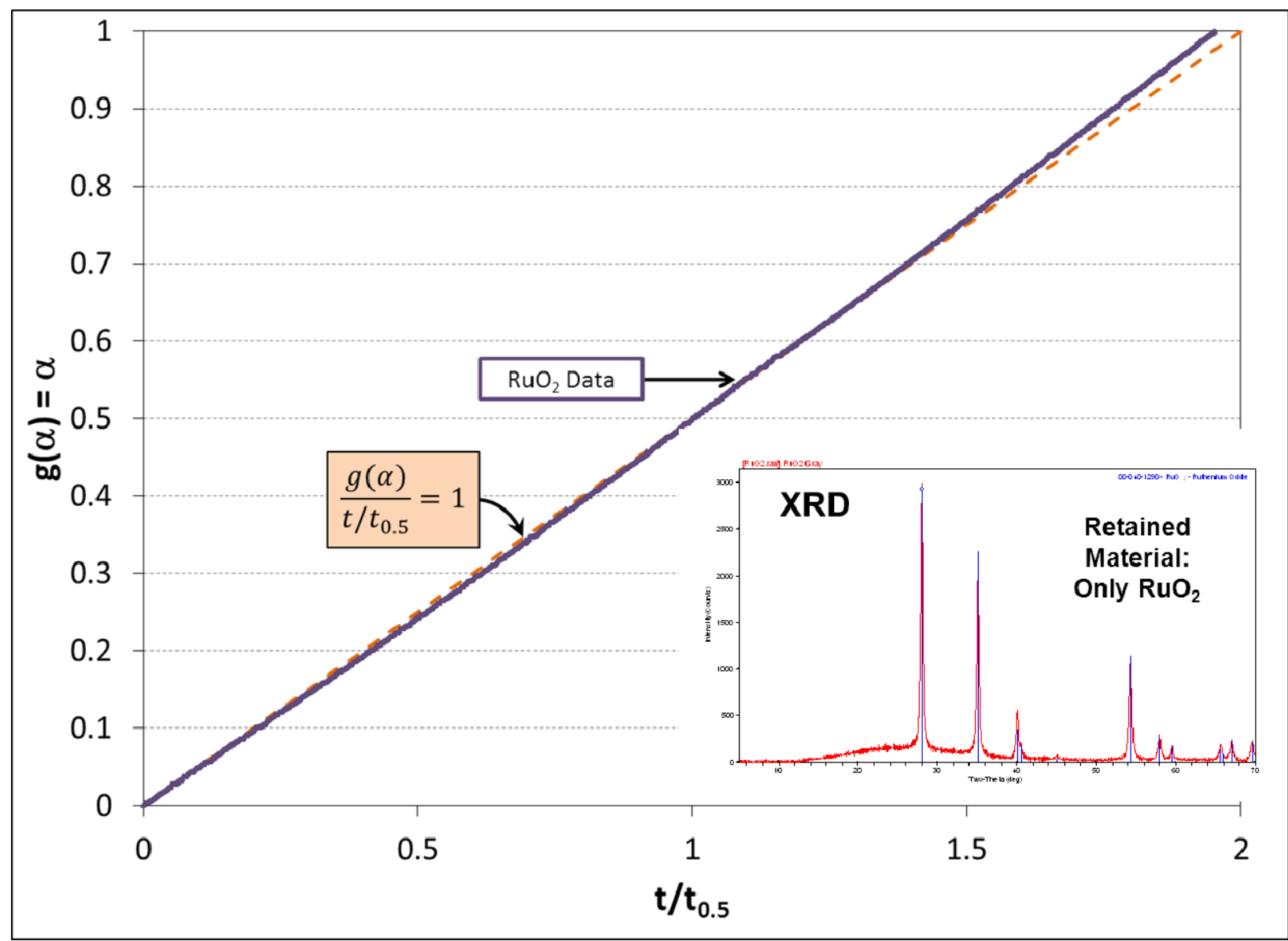

Figure 14. Solid-state kinetic models from Table 3 in terms of $\alpha$ as function of the reduced time scale. Models are compared with the isothermal portion of the TGA data for RuO2 under $22 \%$ SF6 concentration and an ultimate temperature set to $625^{\circ} \mathrm{C}$. Actual isotherm corresponds to $633^{\circ} \mathrm{C}$.

\subsection{Process Flowsheet Development for Separations Based on Fluorination via SF6}

In order to explore UNF treatment processes that might employ gaseous alternate fluorinating agents, an effort has been initiated to develop process flow sheets that employ such agents to separate uranium from UNF. First, a reference flow sheet has been developed that is based on HF- and F2-based UNF treatment processes and reaction steps described in the open literature. Based on this flowsheet, alternative flow sheets are being developed that substitute SF6 as the primary fluorinator. The flow sheets will include all fuel handling operations from initial fuel assembly deconstruction to purification of the UF6 product. The flow sheets will be used to understand the implications of process chemistry changes on the overall UNF treatment process, to help identify technical areas that require more data, and to help evaluate process feasibility, costs, and equipment needs.

Flow sheet development will be an iterative process. Assumptions are made regarding separation factors and the extent of reactions based on the available literature, and that all chemical reactions reach chemical equilibrium. As this suite of flow sheets develops, laboratory data and the results obtained from chemical 
reaction modeling will be used to adjust the models. As more data becomes available on reaction kinetics, more sophisticated process flow sheets are being implemented in Aspen Plus. It is also anticipated that more detailed, dynamic models may be constructed of individual process units using MATLAB, Mathematica, or another software package that allows for solution of time-dependent equations and finite-element calculations.

The current baseline Aspen+ flowsheet simulation is shown below in Figure 15. This process is constructed from information provided in the open literature"'”'. The process begins with disassembly of the fuel rods, which is followed by mechanical chopping and chemical decladding using hydrogen as a zirconium hydriding agent. After decladding, the cladding fragments are separated from the fuel pellets by mechanical agitation and sieving. Advanced voloxidation is used to break down the fuel pellets into a powder, and a high-temperature vacuum distillation process is used to separate volatile oxides and other species from the oxidized UNF. A two-step fluorination process using HF and F2 is used to convert actinide and fission product oxides into fluorides, and the separation of these chemical species is performed on the basis of volatility. Calcium fluoride $(\mathrm{CaF} 2)$ is used as a fluidizing agent in the $\mathrm{HF}$ and F2 fluorinating steps, and is chemically inert. Two product streams are produced; one stream consisting of purified UF6, and another stream consisting of a UF6/PuF6 blend. A UNF treatment process using gaseous fluorinating reagents appears to have some competitive advantages over traditional aqueous processes in terms of the volume of process wastes, the number of process vessels, and the physical size of the plant. In the reference process, the chemical species of interest are present in the form of gases or condensed solids, and no dilute liquid streams are generated. After the voloxidation step, which may be a common front-end to many UNF treatment processes, the number of process vessels is small in comparison to aqueous processes. The size of the vessels is reduced also by eliminating the presence of dilute liquid streams in the process. This fluorination process may also serve as a head-end process for aqueous or pyrochemical approaches.

A modified flowsheet (Figure 16) has been designed in the ASPEN+ software package focusing on the use of SF6 as a fluorinating, agent as opposed to the pure F2 shown in Figure 10. As currently formulated, this flowsheet process is envisioned to be primarily used as a head-end treatment which would be used to remove volatile fluorides from the UNF that has been processed through decladding and voloxidation. Current results indicate that while many of the species where are thermodynamically predicted to form volatile fluoride species do so when exposed to SF6, uranium oxides in particular to this point have not. Therefore this process diagram is set up to show how a UNF material might be moved through the fluorination step with SF6, where a solid product would be rendered composed of uranium and plutonium oxides, although with other solid fluoride species such as CsF and SrF2 would be produced. This flow diagram also assumes that the gas product stream could be put through a condenser to separate any solid fluorides along with species such SO2F2 and SOF4 and the SF6 would be recycled back to the process along with any F2 generated. In this way, the waste streams of gas species that need to be sequestered and treated are minimized while the advantages of controlled fluoride volatility are maintained.

Based on these results, if further conditioning of the uranium/plutonium and other solid residues is desired, the product would be passed on to another process for further conditioning. One such process that could be introduced would be further reaction with NF3, utilizing the work of colleagues at PNNL. This scheme is shown in Figure 17. They have shown that UF6 will readily form from exposure to NF3 at temperatures of approximately $440 \mathrm{oC}$, which should cleanly separate the uranium out from this solid product without any potential contamination of species such as molybdenum, niobium, rhenium, rhodium or similar. This should also leave the plutonium in the bottoms of the reactor along with hot species such as Cs and Sr which may have advantages for implementation. Note that this scheme also assumes 
separation and recycle of fluorinating agents in both fluorination steps so as to minimize the wastes to the treated. 
Figure 15. Block Flow Diagram of Reference UNF Fluorination Process.

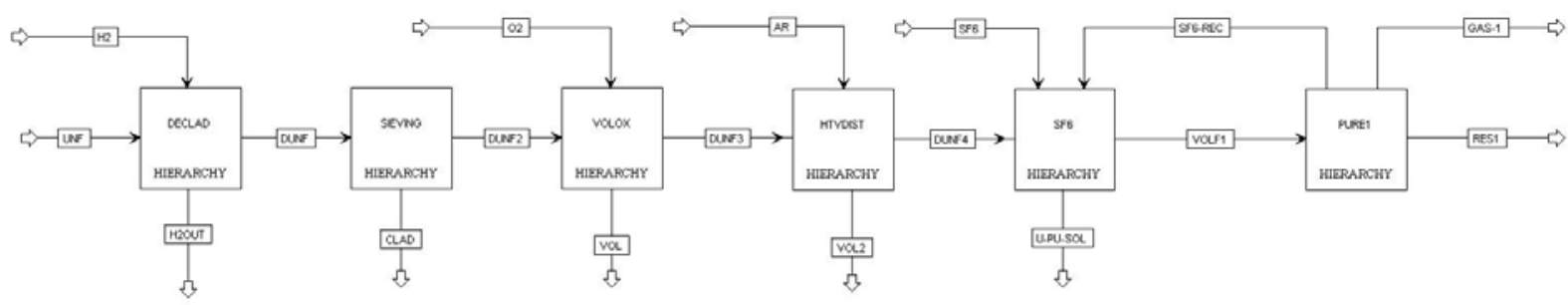

Figure 16. Simplified Process Flow Diagram Incorporating SF6 as the Fluorinating Agent

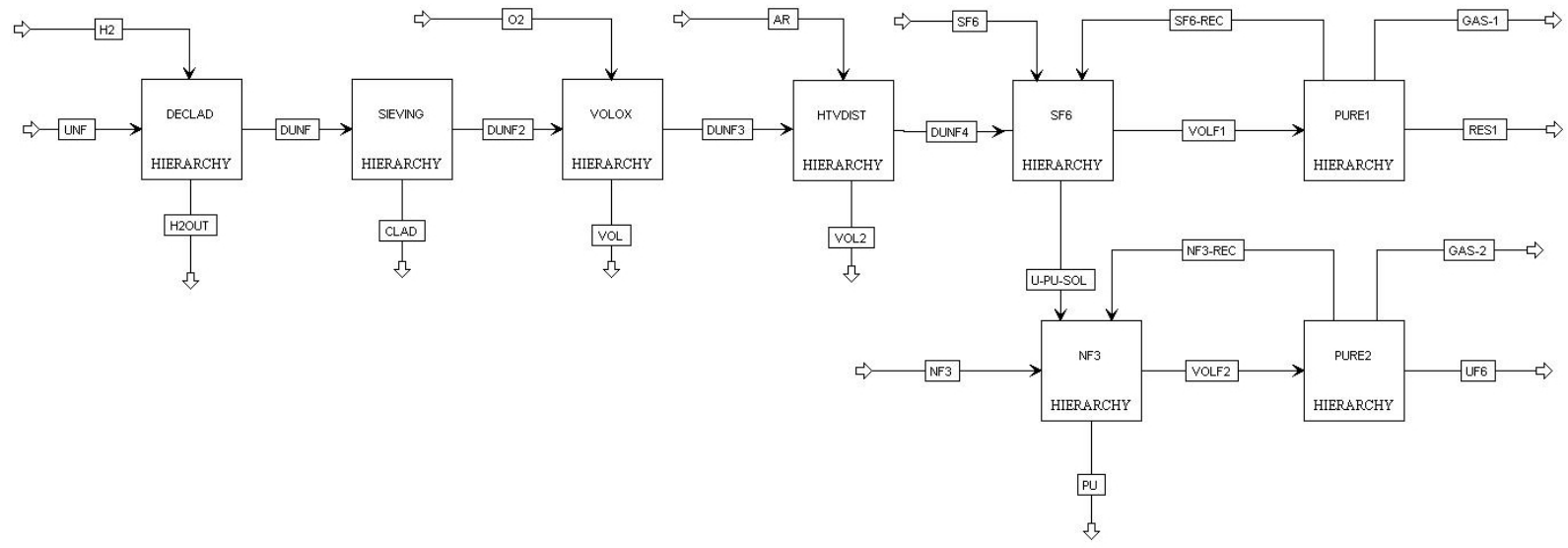

Figure 17. Process Diagram for combined SF6 and NF3 Separations Process which Includes Fluorinating Agent Recycle 
CONCLUSIONS). A purge of inert gas (Ar) was maintained to dilute the $\mathrm{SF}_{6}$ concentration during sample exposure and to avoid any reactive gas backflow to the electronic components residing in the analytical balance area of the instrument. The overall outlet gas stream was exhausted to a water reservoir for dissolution and possible precipitation of any volatile byproducts.

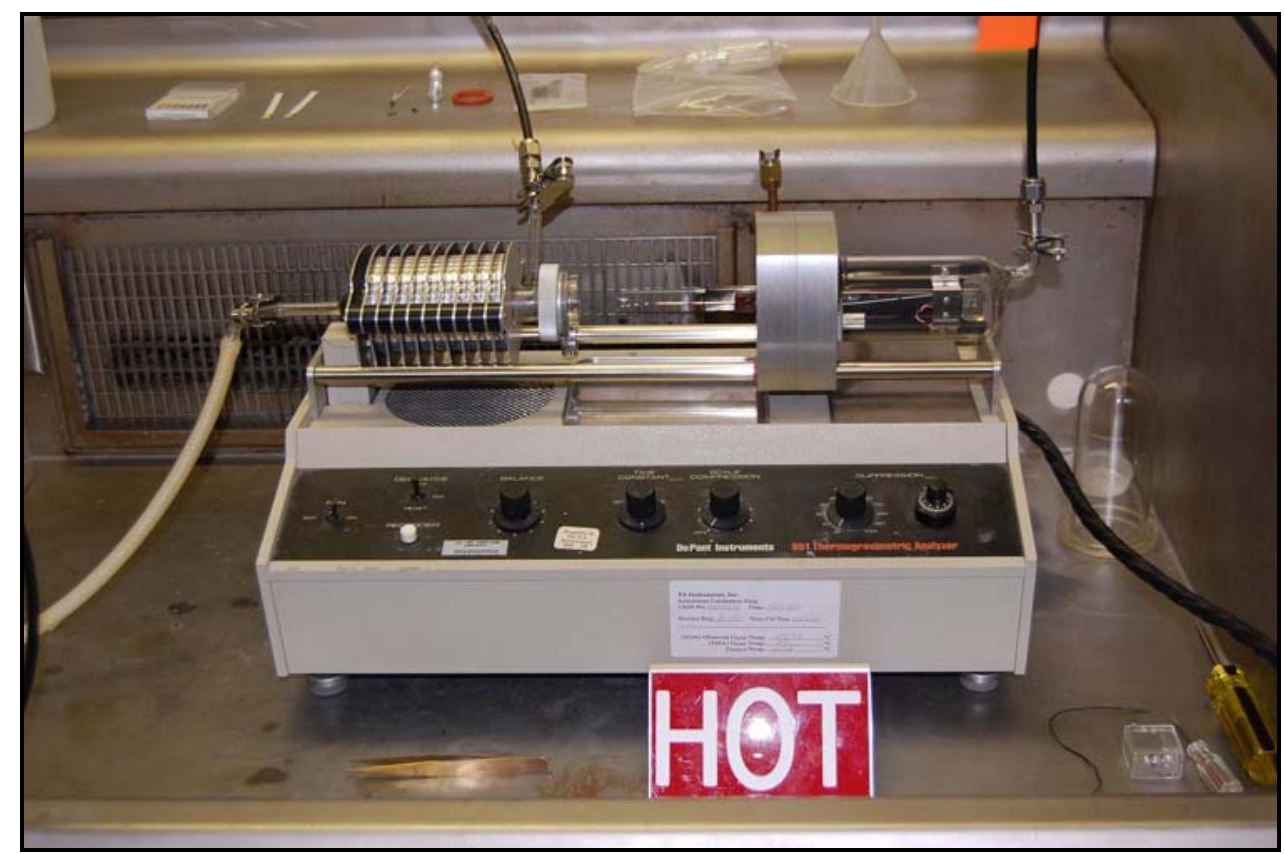

Figure 1. Thermogravimetic analysis unit for testing reactivity of nuclear surrogates and $\mathrm{U}_{3} \mathrm{O}_{8}$

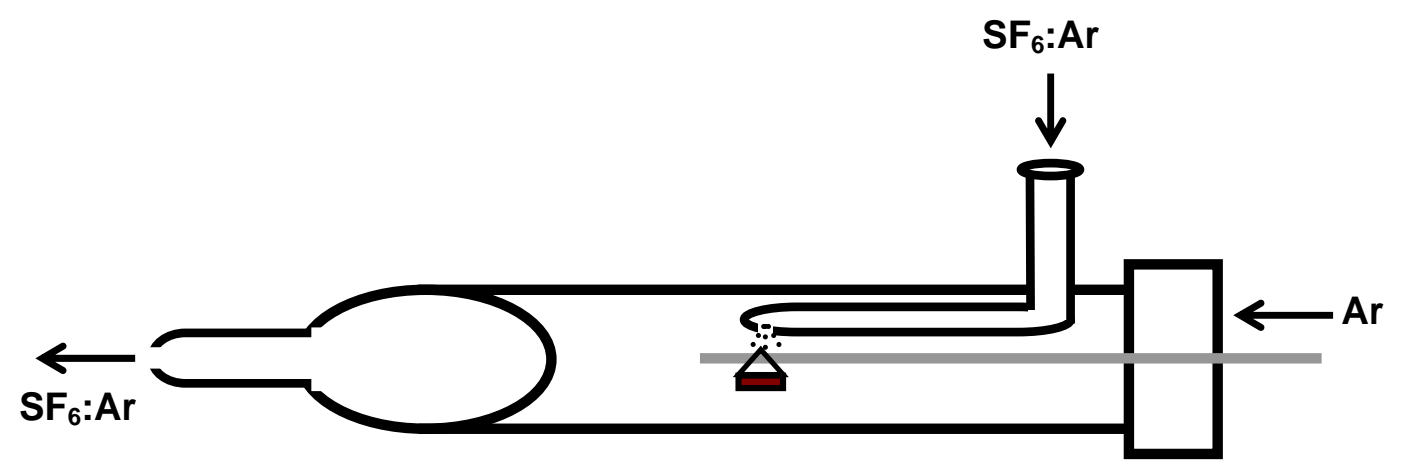

Figure 2. Sketch of modified TGA furnace tube for reactive gas experiments.

Samples were run in platinum $(\mathrm{Pt})$ pans and allowed to equilibrate in the reactive gas for 30 minutes prior to heating. Typical sample masses which were used in the experiments were approximately $10 \mathrm{mg}$, and as typical with TGA the data are presented at $\mathrm{wt} \%$. The samples were initially in powder form, with typical dimensions on the order of $10 \mu \mathrm{m}-100 \mu \mathrm{m}$. XRD data has been previously reported confirming the purity of these samples. The sample mass was monitored during this purging period at the same reactive gas concentration as the heating phase.

Recent runs have focused on the use of a higher temperature Differential Thermal Analysis (DTA) technique that is less sensitive at lower temperatures $\left(<300^{\circ} \mathrm{C}\right)$, but is capable of temperatures as high as $1600^{\circ} \mathrm{C}$. The Dupont DSC/DTA unit used in our experiments is shown below in Figure 3. In DTA, the 
material under study and an inert reference undergo identical thermal cycles, while recording any temperature difference between the two samples. For all experiments reported here, $\mathrm{Al}_{2} \mathrm{O}_{3}$ was used as the inert reference and $\mathrm{Ag}$ was used as the temperature calibration standard. The Dupont DSC/DTA unit seems to be a more robust instrument for the fluorination environments since it made primarily of aluminum oxide with platinum pans rather than quartz glass tubes and rods. In addition, the flow of the reactive gas is vertical from the base, across the sample, and exhausts at the top of the unit.

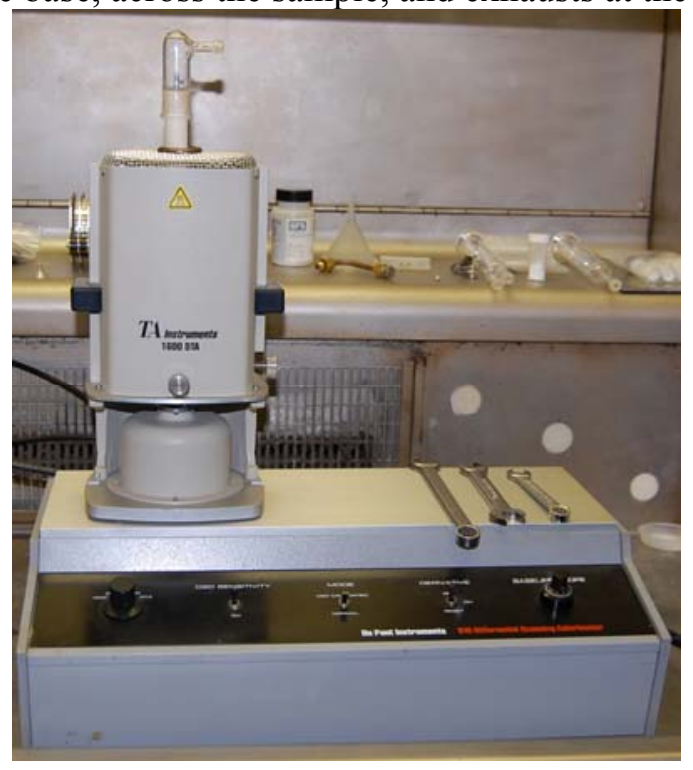

Figure 3. Differential Thermal Analysis unit for testing reactivity of and $\mathrm{U}_{3} \mathrm{O}_{8}$

\subsection{Anticipated Thermophysical Behavior of Samples}


Table 4 lists the oxide and metal materials that were investigated using TGA with mixed $\mathrm{Ar} / \mathrm{SF}_{6}$ streams, the expected fluoride products following reaction with $\mathrm{SF}_{6}$ and their thermal properties. ${ }^{2,8,9,10}$ These properties indicate that the majority of the nuclear surrogate materials exhibit phase transition temperatures far exceeding the sublimation temperature of $\mathrm{UF}_{6}\left(56.5^{\circ} \mathrm{C}\right) .^{2}$ As a result, at temperatures up to $600-650^{\circ} \mathrm{C}$, the reaction with the fluorinated gas $\left(\mathrm{SF}_{6}\right)$ is expected to lead to efficient separation of $\mathrm{U}$ with minimal fluorinated byproducts of $\mathrm{Ru}, \mathrm{Rh}$ and $\mathrm{Re}$. 
Table 4. Oxides and metals characterized by TGA, expected fluoride products and relevant thermophysical properties. ${ }^{3,4,5,6}$

\begin{tabular}{|c|c|c|c|}
\hline $\begin{array}{l}\text { Characterized } \\
\text { Oxide / Metal }\end{array}$ & $\begin{array}{c}\text { Expected Fluoride } \\
\text { Product }\end{array}$ & $\begin{array}{l}\text { Expected Fluoride } \\
\text { Melting Point }\left({ }^{\circ} \mathrm{C}\right)\end{array}$ & $\begin{array}{l}\text { Expected Fluoride } \\
\text { Boiling Point }\left({ }^{\circ} \mathbf{C}\right)\end{array}$ \\
\hline \multirow[t]{3}{*}{$\mathrm{U}_{3} \mathrm{O}_{8}$} & $\mathrm{UF}_{6}$ & 64 (t.p.) & 56.5 (s.p.) \\
\hline & $\mathrm{UF}_{5}$ & 348 & - \\
\hline & $\mathrm{UF}_{4}$ & 1036 & 1450 \\
\hline \multirow[t]{2}{*}{$\mathrm{MoO}_{3}$} & $\mathrm{MoF}_{6}$ & 17.6 & 33.9 \\
\hline & $\mathrm{MoF}_{5}$ & 64 & \\
\hline $\mathrm{Nb}_{2} \mathrm{O}_{5}$ & $\mathrm{NbF}_{5}$ & 80 & 235 \\
\hline \multirow[t]{2}{*}{$\mathrm{CeO}_{2}$} & $\mathrm{CeF}_{4}$ & 838 & decomposes \\
\hline & $\mathrm{CeF}_{3}$ & 1430 & 2330 \\
\hline $\mathrm{Gd}_{2} \mathrm{O}_{3}$ & $\mathrm{GdF}_{3}$ & 1380 & 2280 \\
\hline $\mathrm{Sm}_{2} \mathrm{O}_{3}$ & $\mathrm{SmF}_{3}$ & 1306 & 2330 \\
\hline $\mathrm{Y}_{2} \mathrm{O}_{3}$ & $\mathrm{YF}_{3}$ & 1136 & 2230 \\
\hline $\mathrm{SrO}$ & $\mathrm{SrF}_{2}$ & 1400 & - \\
\hline $\mathrm{HfO}_{2}$ & $\mathrm{HfF}_{4}$ & $>970$ & $>718$ \\
\hline $\mathrm{ZrO}_{2}$ & $\mathrm{ZrF}_{4}$ & 912 & 918 \\
\hline \multirow[t]{2}{*}{$\mathrm{RuO}_{2} / \mathrm{Ru}$} & $\mathrm{RuF}_{5}$ & 101 & 280 \\
\hline & $\mathrm{RuF}_{6}$ & 51 & 70 \\
\hline \multirow[t]{3}{*}{$\mathrm{Rh}_{2} \mathrm{O}_{3} / \mathrm{Rh}$} & $\mathrm{RhF}_{3}$ & sublimes & 600 \\
\hline & $\mathrm{RhF}_{5}$ & 95.5 & - \\
\hline & $\mathrm{RhF}_{6}$ & 70 & 73.5 \\
\hline \multirow[t]{3}{*}{$\mathrm{Re}_{2} \mathrm{O}_{3} / \mathrm{Re}$} & $\mathrm{ReF}_{4}$ & sublimes [8] & $>150[8]$ \\
\hline & $\mathrm{ReF}_{6}$ & 18.5 (t.p.) [9] & 33.7 [9] \\
\hline & $\mathrm{ReF}_{7}$ & 48.3 (t.p.) [9] & 73.7 [9] \\
\hline
\end{tabular}

\section{RESULTS AND DISCUSSION}

\subsection{Non-U Fission Products - Representative UNF Matrix}

Preliminary studies in the early 1970 s of the interaction of $\mathrm{SF}_{6}$ with metals and oxides, revealed the possibility of utilizing this non-toxic gas as an active fluorinating agent. ${ }^{11}$ Those results indicated that both metals and oxides reacted with pure streams of $\mathrm{SF}_{6}$ over temperature ranges of $500-600^{\circ} \mathrm{C}$ and 600 $700^{\circ} \mathrm{C}$, respectively. ${ }^{11}$ Additionally, previous experiments by McNamara et al. ${ }^{12}$ showed that the thermal profile for the reaction of $\alpha-\mathrm{U}_{3} \mathrm{O}_{8}$ powder and $5 \% \mathrm{NF}_{3}$ gas exhibits a rapid, exothermic mass loss onset around $440^{\circ} \mathrm{C}$ at a heating rate of $10^{\circ} \mathrm{C} / \mathrm{min}$ and corresponding to the release of $\mathrm{UF}_{6}$. Based on these results, initial experiments with the $\mathrm{SF}_{6}$ reactive gas were planned at the same heating rate with a maximum temperature $\left(625^{\circ} \mathrm{C}\right)$, similar to the Opalovsky et al. results and above that reported for the $\mathrm{NF}_{3}$ gas (reference?). Each sample was then held for 60 minutes at $625^{\circ} \mathrm{C}$ to monitor reaction rate changes.

Table 5 lists the extrapolated onset temperatures and inflection temperatures from the TGA thermograms of all the characterized oxides/metals for the different conditions. The onset point denotes the temperature at which the mass gain or loss begins. It is extrapolated from the curves since it is a 
reproducible calculation specified by ASTM and ISO standards. The inflection point characterizes the peak of the first derivative of the curve, which indicates the point of greatest rate of mass change after the onset. Table 6 includes a summary of the experimental data for the reactivity of the surrogate materials on exposure to $\mathrm{SF}_{6}$, while Table 7 includes a summary of the products identified after the reaction was complete using EDS. 
Sulfur Hexafluoride Treatment of Used Nuclear Fuel to Enhance Separations

FCRD-SWF-2012-000332

September 28, 2012

Table 5. Extrapolated onset and inflection points of surrogate weight changes as measured by TGA.

\begin{tabular}{|c|c|c|c|c|c|}
\hline $\begin{array}{l}\text { Characterized } \\
\text { Oxide / Metal }\end{array}$ & $\begin{array}{c}\mathrm{SF}_{6} \\
\text { Concentration } \\
(\%)\end{array}$ & $\begin{array}{c}\text { Extrapolated } \\
\text { Onset Time } \\
\text { (min)* }\end{array}$ & $\begin{array}{c}\text { Corresponding } \\
\text { Onset } \\
\text { Temperature } \\
\left({ }^{\circ} \mathrm{C}\right)\end{array}$ & $\begin{array}{l}\text { Inflection } \\
\text { Time } \\
\text { (min)* }\end{array}$ & $\begin{array}{c}\text { Corresponding } \\
\text { Inflection } \\
\text { Temperature } \\
\left({ }^{\circ} \mathbf{C}\right) \\
\end{array}$ \\
\hline \multirow[t]{2}{*}{$\mathrm{CeO}_{2}$} & 10 & 79.7 & 529 & 86.4 & 609 \\
\hline & 22 & 79.3 & 499 & 86.8 & 587 \\
\hline \multirow[t]{3}{*}{$\mathrm{Gd}_{2} \mathrm{O}_{3}$} & 10 & 85.3 & 612 & 88.0 & 640 \\
\hline & 22 & 73.3 & 483 & 81.5 & 573 \\
\hline & 10 & 85.1 & 600 & 93.0 & 688 \\
\hline \multirow[t]{3}{*}{$\mathrm{Sm}_{2} \mathrm{O}_{3}$} & 10 & 85.1 & 613 & 88.0 & 642 \\
\hline & 22 & 82.4 & 579 & 85.0 & 608 \\
\hline & 10 & $\begin{array}{c}88.5(1) \\
108.1(2) \\
\end{array}$ & $\begin{array}{l}633 \\
747 \\
\end{array}$ & $\begin{array}{c}97.0(1) \\
107.5(2)\end{array}$ & $\begin{array}{l}724 \\
747 \\
\end{array}$ \\
\hline \multirow[t]{3}{*}{$\mathrm{Y}_{2} \mathrm{O}_{3}$} & 10 & 82.6 & 578 & 107.0 & 631 \\
\hline & 22 & 83.5 & 593 & 99.0 & 632 \\
\hline & 10 & $\begin{array}{l}88.5(1) \\
98.8(2)\end{array}$ & $\begin{array}{l}638(1) \\
739(2)\end{array}$ & $97.3(1)$ & $722(1)$ \\
\hline \multirow[t]{2}{*}{$\mathrm{SrO}$} & 10 & $\begin{array}{l}71.5(1) \\
79.6(2) \\
\end{array}$ & $\begin{array}{l}429(1) \\
523(2) \\
\end{array}$ & $\begin{array}{l}77.7(1) \\
86.5(2) \\
\end{array}$ & $\begin{array}{l}501(1) \\
604(2) \\
\end{array}$ \\
\hline & 22 & $\begin{array}{l}71.4(1) \\
80.1(2)\end{array}$ & $\begin{array}{l}399(1) \\
499(2)\end{array}$ & $\begin{array}{l}77.2(1) \\
83.6(2)\end{array}$ & $\begin{array}{l}465(1) \\
539(2)\end{array}$ \\
\hline \multirow[t]{2}{*}{$\mathrm{HfO}_{2}$} & 10 & \multicolumn{4}{|c|}{ no change } \\
\hline & 22 & \multicolumn{4}{|c|}{ no change } \\
\hline \multirow[t]{2}{*}{$\mathrm{ZrO}_{2}$} & 10 & \multicolumn{4}{|c|}{ no change } \\
\hline & 22 & \multicolumn{4}{|c|}{ no change } \\
\hline \multirow[t]{2}{*}{$\mathrm{RuO}_{2}$} & 10 & 85.3 & 617 & \multicolumn{2}{|c|}{ undefined - linear } \\
\hline & 22 & 84.8 & 610 & \multicolumn{2}{|c|}{ undefined - linear } \\
\hline \multirow[t]{3}{*}{$\mathrm{Rh}_{2} \mathrm{O}_{3}$} & 10 & $\begin{array}{l}52.3(1) \\
75.5(2) \\
84.5(3) \\
87.1(4)\end{array}$ & $\begin{array}{l}231.5(1) \\
490.5(2) \\
593.8(3) \\
622.7(4)\end{array}$ & $\begin{array}{c}60.4(1) \\
81.6(2) \\
85.5(3) \\
127.2(4)\end{array}$ & $\begin{array}{l}319.1(1) \\
559.7(2) \\
604.9(3) \\
622.2(4)\end{array}$ \\
\hline & 22 & $\begin{array}{l}51.9(1) \\
75.5(2) \\
84.7(3) \\
89.3(4)\end{array}$ & $\begin{array}{l}207.6(1) \\
457.7(2) \\
565.0(3) \\
598.9(4)\end{array}$ & $\begin{array}{c}63.7(1) \\
81.5(2) \\
87.8(3) \\
123.7(4)\end{array}$ & $\begin{array}{l}327.1(1) \\
527.2(2) \\
600.9(3) \\
594.4(4)\end{array}$ \\
\hline & 10 & $\begin{array}{l}53.9(1) \\
74.7(2) \\
85.2(3) \\
95.0(4) \\
97.7(5)\end{array}$ & $\begin{array}{l}246.2(1) \\
479.6(2) \\
599.6(3) \\
708.3(4) \\
737.1(5)\end{array}$ & $\begin{array}{c}65.7(1) \\
81.3(2) \\
93.1(3) \\
96.8(4) \\
102.8(5)\end{array}$ & $\begin{array}{l}376.5(1) \\
555.1(2) \\
687.6(3) \\
727.8(4) \\
747.9(5)\end{array}$ \\
\hline $\mathrm{Re}_{2} \mathrm{O}_{3}$ & 10 & 72.8 & & 78.3 & \\
\hline $\mathrm{Ru}$ & 10 & 81.0 & 561 & \multicolumn{2}{|c|}{ undefined } \\
\hline & 22 & 84.2 & 603 & \multicolumn{2}{|c|}{ undefined } \\
\hline $\mathrm{Rh}$ & 10 & \multicolumn{4}{|c|}{ no change } \\
\hline & 22 & \multicolumn{4}{|c|}{ no change } \\
\hline $\operatorname{Re}$ & 10 & 68.5 & 596 & unde & ed - linear \\
\hline
\end{tabular}


* Times include the 30 min purge period at $25^{\circ} \mathrm{C}$. Parenthesis indicates if multiple onsets.

Table 6. Summary of reactivity results of fission product surrogates as measured by TGA.

\begin{tabular}{|c|c|c|c|c|c|}
\hline $\begin{array}{l}\text { Characterized } \\
\text { Oxide / Metal }\end{array}$ & $\begin{array}{c}\mathrm{SF}_{6} \\
\text { Concentration } \\
(\%)\end{array}$ & $\begin{array}{c}\text { Ultimate / } \\
\text { Isotherm } \\
\text { Temperature - } \\
\text { Nominal }\left({ }^{\circ} \mathrm{C}\right) \\
\end{array}$ & $\begin{array}{c}\text { Ultimate / } \\
\text { Isotherm } \\
\text { Temperature - } \\
\text { Experimental }\left({ }^{\circ} \mathrm{C}\right)\end{array}$ & $\begin{array}{c}\text { Max. } \\
\text { Weight } \\
\text { Change }(\%)\end{array}$ & $\begin{array}{l}\text { Stable / } \\
\text { Volatile }\end{array}$ \\
\hline \multirow[t]{2}{*}{$\mathrm{CeO}_{2}$} & 10 & 625 & 620 & $\begin{array}{l}+5.9 \\
\end{array}$ & Stable \\
\hline & 22 & 625 & 593 & +9.7 & Stable \\
\hline \multirow[t]{3}{*}{$\mathrm{Gd}_{2} \mathrm{O}_{3}$} & 10 & 625 & 633 & +11.3 & Stable \\
\hline & 22 & 625 & 630 & +12.0 & Stable \\
\hline & 10 & 750 & 745 & +21.1 & Stable \\
\hline \multirow[t]{3}{*}{$\mathrm{Sm}_{2} \mathrm{O}_{3}$} & 10 & 625 & 634 & +7.4 & Stable \\
\hline & 22 & 625 & 629 & +8.3 & Stable \\
\hline & 10 & 750 & 750 & +16.2 & Stable \\
\hline \multirow[t]{3}{*}{$\mathrm{Y}_{2} \mathrm{O}_{3}$} & 10 & 625 & 630 & +17.1 & Stable \\
\hline & 22 & 625 & 630 & +19.0 & Stable \\
\hline & 10 & 750 & 732 & +18.8 & Stable \\
\hline \multirow[t]{2}{*}{$\mathrm{SrO}$} & 10 & 625 & 611 & +16.4 & Stable* \\
\hline & 22 & 625 & 584 & +18.3 & Stable* \\
\hline \multirow[t]{2}{*}{$\mathrm{HfO}_{2}$} & 10 & 625 & 635 & no change & Stable \\
\hline & 22 & 625 & 638 & no change & Stable \\
\hline \multirow[t]{2}{*}{$\mathrm{ZrO}_{2}$} & 10 & 625 & 630 & no change & Stable \\
\hline & 22 & 625 & 630 & no change & Stable \\
\hline \multirow[t]{2}{*}{$\mathrm{RuO}_{2}$} & 10 & 625 & 633 & -10.1 & Volatile \\
\hline & 22 & 625 & 633 & -18.4 & Volatile \\
\hline \multirow[t]{3}{*}{$\mathrm{Rh}_{2} \mathrm{O}_{3}$} & 10 & 625 & 622 & no change & Stable \\
\hline & 22 & 625 & 594 & -2.5 & Volatile \\
\hline & 10 & 750 & 743 & -7.0 & Volatile \\
\hline $\mathrm{Re}_{2} \mathrm{O}_{3}$ & 10 & 625 & 630 & -100 & Volatile \\
\hline \multirow[t]{2}{*}{$\mathrm{Ru}$} & 10 & 625 & 625 & $\begin{array}{l}+6.8 \\
\end{array}$ & Stable \\
\hline & 22 & 625 & 632 & +7.3 & Stable \\
\hline \multirow[t]{2}{*}{$\mathrm{Rh}$} & 10 & 625 & 620 & no change & Stable \\
\hline & 22 & 625 & 629 & no change & Stable \\
\hline $\mathrm{Re}$ & 10 & 625 & 630 & -74.0 & Volatile \\
\hline
\end{tabular}

Table 7 summarizes the identified reaction products from the reaction of the different fission products and $\mathrm{SF}_{6}$ at a concentration of $22 \%$. Continuing studies are focused on additional characterization of the reaction products of these fission products by DTA testing. 
Table 7. Summary of identified products of reactive oxides/metals based on EDS spectra (22\% SF6, ultimate temperature: $625^{\circ} \mathrm{C}$ )

\begin{tabular}{|c|c|c|c|}
\hline Characterized Oxide / Metal & $\begin{array}{c}\text { Formed } \\
\text { Fluoride Product }\end{array}$ & $\begin{array}{c}\text { Formed } \\
\text { Sulfide } \\
\text { Product }\end{array}$ & $\begin{array}{c}\text { Other } \\
\text { Formed } \\
\text { Products }\end{array}$ \\
\hline $\mathrm{CeO}_{2}$ & $\mathrm{CeF}_{3}$ & $\mathrm{CeSO}_{4}$ & \\
\hline $\mathrm{Gd}_{2} \mathrm{O}_{3}$ & $\mathrm{GdF}_{3}$, & & \\
\hline $\mathrm{Sm}_{2} \mathrm{O}_{3} \mathrm{O}_{3} \cdot 2 \mathrm{GdF}_{3}$ & $\mathrm{SmOF}$ & & \\
\hline $\mathrm{Y}_{2} \mathrm{O}_{3}$ & $\mathrm{YOF}$ & $\mathrm{Y}_{2} \mathrm{O}_{2} \mathrm{SO}_{4}$ & \\
\hline $\mathrm{SrO}$ & $\mathrm{SrF}_{2}$ & $\mathrm{SrSO}_{4}$ & $\begin{array}{c}\mathrm{SrCO} \\
\mathrm{Sr}(\mathrm{OH})_{2} \cdot \mathrm{H}_{2} \mathrm{O}, \\
\mathrm{Sr}(\mathrm{OH})_{2} \cdot 8 \mathrm{H}_{2} \mathrm{O}\end{array}$ \\
\hline $\mathrm{RuO}_{2}$ & & & \\
\hline $\mathrm{Rh}_{2} \mathrm{O}_{3}$ & & & \\
\hline $\mathrm{Ru}$ & & & \\
\hline
\end{tabular}

\subsection{Uranium Oxides}

Uranium trioxide $\left(\mathrm{UO}_{3}\right)$ and triuranium octoxide $\left(\mathrm{U}_{3} \mathrm{O}_{8}\right)$ samples were tested at multiple temperatures, concentrations and total gas flow rates. These higher stability oxides were chosen for initial testing with the assumption that a voloxidation step will precede any fluorination process, which would convert the used $\mathrm{UO}_{2}$ fuel into pulverized $\mathrm{U}_{3} \mathrm{O}_{8}$.

Figure 4 shows thermograms for the oxides with varied $\mathrm{SF}_{6}$ concentrations at a flow rate of $150 \mathrm{sccm}$. All samples were heated at $10^{\circ} \mathrm{C} \mathrm{min}^{-1}$ to an ultimate temperature of $800^{\circ} \mathrm{C}$, followed by a variableduration isothermal hold. The results show that the $\mathrm{UO}_{3}$ sample readily reacts at temperatures as low as $300^{\circ} \mathrm{C}$ and ambient pressure, although this may be attributed to water loss and not necessarily formation of a volatile product such as $\mathrm{UF}_{6}$. Lengthening the time of the isothermal hold at $800^{\circ} \mathrm{C}$ from 60 to 120 min results in an increased mass loss from 13.3 to $49.0 \%$. Note that at this temperature corrosion of the quartz balancing rod that supports the sample pan may result in an additional mass loss, which must be deconvoluted from the sample weight change. The characterized $\mathrm{U}_{3} \mathrm{O}_{8}$ sample was obtained from SRNL house stock and no previous history could be obtained. The XRD pattern of the sample was consistent with the ICCD database, with a smaller presence of $\mathrm{UO}_{3} \cdot 0.8 \mathrm{H}_{2} \mathrm{O}$. The results for this $\mathrm{U}_{3} \mathrm{O}_{8}$ sample suggest that this oxide is non-reactive up to $800^{\circ} \mathrm{C}$, which we attribute to the material being a hightemperature fired $(\beta)$ version of the oxide. SRNL is in talks with PNNL to acquire a lower-temperature fired version $(\alpha)$ for characterization. Based on the apparently stability of the $\mathrm{U}_{3} \mathrm{O}_{8}$ samples, and difficulty of deconvoluting the $\mathrm{UO}_{3}$ in the TGA, it was decided to explore the reactivity in the DTA due to its enhanced stability at higher temperatures. 


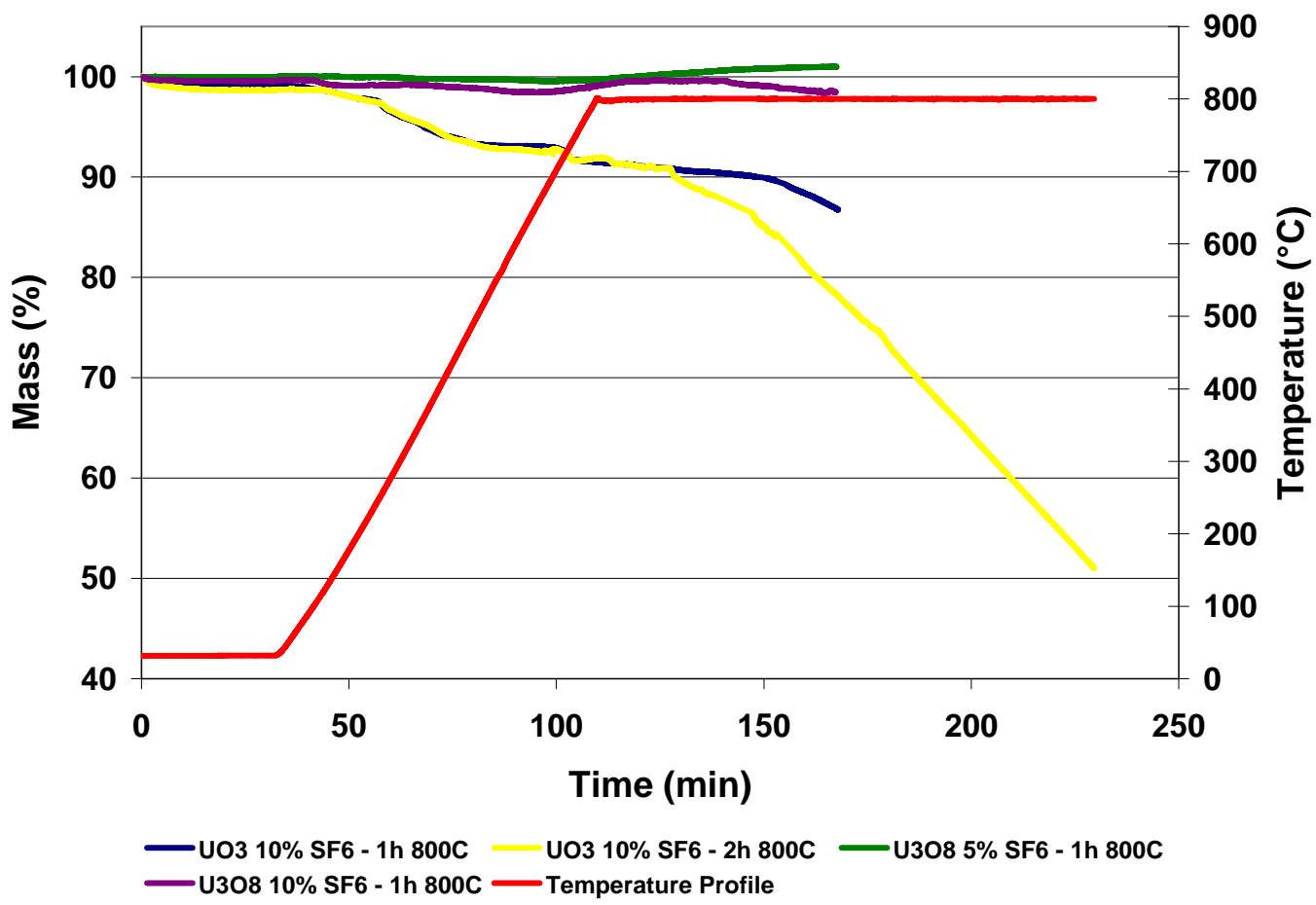

Figure 4. TGA thermal profiles of uranium oxides at varied $\mathrm{SF}_{6}$ concentration and an ultimate temperature of $\mathrm{800}^{\circ} \mathrm{C}$ (variable isotherm hold times).

Figure 5 below shows a run of $\mathrm{U}_{3} \mathrm{O}_{8}$ exposed to an elevated $50 \%$ concentration of $\mathrm{SF}_{6}$ compared to data for $\mathrm{MoO}_{3}$ and $\mathrm{Nb}_{2} \mathrm{O}_{5}$ exposed to a nominal concentration of $25 \% \mathrm{SF}_{6}$. While the data for $\mathrm{U}_{3} \mathrm{O}_{8}$ appears to show rapid weight loss at temperatures greater than $825^{\circ} \mathrm{C}$, this data is not easily interpreted as the effect is difficult to deconvolute from fluorination and subsequent volatilization of the quartz balancing rod supporting the sample pan. However, the data for the $\mathrm{MoO}_{3}$ and $\mathrm{Nb}_{2} \mathrm{O}_{5}$ is interesting, particularly when compared to the behavior of $\mathrm{UO}_{3}$ exposed to $\mathrm{SF}_{6}$ as it indicates that both of these compounds will stay in the solid with the other non-volatiles at lower temperatures. However, Mo oxide is usually regarded as a potential contaminant in the volatile fluoride stream, but these data suggest that it could be effectively left in the ash at temperatures of $\leq 800^{\circ} \mathrm{C}$. 


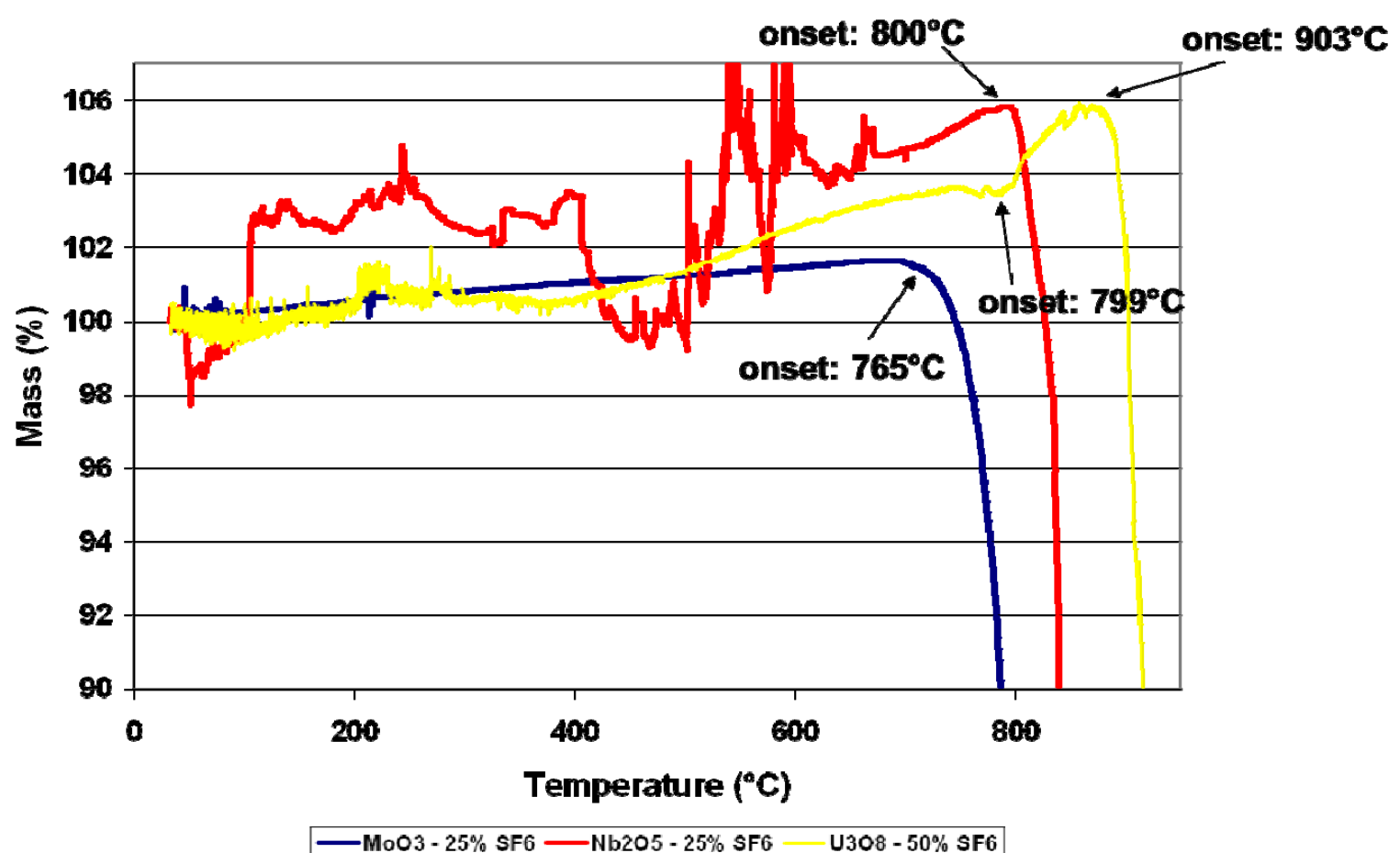

Figure 5. TGAthermal profiles of $\mathrm{MoO}_{3}, \mathrm{Nb}_{2} \mathrm{O}_{5}$, and $\mathrm{U}_{3} \mathrm{O}_{8}$ runs at varied $\mathrm{SF}_{6}$ concentration

Figure 6 shows the DTA thermal profile of $\mathrm{U}_{3} \mathrm{O}_{8}$ exposed to different concentrations of $\mathrm{SF}_{6}$. Initial results suggest that the highly stable oxide does not fluorinate even at concentrations as high as $100 \% \mathrm{SF}_{6}$ $(35 \mathrm{sccm})$ up to a temperature of $1100^{\circ} \mathrm{C}$. Comparison of the three thermal profiles $(0 \%, 25 \%$ and $100 \%$ $\mathrm{SF}_{6}$ ) suggests that the variations in the $25 \% \mathrm{SF}_{6}$ thermogram are likely the result of instrument noise. Continuing studies are focused on the verification of the $\mathrm{U}_{3} \mathrm{O}_{8}$ results at different flow rates, increasing the $\mathrm{SF}_{6}$ resonance time in the sample through modifications of the tortuosity of the gas outlet, as well as the characterization of the reactivity of the lower oxides, $\mathrm{UO}_{3}$ and $\mathrm{UO}_{2}$. 


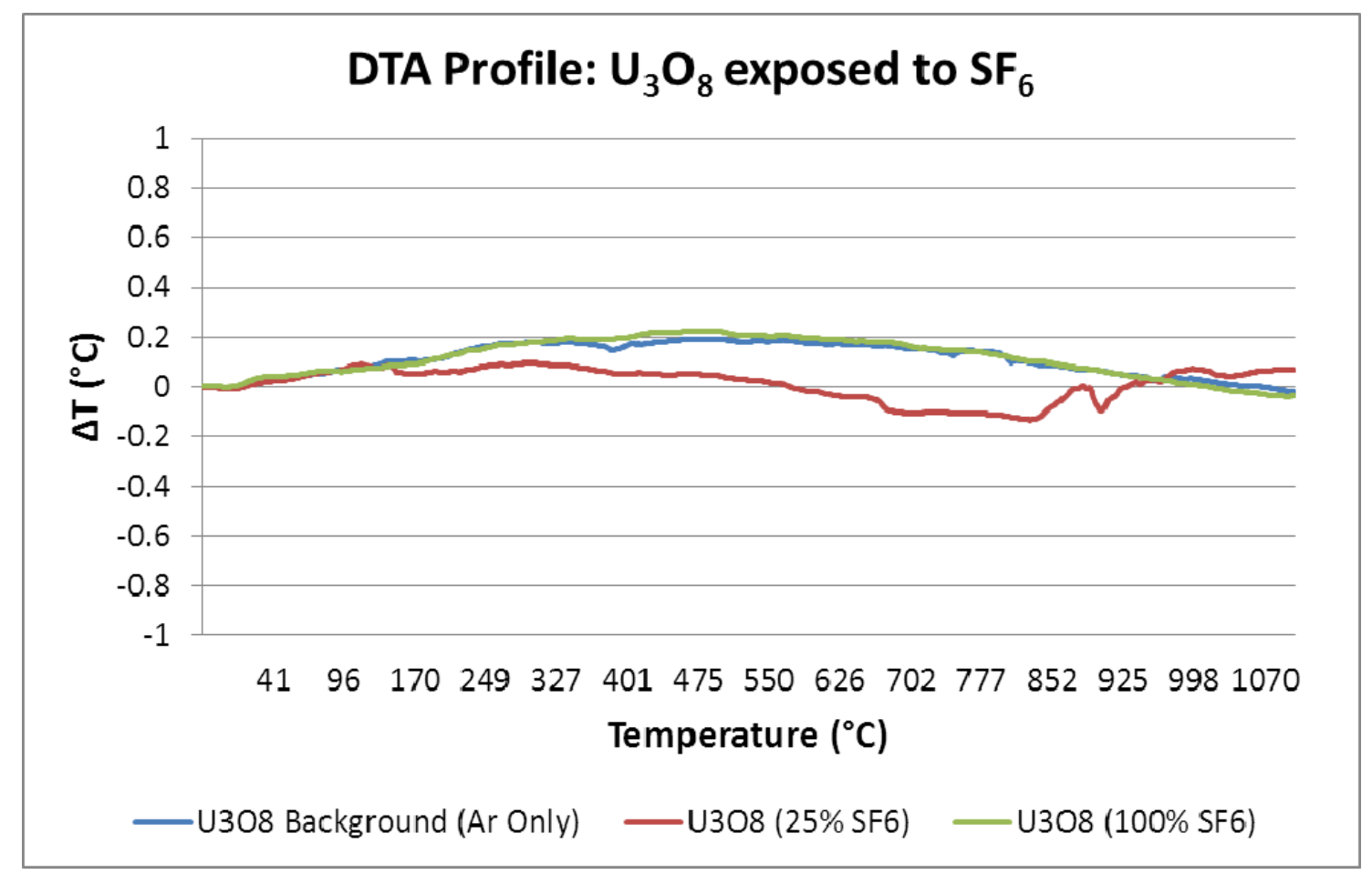

Figure 6. DTA profile of $\mathrm{U}_{3} \mathrm{O}_{8}$ sample exposed to various $\mathrm{SF}_{6}$ concentrations as a function of temperature 


\section{Reaction Pathway and Kinetic Modeling Analysis for Fluorination of UNF with $\mathbf{S F}_{6}$}

The solid-state kinetic models described in Section 1.3 were used and compared with TGA data for some samples to infer possible reaction mechanisms occurring when the surrogates are exposed to $\mathrm{SF}_{6}$. Reduced time plots for the models in Table 3 are shown in Figure 12. The use of fractional conversion as function of a reduced time scale, such as $t / t_{0.5}$, where $t_{0.5}$ corresponds to $\alpha=0.5$, is a convenient method to compare the experimental data with the models. For example, combining the contracting volume $\left(\mathrm{R}_{3}\right)$ model in Table 3 with. Eq. 5 for $\alpha=0.5$ produce the following expressions:

$$
g(0.5)=0.2063=k t_{0.5}
$$

or

$$
k=\frac{0.2063}{t_{0.5}}
$$

Substituting Eq. 8 back into Eq. 5 gives

$$
1-(1-\alpha)^{\frac{1}{3}}=0.2063 \frac{t}{t_{0.5}}
$$

Solving for $\alpha$ gives

$$
\alpha=1-\left(1-0.2063 \frac{t}{t_{0.5}}\right)^{3}
$$

Similarly, the remaining models in Table 3 can be expressed as function of $t / t_{0.5}$. The advantage of this method is that evaluation of the kinetic parameters is not required for an initial assessment of the mechanism while the dependence of $\alpha$ in other variables, such as temperature and pressure, is captured in $t_{0.5}$.

The models shown in Figure 12 are grouped by the mechanism type: nucleation (P and A-series), reaction order (F-series), geometrical contractions (R-series), and diffusion (D-series). According to their shape, the P-series represent the acceleratory models in which conversion is faster with time. The A-series correspond to the sigmoidal shape in which conversion is faster with time until $\alpha=0.5$ and then slower with time. Except for $\mathrm{F}_{0}$, which represents a constant conversion over time, $\mathrm{F}, \mathrm{R}$, and $\mathrm{D}$-series represent the deceleratory models in which conversion is slower with time.

Figure 7 shows new analysis of the isothermal $\left(625^{\circ} \mathrm{C}, 22 \% \mathrm{SF}_{6}\right)$ portion of the TGA data for $\mathrm{Gd}_{2} \mathrm{O}_{3}$ in terms of fractional conversion as function of the reduced time scale. In this plot, $t=0$ represents the time at which the sample starts the isothermal reaction. Under these test conditions, $\mathrm{Gd}_{2} \mathrm{O}_{3}$ starts as an F3 model, i.e. third order kinetics. The initial reaction into $\mathrm{GdF}_{3}$ eventually experiences diffusion limitations, shifting to a D4 model, i.e. a radial steady-state diffusion model known as the Ginstling- 
Brounshtein model. The reaction data then shifted to a third kinetic model (D3), the Jander model, which was developed by modeling diffusion through a plane and then extending it to a spherical geometry.

Expanded analysis of this $\mathrm{Gd}_{2} \mathrm{O}_{3}$ data is shown in Figure 8 in terms of the integral form of the fractional conversion as a function of reduced time scale. This plot also includes XRD analysis performed on the reaction product, which showed the formation of stable $\mathrm{GdF}_{3}$, the anticipated product, as well as an additional by-product, a $\mathrm{Gd}_{2} \mathrm{O}_{3} \cdot \mathrm{GdF}_{3}$ complex. This additional complex could provide an explanation for the shifts in reaction kinetics experienced by the powder. Initially, the reactive gas fluorinates the surface of the oxide powder creating the anticipated fluoride product at a third-order rate. The reactive gas then experiences diffusion limitations through the $\mathrm{GdF}_{3}$ outer layer of the particle, yielding a second internal layer with a crystal structure of $\mathrm{Gd}_{2} \mathrm{O}_{3} \cdot \mathrm{GdF}_{3}$. This layer forms at a steady state, until increased diffusion limitations further slow the reaction of the reactive gas with the particle core.

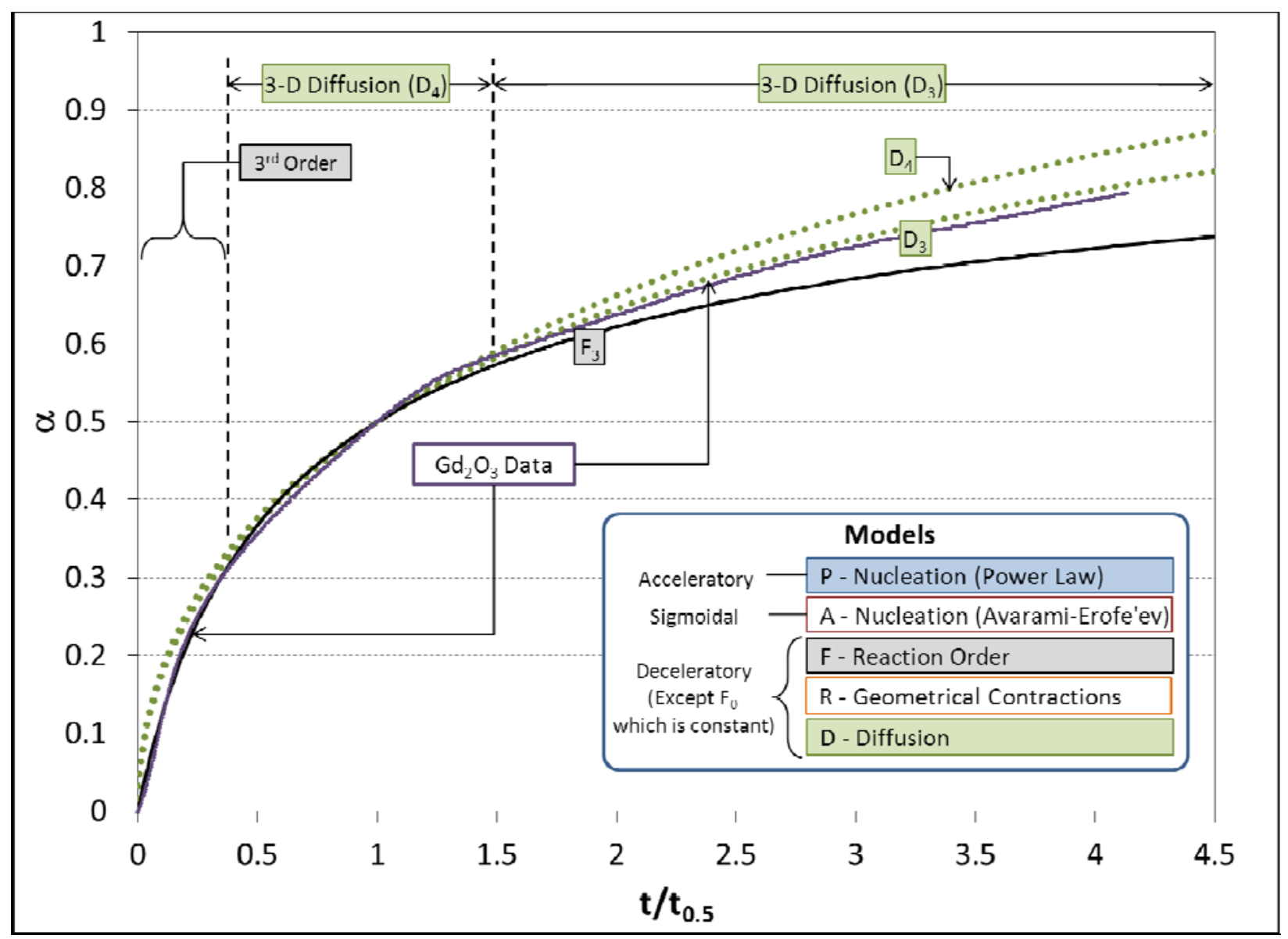

Figure 7. Fitting of solid-state kinetic models to TGA data for $\mathrm{Gd}_{2} \mathrm{O}_{3}$ under $22 \% \mathrm{SF}_{6}$ concentration and an ultimate temperature set to $625^{\circ} \mathrm{C}$. Actual isotherm corresponds to $630^{\circ} \mathrm{C}$. 


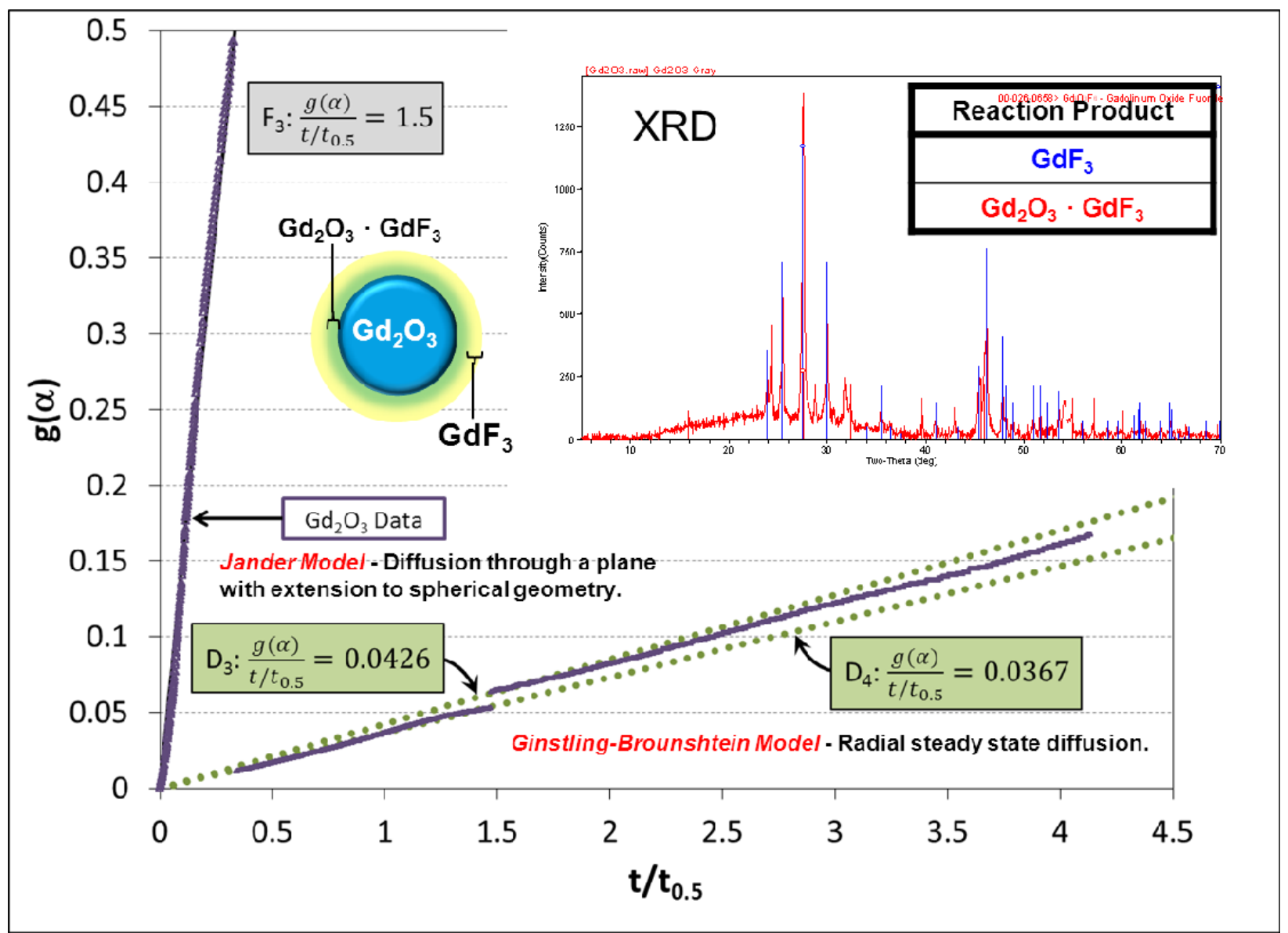

Figure 8. Proposed reaction mechanisms for $\mathrm{Gd}_{2} \mathrm{O}_{3}$ by comparison of XRD characterization of reaction product and fitted solid-state kinetic models $\left(22 \% \mathrm{SF}_{6}, 6_{25}^{\circ} \mathrm{C}\right)$.

TGA data was obtained at different temperatures for the $\mathrm{Gd}_{2} \mathrm{O}_{3}$ surrogate to determine the reaction parameters for the fluorination of $\mathrm{Gd}_{2} \mathrm{O}_{3}$ with $\mathrm{SF}_{6}$, as defined by the kinetic triplet model (Section 1.3), specifically the activation energy, $E_{a}$, and pre-exponential factor $A$. These parameters can be used to predict the reaction rates at a temperature within the empirical range used for the analysis. Figure 9 shows the results of this analysis. 


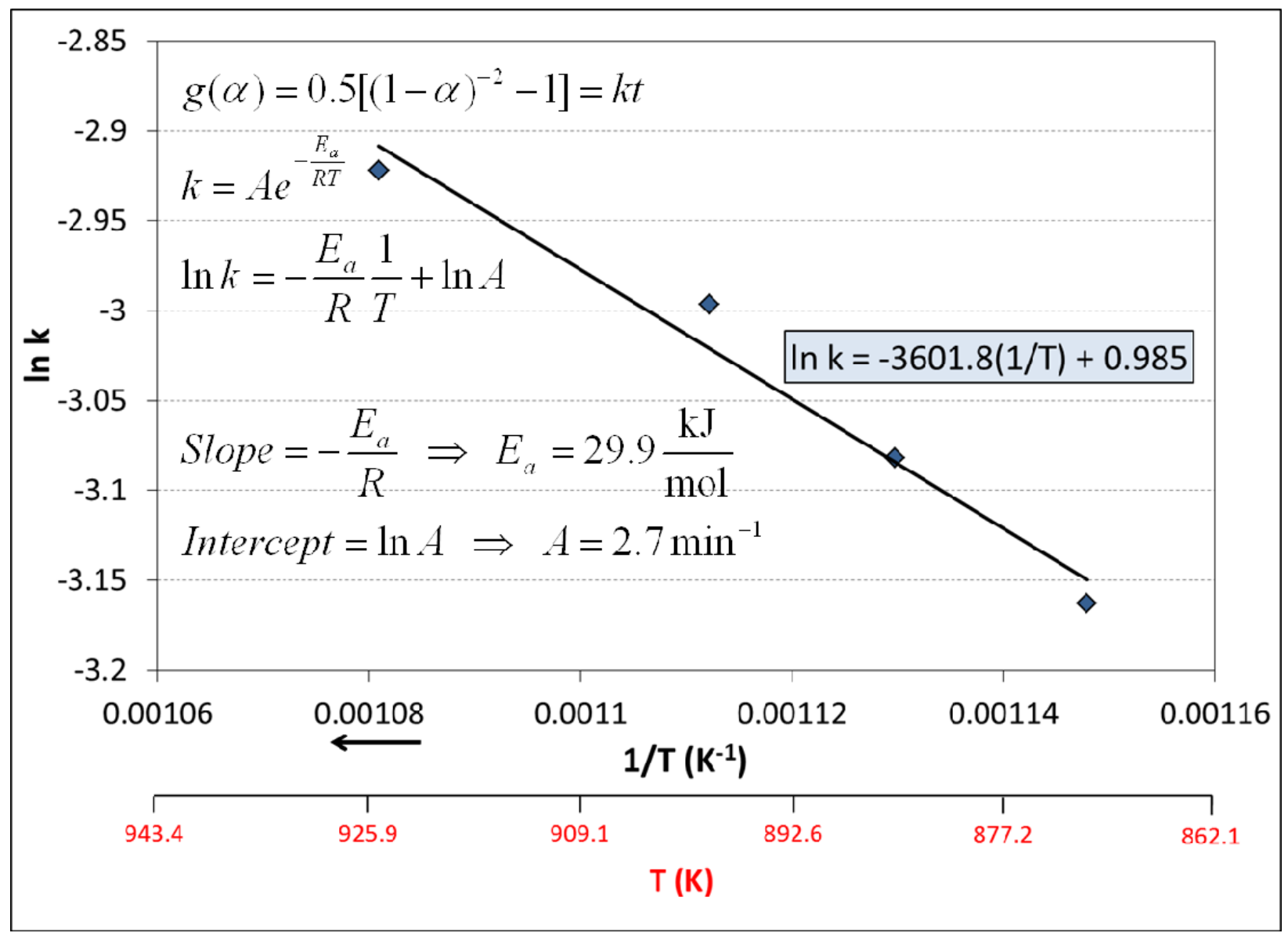

Figure 9. Determination of kinetic parameters $\left(E_{a}, A\right)$ for the reaction of $\mathrm{Gd}_{2} \mathrm{O}_{3}$ and $\mathrm{SF}_{6}$.

Similar analysis was performed on TGA data of $\mathrm{Sm}_{2} \mathrm{O}_{3}$, which confirmed that the reaction with $\mathrm{SF}_{6}$ initially follows third-order kinetics. As a stable product layer is formed on the surface of the oxide particles, the reaction rate slows and follows a 1-D diffusion-limited model. Previously presented XRD data confirmed the formation of only one stable oxyfluoride product, SmOF. This appears to also be the initial stable product from fluorination with another fluorinating agent. ${ }^{13}$ Additional data (not shown) from characterization at $650^{\circ} \mathrm{C}$ showed increased divergence form the 1-D model at increased reaction times, which could indicate the formation of a secondary product layer further limiting gas diffusion, potentially $\mathrm{SmF}_{3}$. The similar diffusion-limited behavior of $\mathrm{Sm}_{2} \mathrm{O}_{3}$ and $\mathrm{Gd}_{2} \mathrm{O}_{3}$ suggests that lanthanide fission products might behave similarly, as they have similar oxidation states (typically 3) and electronegativities. 


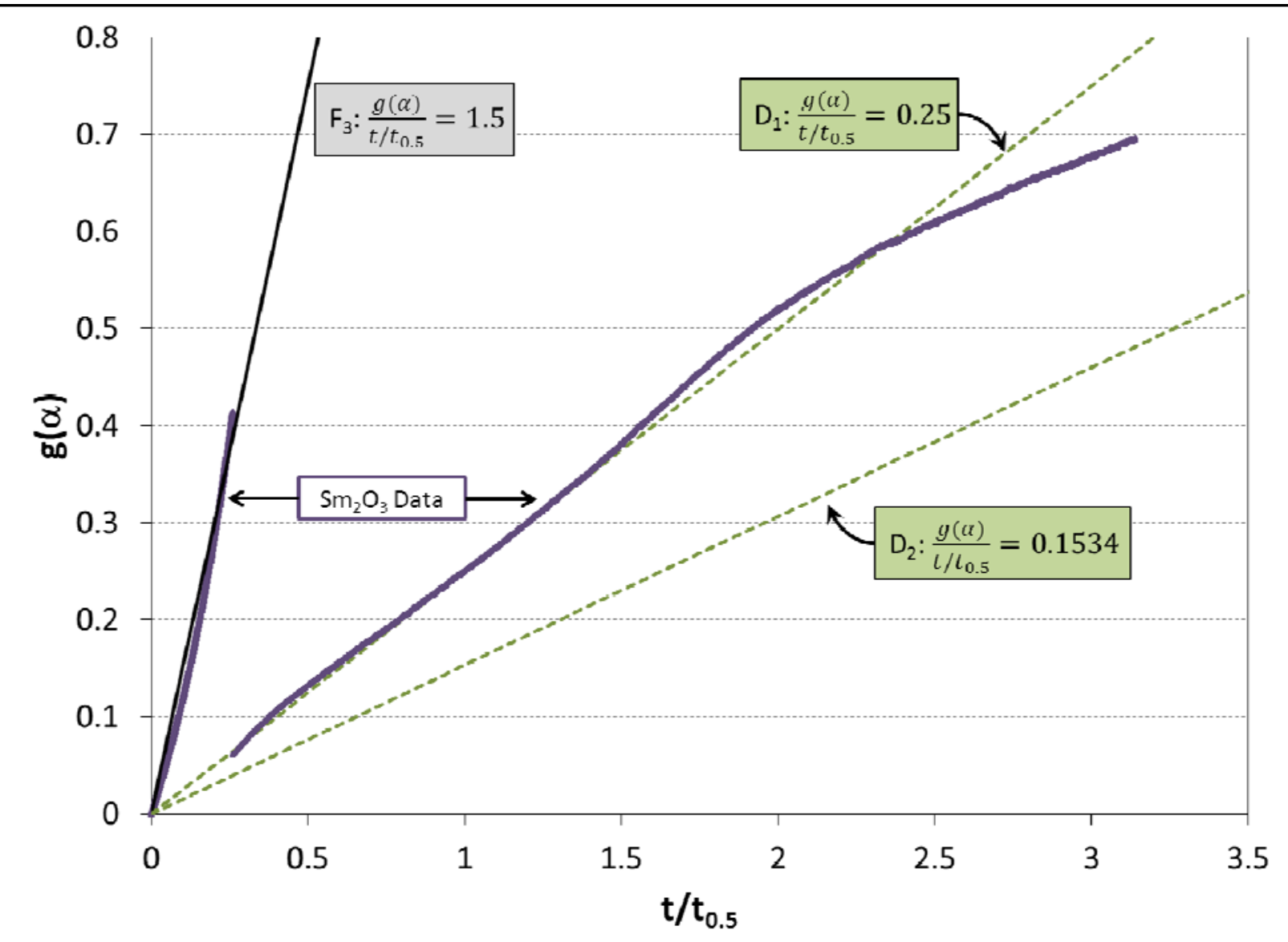

Figure 10. Fitting of solid-state kinetic models to TGA data for $\mathrm{Gd}_{2} \mathrm{O}_{3}$ under $25 \% \mathrm{SF}_{6}$ concentration and an ultimate temperature set to $600^{\circ} \mathrm{C}$.

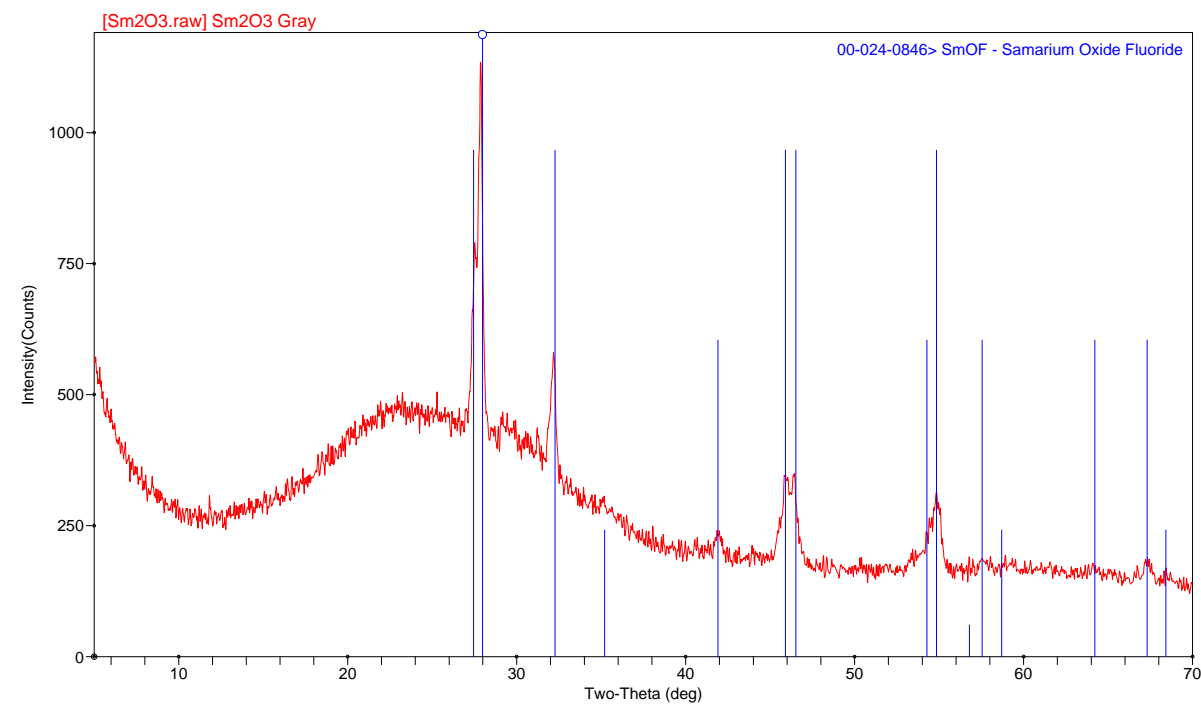

Figure 11. XRD pattern of $\mathrm{Sm}_{2} \mathrm{O}_{3}$ powder reacted with $25 \% \mathrm{SF}_{6}$ to an ultimate temperature of $625^{\circ} \mathrm{C}$. 
The isothermal portion of the TGA data for $\mathrm{Y}_{2} \mathrm{O}_{3}$ (Figure 12), in terms of fractional conversion as function of the reduced time scale,was also previously reportedas an example to compare with the models. In Figure 12, $t=0$ represents the time at which the sample start the isothermal process. It is evident that, under the tested conditions, $\mathrm{Y}_{2} \mathrm{O}_{3}$ follows the $\mathrm{R}_{3}$-model. Although the $\mathrm{R}_{3}$-model is in the category of geometrical contractions, in this case it represents a 3D or volumetric increase in the solid particles as measured by the mass increase measured by TGA. This is supported by the XRD and EDS results previously reported, in which oxyfluoride and oxysulfate species, such as YOF and $\mathrm{Y}_{2} \mathrm{O}_{2} \mathrm{SO}_{4}$ were found in the reacted $\mathrm{Y}_{2} \mathrm{O}_{3}$ powder. Another way to compare the data is by plotting $g(\alpha)$ vs $t / t_{0.5}$. According to Eq. 9 for the $\mathrm{R}_{3}$-model, this will result in a straight line with slope $=0.2063$. Figure 13 shows that the $\mathrm{R}_{3}$-model is a close fit to the isothermal portion of the TGA data for $\mathrm{Y}_{2} \mathrm{O}_{3}$ under $22 \% \mathrm{SF}_{6}$ concentration.

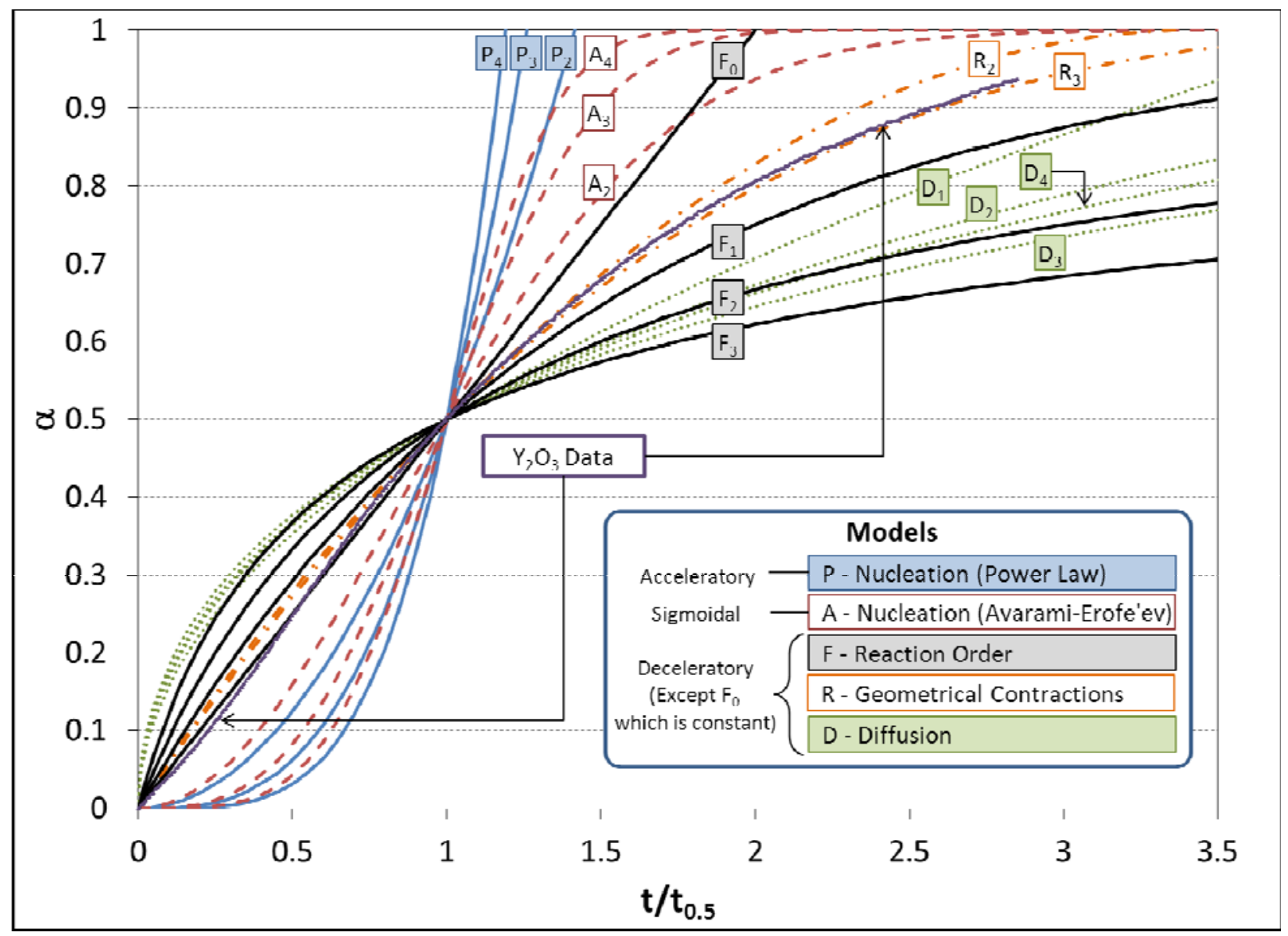

Figure 12. Solid-state kinetic models from Table 3 in terms of $\alpha$ as function of the reduced time scale. Models are compared with the isothermal portion of the TGA data for $\mathrm{Y}_{2} \mathrm{O}_{3}$ under $22 \% \mathrm{SF}_{6}$ concentration and an ultimate temperature set to $625^{\circ} \mathrm{C}$. Actual isotherm corresponds to $630^{\circ} \mathrm{C}$. 


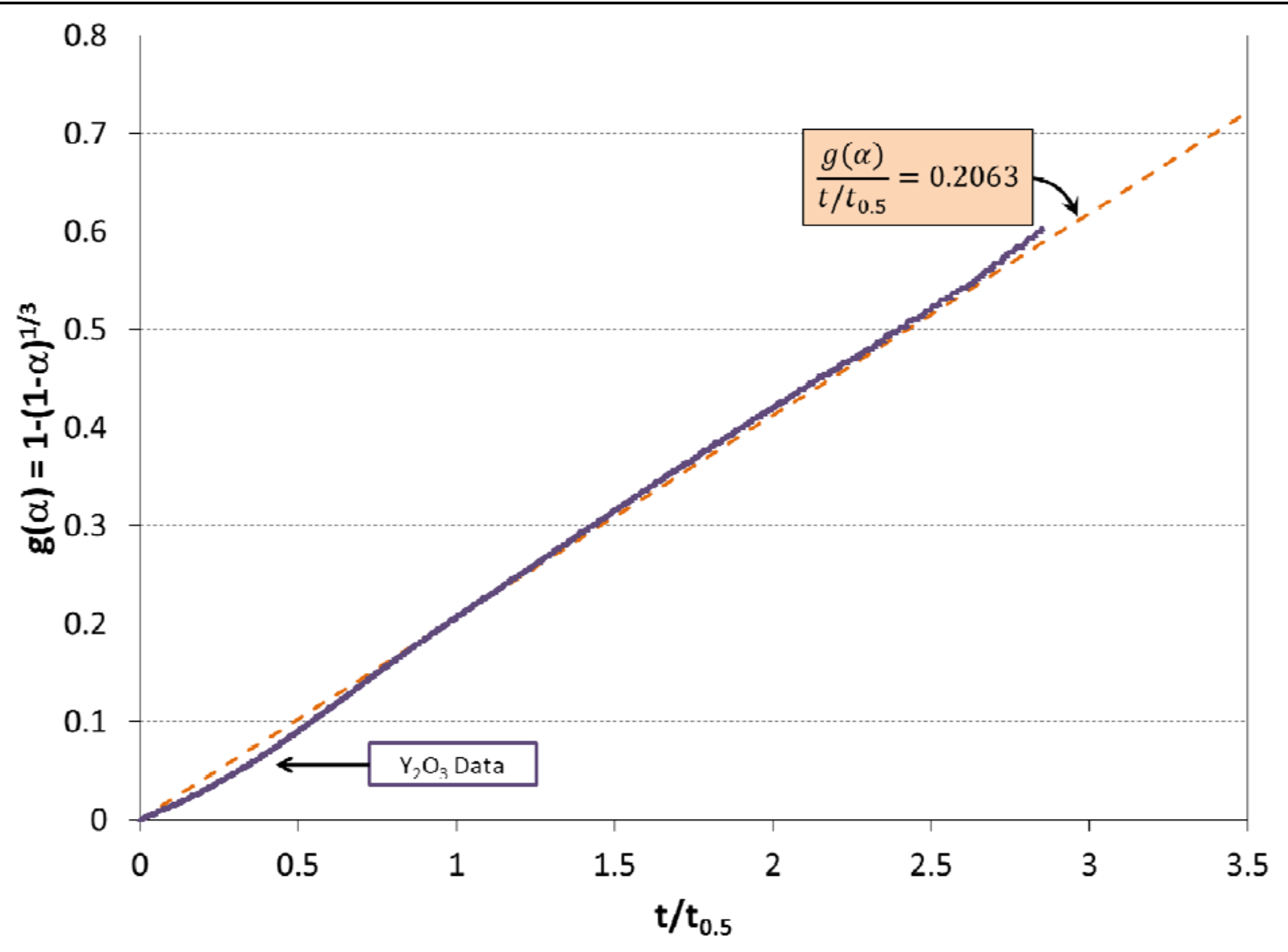

Figure 13. Linear form of the R3-model compared with the isothermal portion of the TGA data for $\mathrm{Y}_{2} \mathrm{O}_{3}$ under $22 \% \mathrm{SF}_{6}$ concentration and an ultimate temperature set to $625^{\circ} \mathrm{C}$. Actual isotherm corresponds to $633^{\circ} \mathrm{C}$.

As a final example, additional analysis of the isothermal portion of the TGA data for $\mathrm{RuO}_{2}$ is presented in Figure 14. For this case, $\mathrm{RuO}_{2}$ follows a zero-order kinetics mode $\left(\mathrm{F}_{0}\right)$. This analysis supports a simple reaction mechanism produces a volatile fluoride species, leaving a fresh oxide surface for continuous reaction. Previously reported XRD and EDS characterization of the material retained in the TGA panconfirmed that only $\mathrm{RuO}_{2}$ is present in the reacted powder, which is the original species present at the beginning of the test.

This section showed how the gas-solid reaction models were compared with the experimental data to obtain some insight of the mechanism undertaking for the different surrogates exposed to $\mathrm{SF}_{6}$. It is intended to apply similar analysis to the remaining surrogates and to the uranium species samples. However, additional experiments at different isothermal temperatures and heating rates are required to elucidate kinetic parameters. Non-isothermal analyses are also possible by applying approximations or numerical methods to evaluate Eq. 6 or using a model-free approach such as the isoconversional method $^{14,15,16,17}$. 


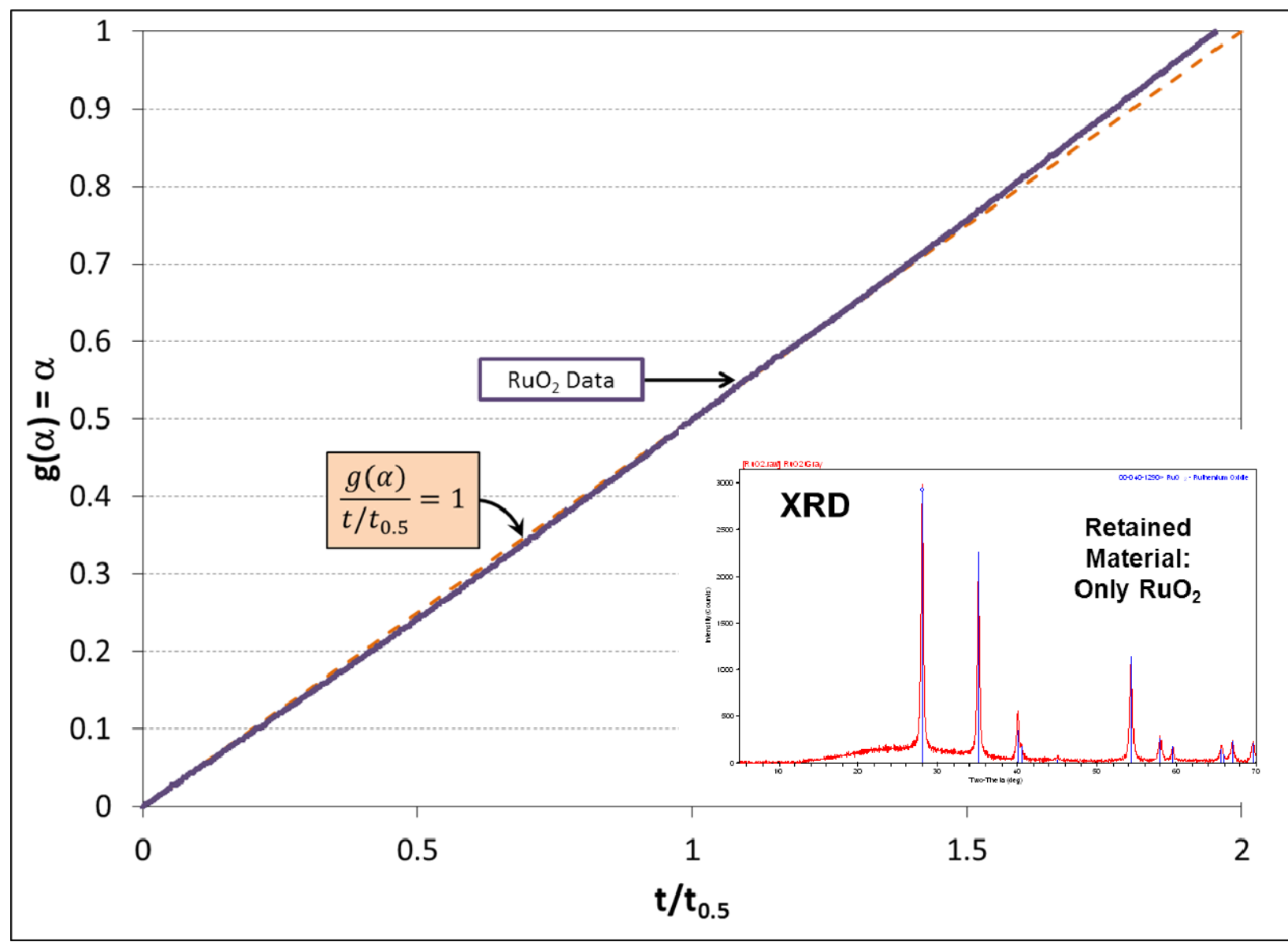

Figure 14. Solid-state kinetic models from Table 3 in terms of $\alpha$ as function of the reduced time scale. Models are compared with the isothermal portion of the TGA data for $\mathrm{RuO}_{2}$ under $22 \% \mathrm{SF}_{6}$ concentration and an ultimate temperature set to $625^{\circ} \mathrm{C}$. Actual isotherm corresponds to $633^{\circ} \mathrm{C}$.

\subsection{Process Flowsheet Development for Separations Based on Fluorination via $\mathrm{SF}_{6}$}

In order to explore UNF treatment processes that might employ gaseous alternate fluorinating agents, an effort has been initiated to develop process flow sheets that employ such agents to separate uranium from UNF. First, a reference flow sheet has been developed that is based on HF- and $F_{2}$-based UNF treatment processes and reaction steps described in the open literature. Based on this flowsheet, alternative flow sheets are being developed that substitute $\mathrm{SF}_{6}$ as the primary fluorinator. The flow sheets will include all fuel handling operations from initial fuel assembly deconstruction to purification of the $\mathrm{UF}_{6}$ product. The flow sheets will be used to understand the implications of process chemistry changes on the overall UNF treatment process, to help identify technical areas that require more data, and to help evaluate process feasibility, costs, and equipment needs.

Flow sheet development will be an iterative process. Assumptions are made regarding separation factors and the extent of reactions based on the available literature, and that all chemical reactions reach chemical

equilibrium. As this suite of flow sheets develops, laboratory data and the results obtained from chemical 
reaction modeling will be used to adjust the models. As more data becomes available on reaction kinetics, more sophisticated process flow sheets are being implemented in Aspen Plus. It is also anticipated that more detailed, dynamic models may be constructed of individual process units using MATLAB, Mathematica, or another software package that allows for solution of time-dependent equations and finite-element calculations.

The current baseline Aspen+ flowsheet simulation is shown below in Figure 15. This process is constructed from information provided in the open literature ${ }^{18,19,20,21,22,23,24}$. The process begins with disassembly of the fuel rods, which is followed by mechanical chopping and chemical decladding using hydrogen as a zirconium hydriding agent. After decladding, the cladding fragments are separated from the fuel pellets by mechanical agitation and sieving. Advanced voloxidation is used to break down the fuel pellets into a powder, and a high-temperature vacuum distillation process is used to separate volatile oxides and other species from the oxidized UNF. A two-step fluorination process using $\mathrm{HF}$ and $\mathrm{F}_{2}$ is used to convert actinide and fission product oxides into fluorides, and the separation of these chemical species is performed on the basis of volatility. Calcium fluoride $\left(\mathrm{CaF}_{2}\right)$ is used as a fluidizing agent in the $\mathrm{HF}$ and $\mathrm{F}_{2}$ fluorinating steps, and is chemically inert. Two product streams are produced; one stream consisting of purified $\mathrm{UF}_{6}$, and another stream consisting of a $\mathrm{UF}_{6} / \mathrm{PuF}_{6}$ blend. A UNF treatment process using gaseous fluorinating reagents appears to have some competitive advantages over traditional aqueous processes in terms of the volume of process wastes, the number of process vessels, and the physical size of the plant. In the reference process, the chemical species of interest are present in the form of gases or condensed solids, and no dilute liquid streams are generated. After the voloxidation step, which may be a common front-end to many UNF treatment processes, the number of process vessels is small in comparison to aqueous processes. The size of the vessels is reduced also by eliminating the presence of dilute liquid streams in the process. This fluorination process may also serve as a head-end process for aqueous or pyrochemical approaches.

A modified flowsheet (Figure 16) has been designed in the ASPEN+ software package focusing on the use of $\mathrm{SF}_{6}$ as a fluorinating, agent as opposed to the pure $\mathrm{F}_{2}$ shown in Figure 10. As currently formulated, this flowsheet process is envisioned to be primarily used as a head-end treatment which would be used to remove volatile fluorides from the UNF that has been processed through decladding and voloxidation. Current results indicate that while many of the species where are thermodynamically predicted to form volatile fluoride species do so when exposed to $\mathrm{SF}_{6}$, uranium oxides in particular to this point have not. Therefore this process diagram is set up to show how a UNF material might be moved through the fluorination step with $\mathrm{SF}_{6}$, where a solid product would be rendered composed of uranium and plutonium oxides, although with other solid fluoride species such as $\mathrm{CsF}$ and $\mathrm{SrF}_{2}$ would be produced. This flow diagram also assumes that the gas product stream could be put through a condenser to separate any solid fluorides along with species such $\mathrm{SO}_{2} \mathrm{~F}_{2}$ and $\mathrm{SOF}_{4}$ and the $\mathrm{SF}_{6}$ would be recycled back to the process along with any $\mathrm{F}_{2}$ generated. In this way, the waste streams of gas species that need to be sequestered and treated are minimized while the advantages of controlled fluoride volatility are maintained.

Based on these results, if further conditioning of the uranium/plutonium and other solid residues is desired, the product would be passed on to another process for further conditioning. One such process that could be introduced would be further reaction with $\mathrm{NF}_{3}$, utilizing the work of colleagues at PNNL. This scheme is shown in Figure 17. They have shown that $\mathrm{UF}_{6}$ will readily form from exposure to $\mathrm{NF}_{3}$ at temperatures of approximately $440^{\circ} \mathrm{C}$, which should cleanly separate the uranium out from this solid product without any potential contamination of species such as molybdenum, niobium, rhenium, rhodium or similar. This should also leave the plutonium in the bottoms of the reactor along with hot species such as $\mathrm{Cs}$ and $\mathrm{Sr}$ which may have advantages for implementation. Note that this scheme also assumes 
separation and recycle of fluorinating agents in both fluorination steps so as to minimize the wastes to the treated. 


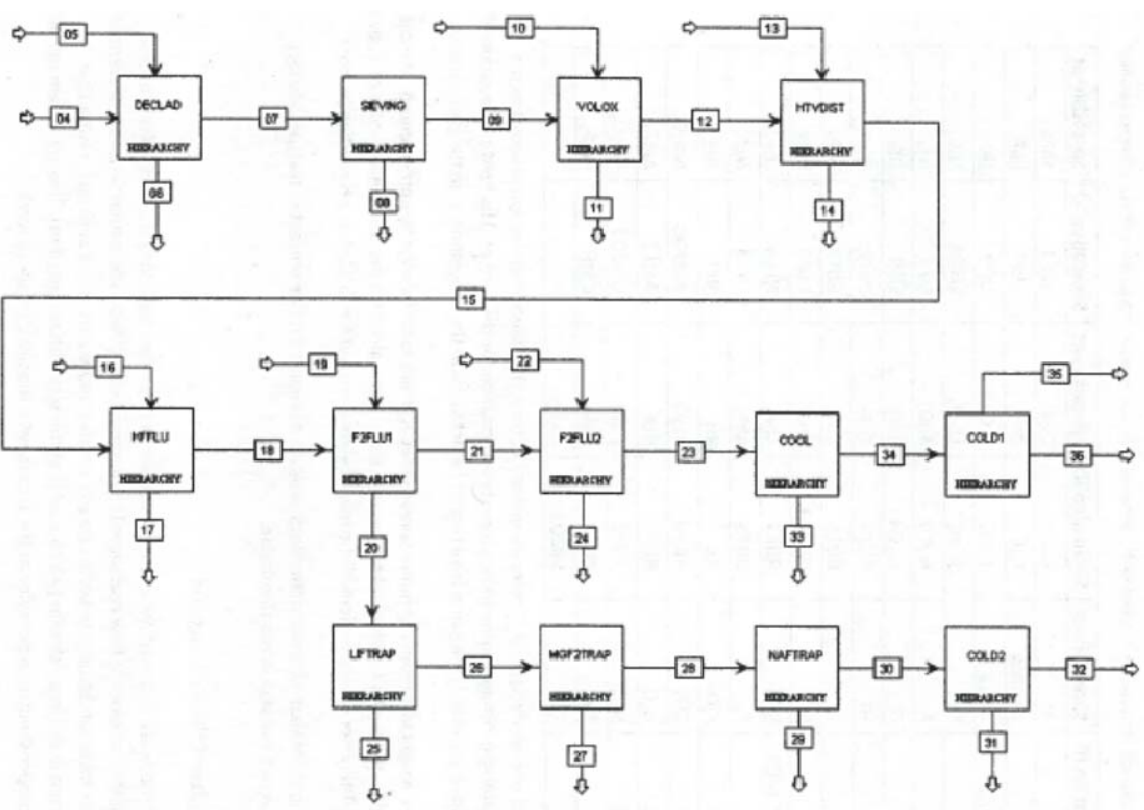

Figure 15. Block Flow Diagram of Reference UNF Fluorination Process.

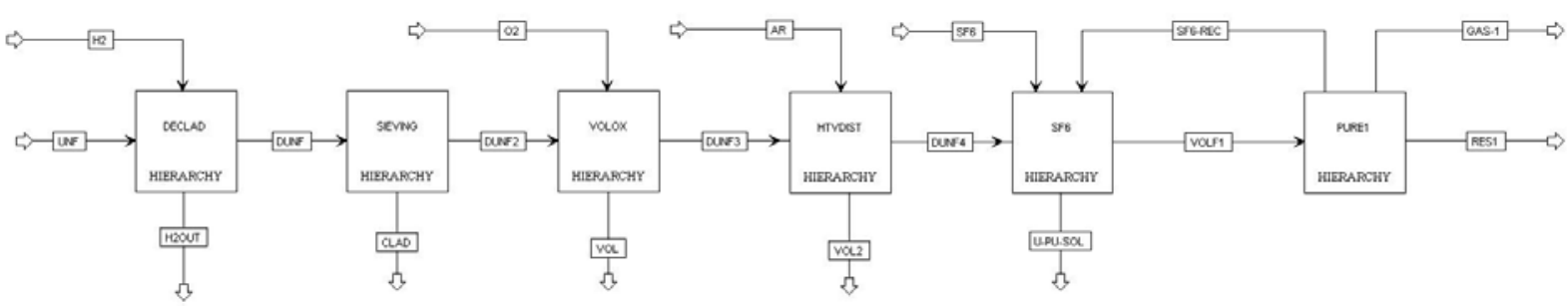

Figure 16. Simplified Process Flow Diagram Incorporating $\mathrm{SF}_{6}$ as the Fluorinating Agent

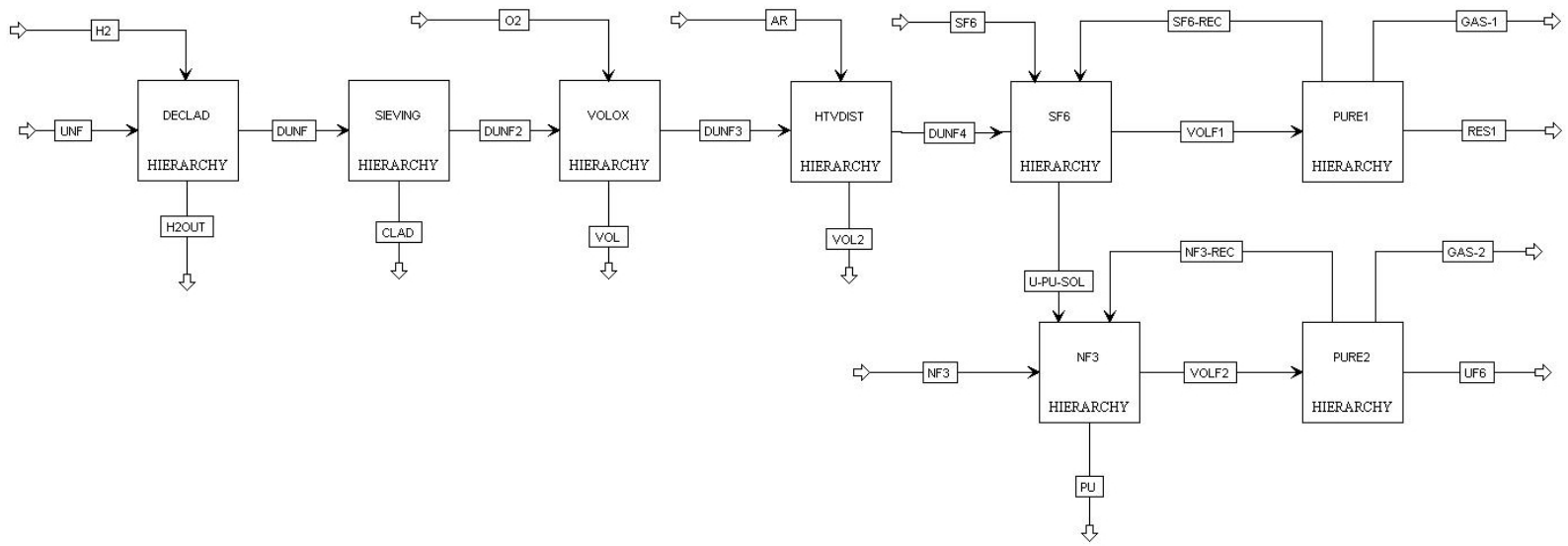

Figure 17. Process Diagram for combined $\mathrm{SF}_{6}$ and $\mathrm{NF}_{3}$ Separations Process which Includes Fluorinating Agent Recycle 


\section{CONCLUSIONS}

The possibility of developing reactive gas recycling technologies for UNF is attractive due to the possibility of developing cleaner unit operations and reduced waste form volumes. The reactivity of a large number of nuclear surrogate oxides and metals was characterized at varied $\mathrm{SF}_{6}$ concentrations and temperature profiles using TGA and DTA techniques, coupled with chemical analysis comprised of SEM, EDS and XRD. The preliminary experiments indicate that fluorination and sulfidation of these materials overwhelmingly results in stable and non-volatile compounds, with key elements forming volatile fluorides which is consistent with the concept of using fluorination as a key step for UNF separation and recycle.

Of the non-radioactive surrogate materials that have been investigated, $\mathrm{CeO}_{2}, \mathrm{Gd}_{2} \mathrm{O}_{3}, \mathrm{Sm}_{2} \mathrm{O}_{3}, \mathrm{Y}_{2} \mathrm{O}_{3}, \mathrm{HfO}_{2}$, $\mathrm{ZrO}_{2}, \mathrm{Ru}$, and $\mathrm{Rh}$ all exhibit formation of stable non-volatile compounds under ambient pressure and moderate $\mathrm{SF}_{6}$ concentration up to temperatures of $625^{\circ} \mathrm{C}$, while $\mathrm{SrO}, \mathrm{RuO}_{2}, \mathrm{Rh}_{2} \mathrm{O}_{3}, \mathrm{Re}_{2} \mathrm{O}_{3}$, and $\mathrm{Re}$ all formed volatile compounds under these sample conditions. A set of experiments taking a selected subset of these compounds up to higher temperatures of $750^{\circ} \mathrm{C}$ demonstrated consistent behavior. Experiments performed with two phases of uranium oxide, $\mathrm{UO}_{3}$ and $\mathrm{U}_{3} \mathrm{O}_{8}$ (presumably $\beta$-phase $\mathrm{U}_{3} \mathrm{O}_{8}$ ), indicated that the $\mathrm{UO}_{3}$ sample may react to form a volatile fluorinated species under ambient pressure, moderate concentrations of $\mathrm{SF}_{6}$, and temperatures well below $800^{\circ} \mathrm{C}$ although the extent of volatility is limited. The volatile species is presumably $\mathrm{UF}_{6}$, as this would be consistent with known U-F chemistry. Samples of the water reservoir attached to the gas effluent, where $\mathrm{UF}_{6}$ is expected to precipitate out, have indicated that $\mathrm{U}$ is present in the water confirming limited volatility. Experiments with $\mathrm{MoO}_{3}$ and $\mathrm{Nb}_{2} \mathrm{O}_{5}$ exposed to $\mathrm{SF}_{6}$ indicate that these could be separated from uranium oxides via volatilization of $\mathrm{UF}_{6}$ at slightly higher temperatures $\leq 800^{\circ} \mathrm{C}$. Higher temperature DTA experiments, in excess of $1000^{\circ} \mathrm{C}$, indicate that the SRNL $\mathrm{U}_{3} \mathrm{O}_{8}$ does not experience significant volatility at these temperatures. Uranium oxides produced at ORNL will be tested to determine if the materials currently being used at SRNL are indicative of the general fluorination and volatility of $\mathrm{U}_{3} \mathrm{O}_{8}$, since literature sources suggest that $\mathrm{SF}_{6}$ should form $\mathrm{UF}_{6}$ in this temperature range.

An effort to evaluate a suite of models to determine most probable reaction pathway has been initiated, along with a related effort to enable the determination of Arrhenius kinetic parameters. These techniques have been applied to a preliminary set of data to demonstrate their applicability, and will be used more extensively as the project continues. A preliminary project flowsheet analysis has been developed, which considers a series of unit operations based on information that is available in the open literature and patents. This basic flow diagram has been migrated into $\mathrm{ASPEN}^{+}$, a commercially available process analysis software package that is commonly used to develop industrial processes. This model will be used to benchmark the model itself, and is being modified to incorporate different process alternatives such as the use of $\mathrm{SF}_{6}$ as a fluorinating agent.

Based on current results of the research at $\mathrm{SRNL}$ on $\mathrm{SF}_{6}$ fluoride volatility for UNF separations, $\mathrm{SF}_{6}$ treatment renders all anticipated volatile fluorides studied to be volatile, and all non-volatile fluorides studied to be non-volatile, with the notable exception of uranium oxides. This offers an excellent opportunity to use this as a head-end separations treatment process because:

1. $\mathrm{SF}_{6}$ can be used to remove volatile fluorides from a UNF matrix while leaving behind uranium oxides. Therefore an agent such as $\mathrm{NF}_{3}$ should be able to very cleanly separate a pure $\mathrm{UF}_{6}$ stream, leaving compounds such as $\mathrm{PuF}_{4}, \mathrm{SrF}_{2}$ and $\mathrm{CsF}$ as residue after the UNF matrix has been pre-treated with $\mathrm{SF}_{6}$.

2. Due to the fact that the uranium oxide is not separated in the volatilization step upon direct contact with $\mathrm{SF}_{6}$ at moderately high temperatures $\left(\leq 1000^{\circ} \mathrm{C}\right)$, this fluoride approach may be well-suited for head-end processing for Gen IV reactor designs where the LWR is treated as a 
fuel stock, and it is not desired to separate the uranium from plutonium, but it is desired to separate many of the volatile fission products.

3. It is likely that removal of the volatile fission products from the uranium oxide should simplify both traditional and next generation pyroprocessing techniques.

4. $\mathrm{SF}_{6}$ treatment to remove volatile fission products, with or without treatment with additional fluorinators, could be used to simplify the separations of traditional aqueous processes in similar fashion to the FLUOREX process.

\section{PATH FORWARD}

The current results indicate that the majority of the fission products form stable solid fluorides and sulfides, while a subset of the fission products form volatile fluorides such as molybdenum fluoride and niobium fluoride, as predicted thermodynamically. A key result is the verification that $\mathrm{SF}_{6}$ requires high temperatures for volatilization of uranium oxides to $\mathrm{UF}_{6}$, and thus is well positioned as a head-end treatment for other separations technologies, such as the volatilization of uranium oxide by $\mathrm{NF}_{3}$ as reported by colleagues at PNNL, advanced pyrochemical separations or traditional full recycle approaches.

Future work should be conducted in FY13 to determine the separations efficiency of a combined $\mathrm{SF}_{6} / \mathrm{NF}_{3}$ separations approach which could be used as a stand-alone separations technology or a head-end process. SRNL is continuing to map out the kinetic analysis of the formation of the non-volatile and volatile fission products, as well as investigating the effect of controlled decomposition of $\mathrm{SF}_{6}$ on its reactivity with uranium oxides. SRNL will continue to develop the process flow diagrams to enable this technology to be evaluated as potential separations technology or head-end process for aqueous or pyrochemical approaches.

\section{References}

'. Kani, Y., et al., "New recycling system for spent nuclear reactor fuel using fluoride volatility method." Journal of Fluorine Chemistry, 130 (1): p. 74-82. (2009)

${ }^{2}$. Uhlif, J. and M. Marecek, "Fluoride volatility method for recycling of LWR and FR fuels." Journal of Fluorine Chemistry, 130(1): p. 89-93. (2009)

3. Gray, J.; Korinko, P.; Garcia-Diaz, B.; Visser, A.; Adams, T. "Reactive Gas Recycle for Used Nuclear Fuel.” FCRD Annual Report, FCRD-SEPA-2010-000177. (2010)

${ }^{4}$. Khawam, A. and Flanagan, D. R., "Basics and applications of solid-state kinetics: a pharmaceutical

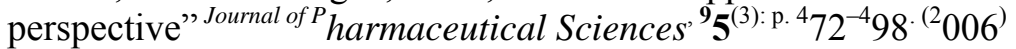

5 . Khawam, A. and Flanagan, D. R., "Solid-state kinetic models: basics and mathematical fundamentals"

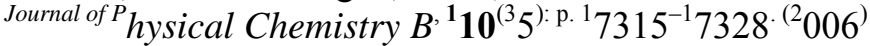

${ }^{6}$. Khawam, A. and Flanagan, D. R., "Basics and applications of solid-state kinetics: a pharmaceutical perspective" Journal of ${ }^{P}$ harmaceutical Sciences, ${ }^{9} 5^{(3): \text { p. }{ }^{4}} 72^{-4} 98^{\cdot(2} 006^{)}$

7. Khawam, A. and Flanagan, D. R., "Solid-state kinetic models: basics and mathematical fundamentals"

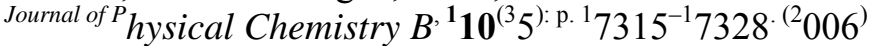


${ }^{8}$. LaValle, D.E., R. M. Steele, and W.T. Smith Jr, "Rhenium nitrogen fluoride and rhenium tetrafluoride.". Journal of Inorganic and Nuclear Chemistry, 28(1): p. 260-263. (1966)

9 . Malma, J.G. and H. Seliga, "The vapour-pressures and other properties of ReF6 and ReF7." Journal of Inorganic and Nuclear Chemistry, 20(3-4): p. 189-197. (1961)

${ }^{10}$. LaValle, D.E., Steele, R.M., Wilkinson, M.K, Yakel Jr., H.L., "The preparation and crystal structure of molybdenum (III) fluoride." Journal of the American Chemical Society, 82(10): p. 2433-2434. (1960)

${ }^{11}$. Opalovsky, A.A. and Lobkov, E.U., "Interaction of sulphur hexafluoride with metals and oxides." Journal of Fluorine Chemistry, 2: p. 349-359. (1973).

${ }^{12}$. McNamara, B., R. Scheele, A. Kozelisky, and M. Edwards, "Thermal reactions of uranium metal, UO2, U3O8, UF4, and UO2F2 with NF3 to produce UF6." Journal of Nuclear Materials, 394(2-3): p. 166-173. (2009)

${ }^{13}$. Work, D.E. and Eick H.A, "The vaporization thermodynamics of samarium oxide fluoride," Journal of Physical Chemistry, 74(16), p. 3130-3134 (1970).

14. Cupic, Z., Jovanovic, D., Krstic J., Vukelic, N., and Nedic, Z., "Non-sothermal kinetic characterization of a gas-solid reaction by TG analysis" Journal of the Serbian Chemical Society, ${ }^{7} \mathbf{0}^{(1} 1^{): \text {p. }}{ }^{1} 301^{-1} 311^{\cdot{ }^{(2} 005^{)}}$

${ }^{15}$. Orfao, J. J. M. and Martins, F. G., "Kinetic analysis of thermogravimetric data obtained under linear temperature programming - a method based on calculations of the temperature integral by interpolation" Thermochimica Acta, $\left.{ }^{39} \mathbf{0}^{(1}-2\right)^{): ~ p . ~}{ }^{1} 95^{-2} 11^{\cdot(2} 002^{)}$

${ }^{16}$. Burnham, A. K. and Dinh, L. N., "A comparison of isoconversional and model-fitting approaches to kinetic parameter estimation and application predictions" Journal of Thermal Analysis and Calorimetry, 89(2): p. ${ }^{4} 79^{-4} 90$ $\left.{ }^{(2} 007\right)$

${ }^{17}$. Vyazovkin, S. and Wight, C. A., "Kinetics in solids" Annual Review of Physical Chemistry, $4 \mathbf{8}^{\left.\text {: p. }{ }^{125-4} 9^{(1} 997\right)}$

${ }^{18}$.Westphal, B.R., Bateman, K.J., Lind, R.P., Howden, K.L., Del Cul, G.D., "Fission Product Removal from Spent Oxide Fuel by Head-End Processing", Paper No 345, Proceedings of GLOBAL 2005, Tsukuba, Japan, October 9-13, 2005.

${ }^{19}$. U.S. Patent 7,208,129 B2, "Reprocessing Method by Fluoride Volatility Process Using Solid-Gas Separation”, I. Amamoto, K. Sato, Japan Nuclear Cycle Development Institute. (2007)

${ }^{20}$. KAERI/TR-3622/2008, "Evaluation of the Effects of Advanced Voloxidation Process on Pyroprocessing. I. Radiation and Decay Heat Analysis of the Advanced Voloxidation Process", September 2008, Korea Atomic Energy Research Institute. (2008)

${ }^{21}$. Goff, A.C., Alexander, C.W., "Decay Characteristics of Once-Through LWR and LMFBR Spent Fuels, High-Level Wastes, and Fuel Assembly Structural Material Wastes", ORNL/TM-7431, Oak Ridge National Laboratory. (1980)

${ }^{22}$. Tripp, J., Soelberg, N., Wigelund, R., "Innovative Separations Technologies", FCR\&D-SYSA-2011000097, Idaho National Laboratory. (2011)

${ }^{23}$. Naegeli, R.E., "Calculation of the Radionuclides in PWR Spent Fuel Samples for SFR Experiment Planning”, SAND2004-2757, Sandia National Laboratories. ( 2004)

${ }^{24}$. Parkison, A.J., "Hydride Production in Zircaloy-4 as a Function of Time and Temperature", Masters of Science Thesis, Nuclear Engineering, Texas A\&M University. (2008) 